Universidade de São Paulo

Instituto de Astronomia, Geofísica e Ciências Atmosféricas

Departamento de Geofísica

Dissertação de Mestrado

\title{
Inversão conjunta 1D de dados de \\ SEV e TDEM: Aplicações em hidrogeologia
}

Aluno: Cassiano Antonio Bortolozo

Orientador: Prof. Dr. Jorge Luís Porsani 
"Yo Adrian, I did it !"

- Rocky Balboa 


\section{Agradecimentos}

Em primeiro lugar gostaria de agradecer muito a Deus por me possibilitar desenvolver esse trabalho e me ajudar nas horas que mais necessitava.

Gostaria de agradecer muito meus pais pelo apoio incondicional que me deram durante esse período de mestrado assim como sempre fizeram. Se hoje estou aqui devo tudo a eles.

Gostaria de agradecer a minha namorada Luana que durante a fase final do mestrado sempre esteve do meu lado e sempre foi compreensiva com os períodos em campo e os finais de semana no IAG.

Gostaria de agradecer meu orientador Jorge Porsani que acreditou em mim quando outros não acreditaram e me chamou para desenvolver esse trabalho.

Um grande agradecimento ao Prof. Fernando Santos pelo grande auxilio no desenvolvimento do trabalho e pelo grande companheirismo.

Gostaria de agradecer meus companheiros de trabalho Emerson e Vinicius pelas horas de discussões sobre geofísica, as horas de baixo do sol em campo e as horas nos bares da vida tomando umas.

Gostaria de agradecer aos meus amigos aqui da pós da geofísica pelo companheirismo e auxilio em todos os momentos. Em especial o Fábio Dias, companheiro desde a graduação, Bob, Nilton, Oleg, Eduardo (Matacão), Helen, Gabriel, Renata, Luciana, Alan, Andrea, dentre muitos outros.

Aos companheiros do IAG Vitor, Will, Divanir (Limeira), Cauã e muitos outros também.

Ao pessoal lá do Ap da Fubangação Limeira, Jorge e Gilmar.

Não posso esquecer também o pessoal da meteorologia que sempre foram meus amigos e companheiros. Em especial o Leke, Lu Eto, Lu Prado, Dylon, Angelica, Felippe, Dany entre muitos outros (de novo).

Ao pessoal da secretaria da Geofísica, a Teca e a Virgínia, que auxiliam a gente em todos os aspectos.

Aos técnicos de geofísica Ernande (tecnicuzão) e Marcelo (tecnicuzinho). 
Um grande agradecimento a todos que foram (arrastados) pra campo como o Tiago (XV), o Limeira, o Mazza e o Vinicius.

Agradecendo também ao pessoal de Bebedouro - SP seu Zé Cagnin, dona Didi e o Marcelo que nos divertiu em campo com suas mágicas. Não esquecendo do pessoal do Chiquinho Sorvetes.

Sem esquecer das "tias" do café e do pessoal da limpeza, que me proporcionaram ficar acordado num lugar limpo.

Também agradeço a CAPES pela bolsa de estudos que me financiou esse tempo todo. E a FAPESP (Processos nos. 2007/04325-0 e 2009/08466-3) que financiaram o projeto de Bebedouro.

Todos aqui foram fundamentais para o desenvolvimento deste trabalho, sem eles esse trabalho não seria realizado. 


\section{Sumário}

SUMÁRIO.

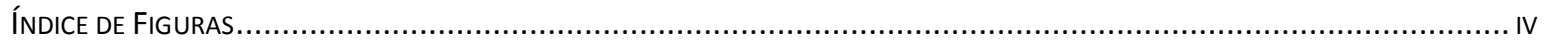

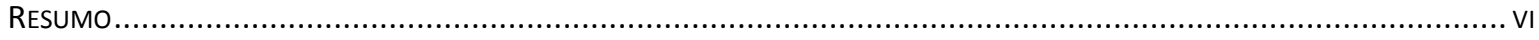

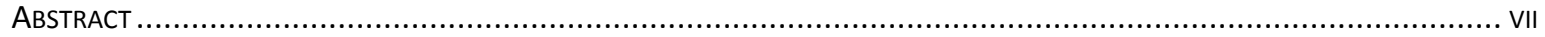

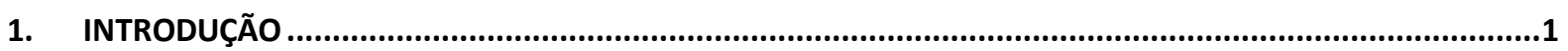

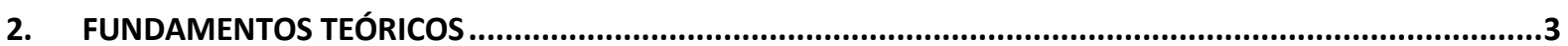

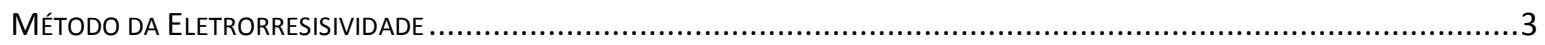

Condução Elétrica Num Meio Contínuo....................................................................................

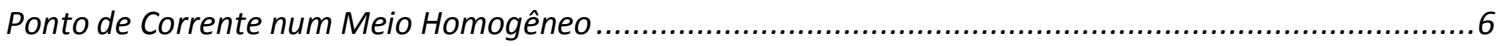

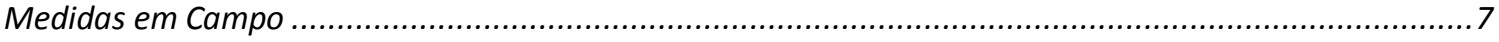

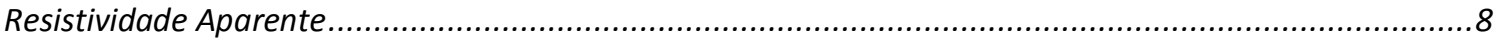

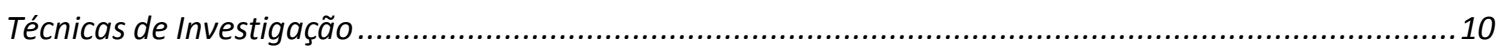

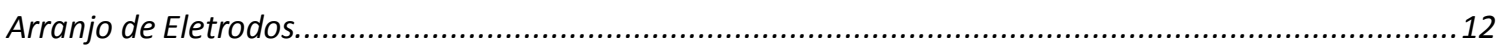

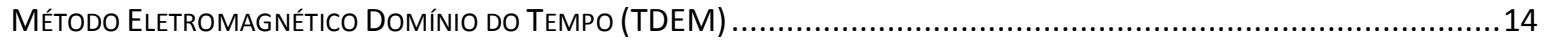

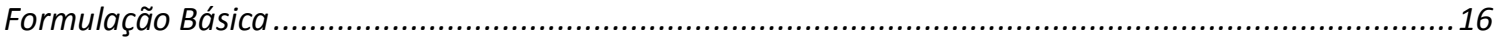

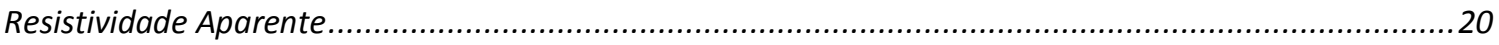

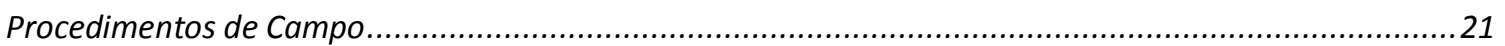

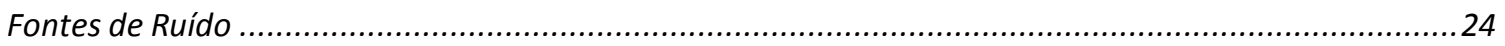

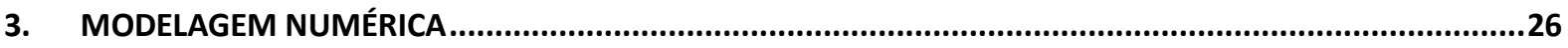

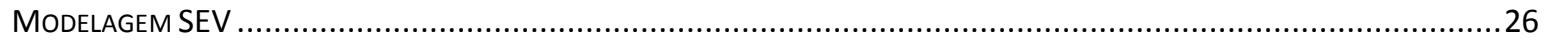

Distribuição do Potencial Elétrico na Superfície de Um Meio Estratificado ..........................................27

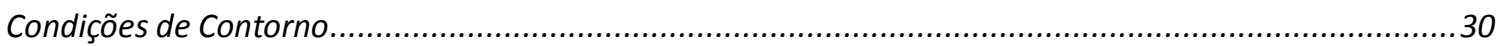

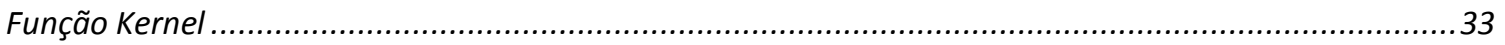

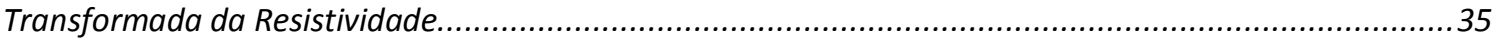

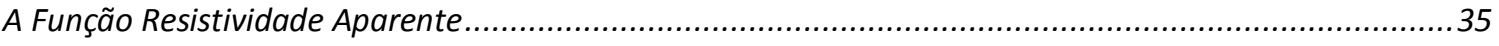

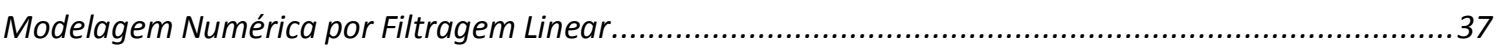

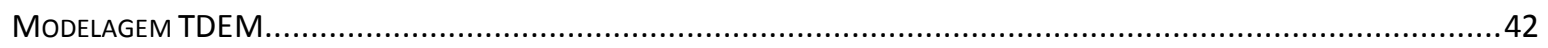

Equações de Maxwell no Domínio da Freqüência .......................................................................43

Dipolo Magnético Horizontal em um Meio Estratificado ..........................................................45

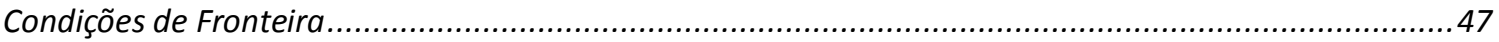

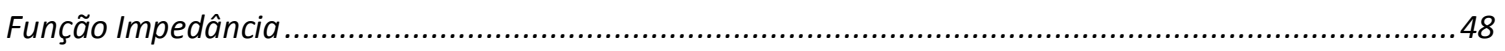

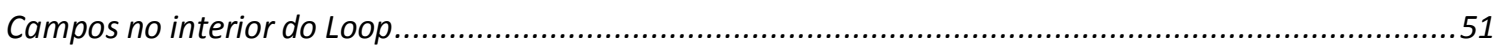

Modelagem Numérica por Filtragem Linear....................................................................5

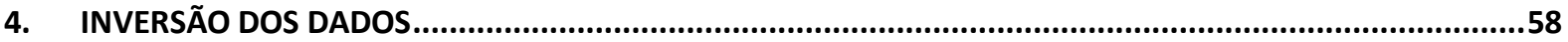

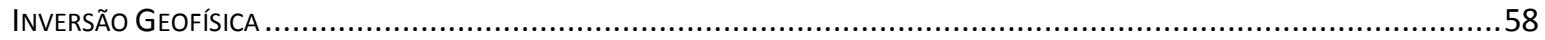




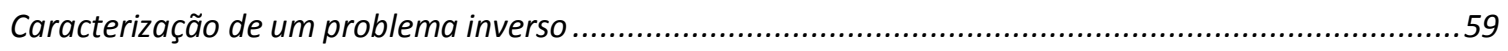

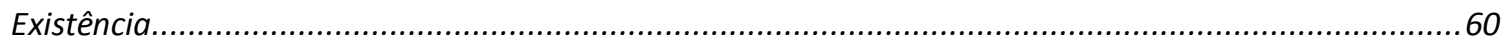

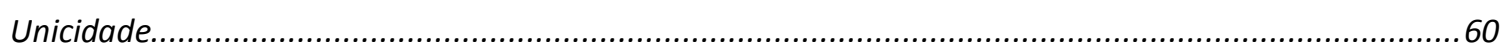

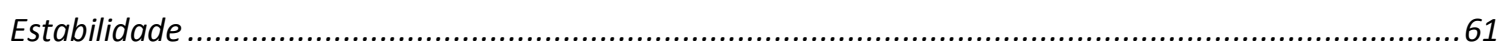

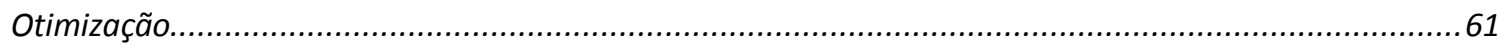

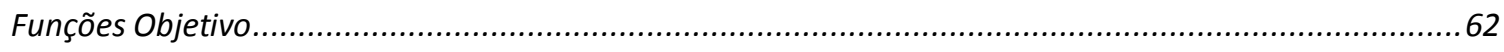

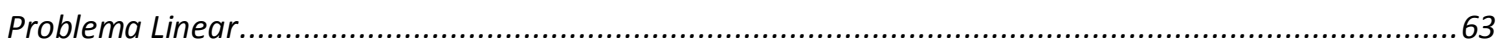

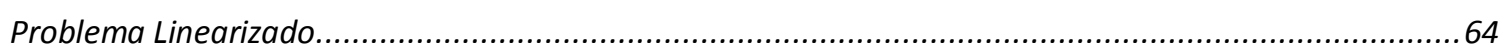

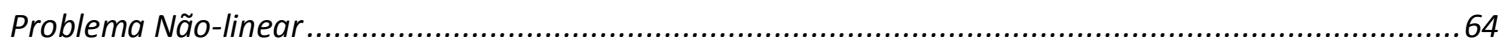

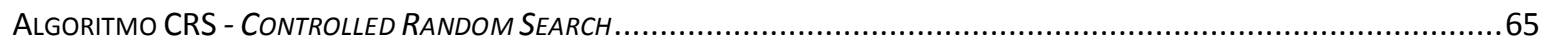

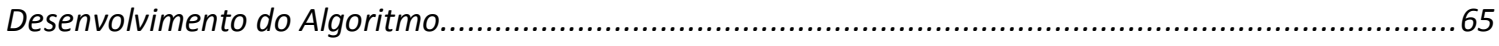

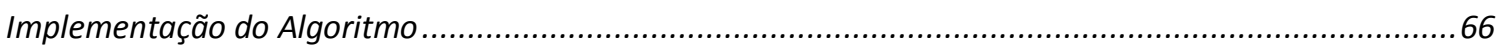

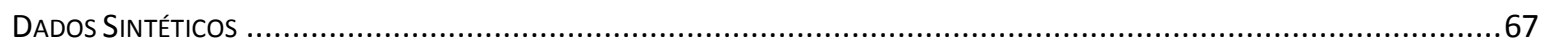

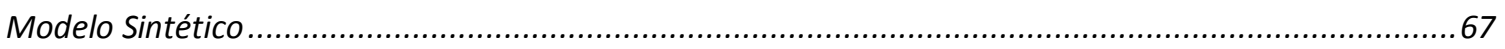

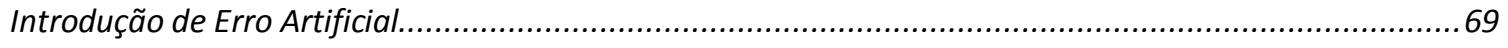

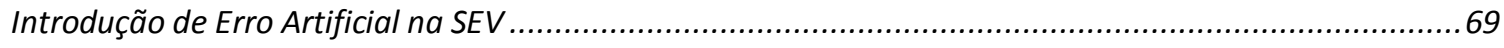

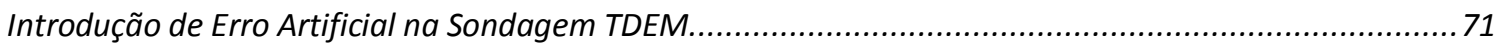

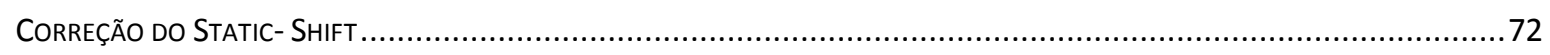

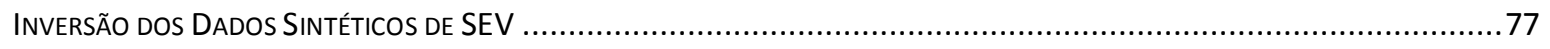

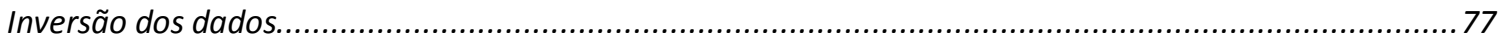

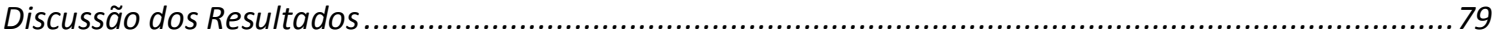

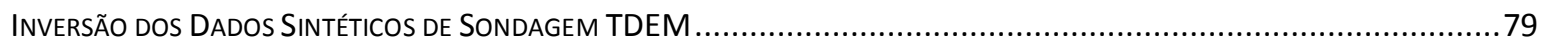

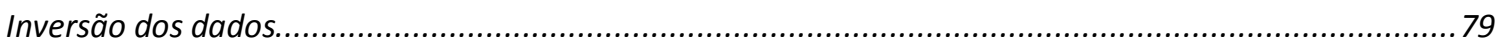

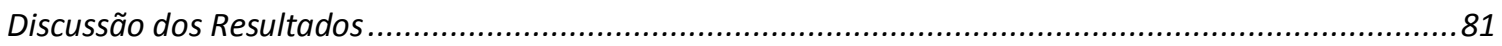

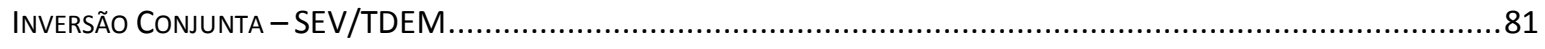

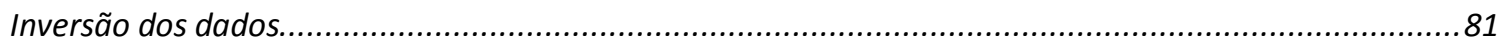

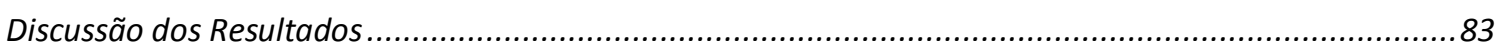

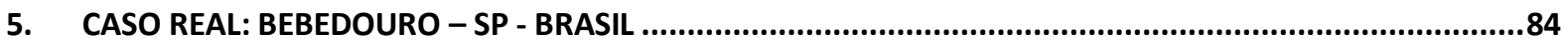

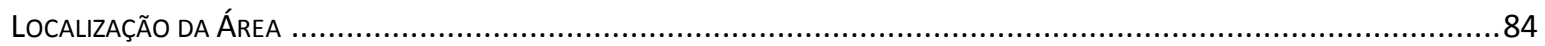

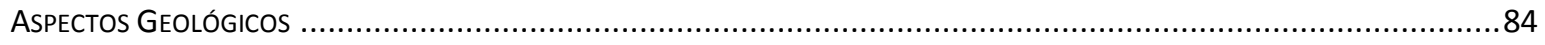

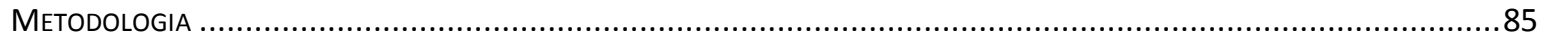

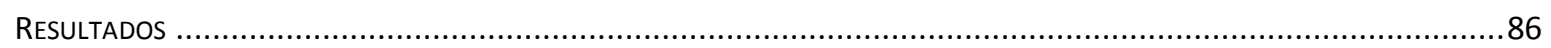

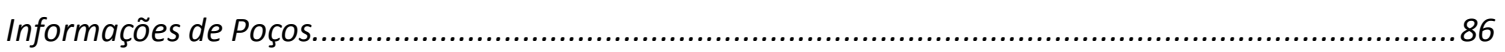

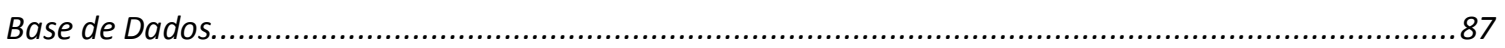

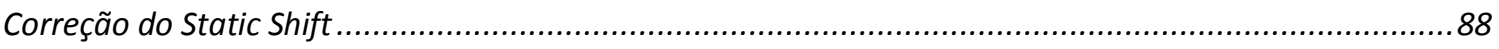

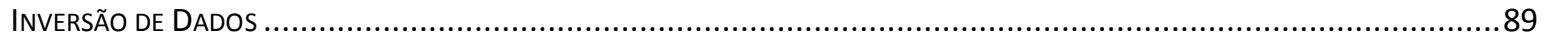

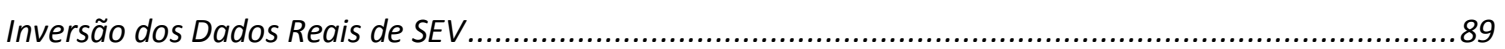

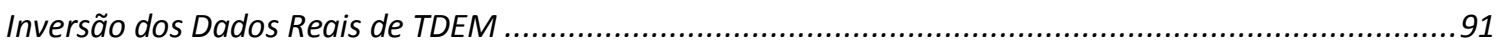




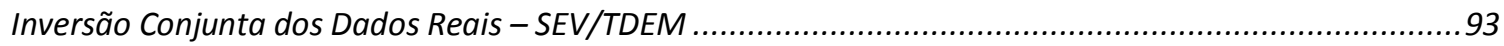

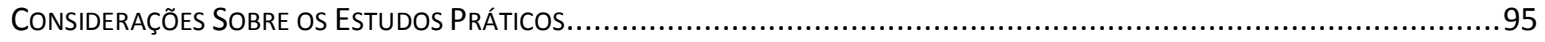

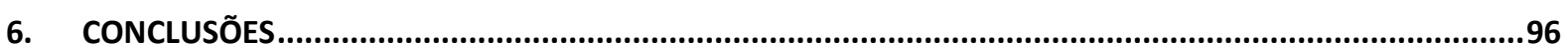

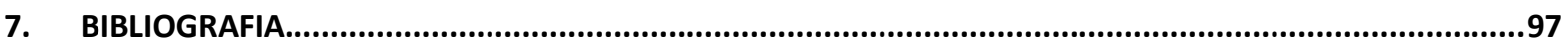

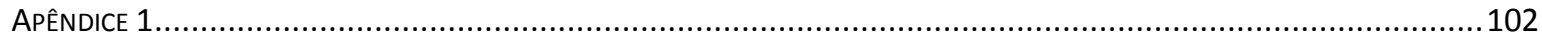




\section{Índice de Figuras}

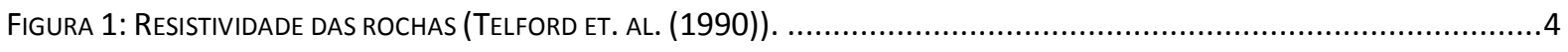

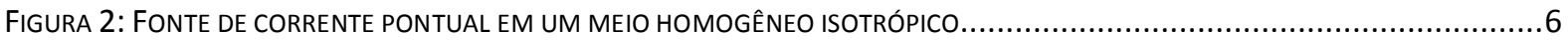

Figura 3: ARRANJo com quatro eletrodos. DoIS EXTERnOS DE INJEÇÃo DE CORRENTE E DOIS CENTRAIS PARA MEDIDAS DE

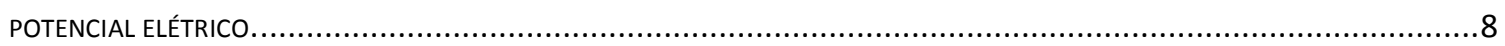

Figura 4: Distorções do fluXo de CORRENTE NUM MEIO heterogêneo. (AdPTAdo de BURGUer ET. AL.,1992) ....................9

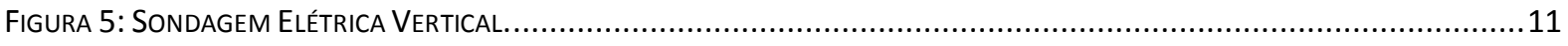

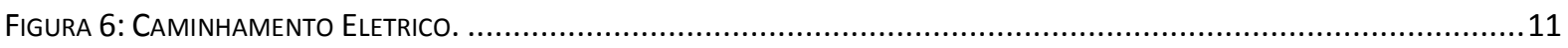

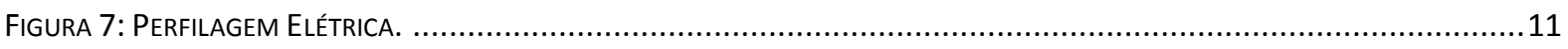

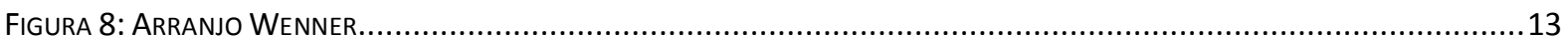

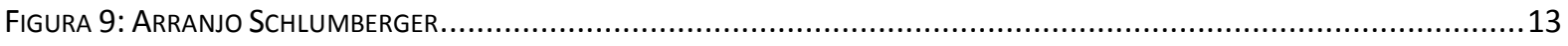

FIGURA 10: CORRENTES SECUNDÁRIAS GERADAS NO SUBSOLO. O PADRÃO DE PROPAGAÇÃO DAS CORRENTES NO SUBSTRATO É NA FORMA DE "SMOKE RINGS" (ANÉIS DE FUMAÇA). ADAPTADO DE (MCNEILL, 1994).............................................15

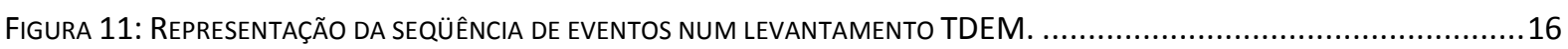

Figura 12: RepresentaÇÃo dos diversos tipos de ARRANJos tDEM. NA Figura “Tx” Representa os loops transmissores E

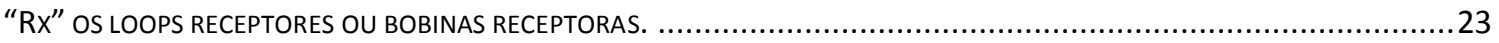

Figura 13: Fontes de Ruídos no método tDEM. Em “A” temos o acoplamento galvânico e em “B” o acoplamento CAPACITIVO.

FIGURA 14: REPRESENTAÇÃo dO MODELO GEOELÉTRICO dO SUBSOLO PARA A MODELAGEM DA SONDAGEM ELÉTRICA VERTICAL.......27

FIGURA 15: REPRESENTAÇÃO DA TRANSFORMADA DA RESISTIVIDADE $T$ PARA UMA TERRA ESTRATIFICADA COM $N$ CAMADAS. ........40

Figura 16: Modelagem SEV. EM “A” É Mostrado a RepresentaÇÃo de modelo geoléÉtrico. EM “B” É mostrado a RESPOSTA DESSE MODELO POR MEIO DE UM GRÁFICO DE RESISTIVIDADE APARENTE (OHM.M) POR AB/2 (M)..................42

FIGURA 17: REPRESENTAÇÃO DO MODELO GEOELÉTRICO DO SUBSOLO PARA A SONDAGEM TDEM.....................................43

FIGURA 18: RePRESENTAÇÃO DE RTE PARA UMA TERRA ESTRATIFICADA COM $N$ CAMADAS. .............................................53

Figura 19: Modelagem tDEM. Em “A” É mostrado a Representação de modelo geoelétrico. EM “B” É MOStrado A RESPOSTA DESSE MODELO POR MEIO DE UM GRÁFICO DE IMPEDÂNCIA (V/I) POR TEMPO (T) ................................56

Figura 20: Modelagem tDEM. Em “A” É Mostrado a RepresentaÇÃo de modelo geoelétrico. EM “B” É mostrado a RESPOSTA DESSE MODELO POR MEIO DE UM GRÁFICO DE RESISTIVIDADE APARENTE (OHM.M) POR TEMPO (T)...................57

Figura 21: FluXograma do funCIONAMENTO do ALGORITMO CRS - CONTROLLED RANDOM SEARCH...............................66

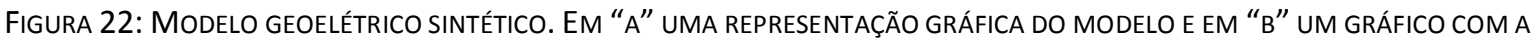

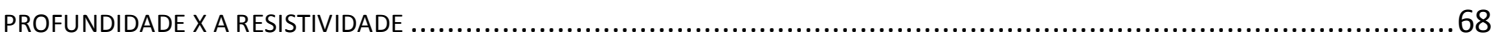

FIGURA 23: CoMPARAÇÃo ENTRE UMA CURVA SINTÉTICA COM RUÍdO E UMA CURVA REAL DE SEV.....................................70

FIGURA 24: COMPARAÇÃo ENTRE UMA CURVA SINTÉTICA COM RUÍDO E UMA CURVA REAL DE SONDAGEM TDEM. .....................72

Figura 25: CuRVAS de SONDAGEM ELÉTRICA E SONDAGEM TDEM NA ESCALA DE AB/2 (M) .......................................75

FIGURA 26: CURVAS DE SONDAGEM ELÉTRICA E SONDAGEM TDEM NA ESCALA DE TEMPO (S) .......................................75 
FIGURA 27: FIGURA COM VÁRIOS GRÁFICOS DE RESISTIVIDADE APARENTE (OHM.M) POR AB/2 (M). OS QUADRADOS PRETOS REPRESENTAM AS CURVAS DE SEV SEM CORREÇÃO DO STATIC SHIFT. OS QUADRADOS BRANCOS AS CURVAS DE SEV COM A CORREÇÃO DO STATIC SHIFT. E OS TRIÂNGULOS PRETOS AS CURVAS TDEM COM A ESCALA MUDADA PARA AB/2 (M). AdAPTADO DE MEJU (2005)

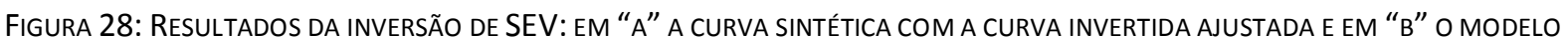
INVERTIDO COMPARADO COM O REAL. 78

Figura 29: Resultados da inVERSÃo do TDEM: EM “A” A CURVA SintétICA COM A CURVA INVERTIDA AJUSTADA E EM “ $B$ ” O MODELO INVERTIDO COMPARADO COM O REAL.

FIgURA 30: RESULTADOS DA INVERSÃo CONJUNTA SEV/TDEM: EM “A” A CURVA SINTÉTICA DA SEV COM A CURVA INVERTIDA AJUSTADA, EM “B” A CURVA SinTÉtICA do TDEM COM A CURVA INVERTIDA AJUSTADA E EM “C” O MOdelo INVERTIDO COMPARADO COM O REAL.

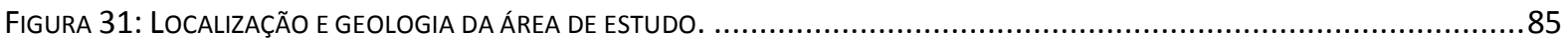

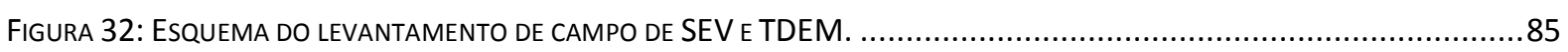

FIGURA 33: DADOS DE UM POÇO PRÓXIMO AOS LEVANTAMENTOS DE SEV E TDEM....................................................86

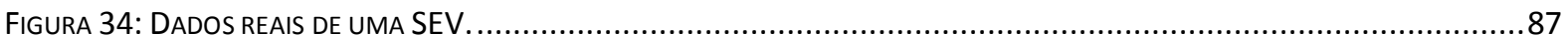

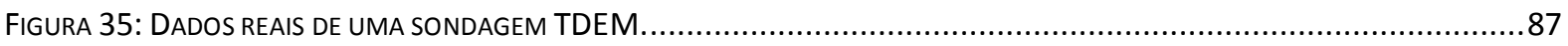

Figura 36: CoRreÇÃo do ESTATIC SHIFT dA CURVA de SEV NA ESCALA DE TEMPO (S). EM AZUL A CURVA SEM CORREÇÃo do STATIC SHIFT, EM VERMELHO A CURVA CORRIGIDA E EM PRETO A CURVA DA SONDAGEM TDEM.

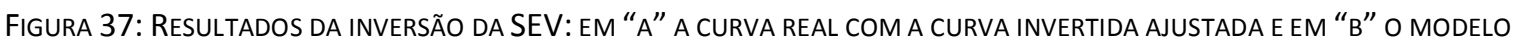
INVERTIDO COMPARADO COM O MODELO MÉDIO INICIAL.

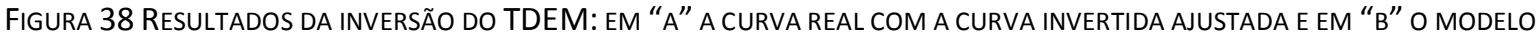
INVERTIDO COMPARADO COM O MODELO MÉDIO INICIAL.

Figura 39: RESULTAdOS dA INVERSÃo CONJUNTA SEV/TDEM: EM “A” A CURVA REAL DA SEV COM A CURVA INVERTIDA AJUSTADA, EM “ $B$ ” A CURVA REAL DO TDEM COM A CURVA INVERTIDA AJUSTADA E EM “ $C$ ” O MODELO INVERTIDO COMPARADO COM O MODELO MÉDIO INICIAL 


\section{$\underline{\text { Resumo }}$}

As sondagens elétricas verticais (SEV) e as sondagens eletromagnéticas no domínio do tempo (TDEM) são muito usadas em estudos ambientais, hidrogeológicos e em exploração mineral. A interpretação desses dados feita individualmente com modelos unidimensionais normalmente acarreta em resultados ambíguos. Isso acontece devido ao fato de que cada metodologia "enxerga" a subsuperfície de uma forma diferente. No caso da SEV as estruturas resistivas são bem detectadas, já no caso da sondagem TDEM as estruturas condutivas é que são detectadas com melhor precisão. Outra diferença é a capacidade da SEV conseguir identificar melhor as estruturas rasas, por outro lado, as sondagens TDEM permitem investigar as estruturas mais profundas. Nesta pesquisa foram exploradas as potencialidades das SEVs e das sondagens TDEM, visando obter uma interpretação dos dados mais consistentes. Neste sentido foi desenvolvido um programa em Matlab para a inversão conjunta 1D de dados de SEV e TDEM, na qual explora "o melhor" de ambos os métodos. $O$ algoritmo desenvolvido foi testado inicialmente com dados sintéticos e posteriormente foi empregado em dados reais adquiridos na bacia sedimentar do Paraná, na região de Bebedouro no Estado de São Paulo. O resultado final da inversão conjunta de dados de SEV/TDEM permitiu obter um modelo geoelétrico que mais se assemelha às condições geológicas reais, e cujas ambigüidades, que são inerentes ao processo de interpretação, foram minimizadas. Os resultados tanto com dados sintéticos quanto com dados reais foram são bastante promissores, mostram uma melhor recuperação dos meios modelados e um grande potencial de aplicações em estudos geocientíficos, em particular em estudos hidrogeológicos.

Palavras chave: Inversão SEV, Inversão TDEM, Inversão Conjunta SEV/TDEM, Bacia do Paraná, Bebedouro - SP, Brasil. 


\section{Abstract}

Electrical (DC) and transient electromagnetic (TEM) soundings have been used in a great number of environmental, hydrological and mining exploration studies. The data interpretation usually is done individually by $1 \mathrm{D}$ models resulting in ambiguous results. This fact can be explained by how the two different methodologies observe the medium below the surface. The vertical electrical sounding (VES) is good at marking very resistive structures, while the transient electromagnetic sounding (TEM) is very sensitive to map conductive structures. Another difference is that the VES detects better shallow structures, while the TEM soundings can reach deeper ones. In this research we explore the potentials of the both VES and TEM soundings, in order to obtain a more consistent interpretation of the data. In this way, a Matlab program for the joint inversion for DC and TEM soundings was developed aiming explore the best of the both methods. Initially, the algorithm was tested with synthetic data and after were used real data from Paraná Sedimentary Basin in Bebedouro region, São Paulo State. The geoelectrical model obtained from joint inversion of DC and TEM data are more similar to the real geological condition and the ambiguities were minimized. The results with synthetic and real data shows that the joint inversion of DC/TEM is better for recovering the simulated models and shows a great potential in geological studies, particularly in hidrogeological studies.

Keywords: VES inversion, TEM inversion, Joint Inversion VES/TEM, Paraná Basin, Bebedouro - SP, Brazil. 


\section{Introdução}

Na geofísica aplicada à exploração de recursos naturais, as ambigüidades no processo de interpretação dos resultados estão sempre presentes. Uma forma de reduzir tais ambigüidades consiste na utilização em conjunto de mais de um método geofísico. Com uma gama maior e mais abrangente de dados, as ambigüidades podem ser reduzidas e o resultado final pode, por sua vez, se tornar mais confiável. Dessa forma o problema em questão consiste em buscar informações confiáveis das propriedades físicas da subsuperfície. Os dados podem ser referentes a uma mesma propriedade física ou a uma porção delas, podendo ser estudada sob diferentes formas. A resistividade elétrica, por exemplo, pode ser obtida tanto por meio dos métodos elétricos, como também por métodos eletromagnéticos.

Os métodos elétricos (DC) são muito utilizados na geofísica brasileira e mundial. As aplicações desses métodos vão desde geotecnia, passando por mineração, estudos ambientais e hidrogeológicos. São muito utilizados devido o seu baixo custo relativo, rapidez e confiabilidade dos levantamentos. Os levantamentos eletromagnéticos, também muito difundidos, são utilizados em exploração mineral, geotecnia e hidrogeologia. Eles podem ser divididos em métodos eletromagnéticos no domínio da freqüência (FDEM) e no domínio do tempo (TDEM). Mesmo sendo pouco utilizado no Brasil, o TDEM possui grande potencial para diversos estudos, principalmente em estudos hidrogeológicos. E assim como todos os métodos geofísicos, possui vantagens e limitações.

O método eletromagnéticos no domínio do tempo (TDEM) ou Transient Electromagnetic (TEM) é muito bom para marcar com precisão estruturas condutivas, além de possuir uma grande profundidade de investigação (em relação ao tamanho do loop utilizado). O método da sondagem elétrica vertical (DC) por sua vez define muito bem estruturas resistivas, além de conseguir detectar as camadas mais superficiais do subsolo. Dessa forma, os métodos DC e TDEM são complementares entre si. No caso do método da eletrorresistividade (técnica de sondagem elétrica vertical - SEV), a resistividade elétrica é obtida em função da abertura dos eletrodos de correntes. Já no caso da sondagem TDEM a resistividade é obtida em função do tempo de resposta do meio. Este fato gera problemas de equivalência no processo de inversão dos dados. Sendo assim é necessário um método computacional para o processamento e interpretação desses resultados.

Para se poder analisar os resultados de SEV e TDEM de forma mais precisa e confiável é necessário fazer a inversão conjunta das duas bases de dados. Neste caso, a inversão dos dados de 
SEV e TDEM é feita simultaneamente. Os trabalhos pioneiros relacionados com a inversão conjunta de dados magnetoteluricos (MT) e sondagens elétricas verticais (SEV) são atribuídos a Vozoff \& Jupp (1975). Nesse artigo é mostrado as vantagens da inversão conjunta, mostrando como esse processo é sinérgico, i.e., o resultado final é mais que a soma dos resultados individuais dos dois métodos. Nesta linha de estudos, alguns trabalhos internacionais já trataram das vantagens da inversão conjunta de dados DC e TDEM (Raiche et al., 1985; Yang \& Tong, 1988; Meju, 1996). Santos at. al. (2009) fizeram um estudo comparativo entre diversos métodos de inversão para esse problema de inversão conjunta. Todos mostram as vantagens da utilização conjunta das duas metodologias. As aplicações para a inversão conjunta desses métodos vão de estudos hidrogeológicos (Goldman et al., 1994; Albouy et al., 2000) até estudos de potencial de risco de encostas (Schmutz et. al., 2000, Schmutz et. al., 2009).

Nas pesquisas realizadas na literatura específica, constatou-se que no Brasil ainda não foram desenvolvidas pesquisas na área de inversão conjunta de dados de SEV e TDEM. Pelo menos não foram encontradas referências nesta linha de pesquisa até o presente momento. Dessa forma, esta pesquisa abordará o problema de inversão conjunta de dados geoelétricos, onde se propõe o desenvolvimento e a implementação de um algoritmo para a inversão conjunta (1D) de dados de SEV e TDEM. Os resultados da inversão conjunta serão comparados com os resultados das inversões individuais, visando uma análise da diferença das interpretações quando se trabalha com métodos individualmente e em conjunto. Portanto, esta pesquisa poderá ser de grande interesse principalmente pela sua aplicação em estudos hidrogeológicos, com ênfase no mapeamento de aqüíferos sedimentares e fraturados em solos tropicais. 


\section{Fundamentos Teóricos}

\section{Método da Eletrorresisividade}

O método da eletrorresistividade busca determinar a distribuição da resistividade elétrica nas camadas do substrato. O método consiste em injetar correntes elétricas, geradas de forma artificial, no solo. Então são medidas na superfície as diferenças de potencial e dessa forma é possível ter um idéia da distribuição das propriedades elétricas da subsuperfície. A variação da resistividade então é associada a diferentes materiais geológicos ou variações na composição na mesma feição geológica, devido à presença de água, fraturas, composição mineralógica etc.

A resistividade é uma propriedade física intrínseca de um material. Ela é definida como a resistência em ohms entre as faces opostas de um cubo unitário do material. Para um cilindro condutor de resistência $d R$, comprimento $d L$ e área de seção transversal $d A$, a resistividade é dada por:

$$
\rho=\frac{d R d A}{d L}
$$

no SI a unidade de resistividade é o ohm-metro (Ohm.m).

A resistividade elétrica é uma propriedade física das mais variáveis. Certos minerais, como metais nativos e grafite, conduzem eletricidade via passagem de elétrons (condutividade eletrônica). Porém a maior parte dos minerais formadores de rochas é isolante. A corrente elétrica então é conduzida principalmente através da passagem de íons nas águas dos poros (condutividade iônica). A maior parte das rochas conduz eletricidade por processos eletrolíticos mais que por processos eletrônicos. Essa condutividade iônica é principalmente devido à quantidade de água, a natureza dos sais dissolvidos e a porosidade total comunicante.

Praticamente todas as rochas possuem porosidade, em proporção maior ou menor, os quais podem estar ocupados, totais ou parcialmente, por eletrólitos. As rochas cristalinas por sua vez, possuem porosidade intergranular insignificante. Porém são condutoras ao longo de fraturas ou fissuras (onde pode percolar água). Em comum está o fato de tanto os poros cheios de eletrólitos quanto fraturas condutoras se comportarem como condutores iônicos onde dessa forma possuem 
resistividades muito variáveis. Na Figura 1 é mostrado o intervalo de resistividades esperado para os tipos de rocha comum.

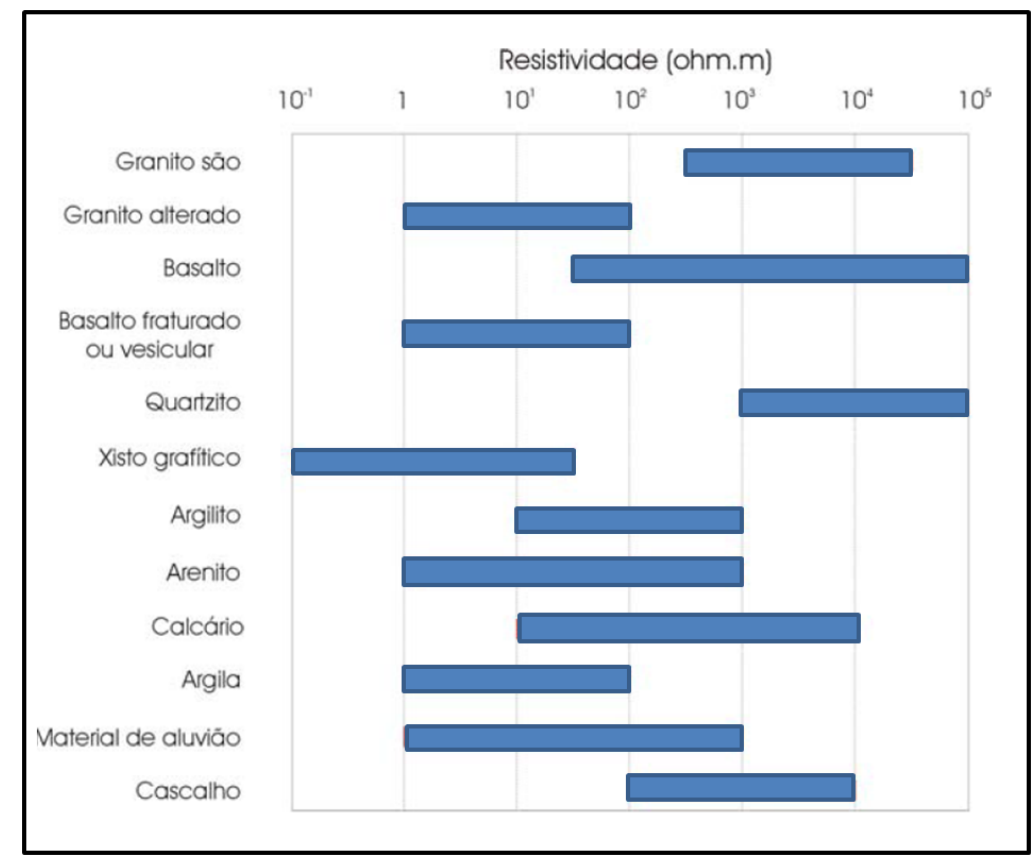

Figura 1: Resistividade das rochas (Telford et. al. (1990)).

Pela Figura 1 pode-se ver que um mesmo tipo litológico pode apresentar uma ampla variação nos valores de resistividade. Para se efetuar uma correlação adequada com a geologia, em uma determinada área de estudo, é fundamental a localização geográfica e o entendimento da geologia local em termos estratigráficos. Uma vez que as margens de variação de resistividade numa área de estudo são muito mais reduzidas. Dessa forma é possível identificar as rochas em função da resistividade.

\section{Condução Elétrica Num Meio Contínuo}

A corrente elétrica $I(A)$ em um condutor curto, fino e linear, de seção transversal uniforme é dada segundo a Lei de Ohm tal que: 


$$
I=-\frac{d V}{R}
$$

onde $d V$ é a diferença de potencial $(V)$ entre as extremidades do condutor e $R(\Omega)$ é a resistência do condutor. O sinal de menos na equação 2.2 expressa o fato do fluxo de corrente ser no sentido do maior para o menor potencial, ou seja, na direção oposta ao aumento do potencial (o gradiente). $R$ é diretamente proporcional ao comprimento $d l(m)$ do condutor e inversamente a seção transversal $s\left(m^{2}\right)$ tal que:

$$
R=\rho \frac{d l}{S}
$$

onde a constante de proporcionalidade $\rho$ é a resistividade $(\Omega . m)$ do material condutor. Deve-se tomar cuidado com a distinção entre resistência e resistividade. A resistência é uma característica de um caminho particular pela qual passa uma corrente. Já a resistividade é uma propriedade física de um material.

Das equações 2.2 e 2.3 temos que:

$$
\frac{I}{S}=-\frac{1}{\rho} \frac{d V}{d l}
$$

o lado esquerdo da equação é a densidade de corrente $j$ (a corrente por área unitária de seção transversal, $\left.\mathrm{A} \cdot \mathrm{m}^{-2}\right)$, enquanto $-d V / d l$ do lado direito é o campo elétrico $E\left(\mathrm{~V} \cdot \mathrm{m}^{-1}\right)$ na direção do vetor densidade de corrente. Dessa forma

$$
j=\frac{E}{\rho}
$$

ou de outra forma

$$
j=\sigma E
$$

onde $\sigma$ é a condutividade do material, Siemen por metros $\left(\mathrm{S} . \mathrm{m}^{-1}\right)$, também chamada de mho por

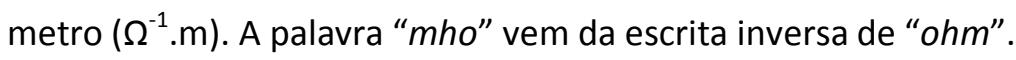

Se fizermos o comprimento $d l$ em 2.4 tender a zero e considerarmos o condutor linear como um elemento homogêneo e isotrópico de um meio contínuo, como um bloco de rocha,então, tanto a equação 2.5 quanto a 2.6 expressam a lei de Ohm para tal meio. Num meio isotrópico $\sigma$ e $\rho$ são independentes da direção do fluxo de corrente. 
Considere um eletrodo pontual na superfície de uma terra homogênea e isotópica que se estende infinitamente para baixo e para os lados, com resistividade $\rho$, conforme a Figura 2 :

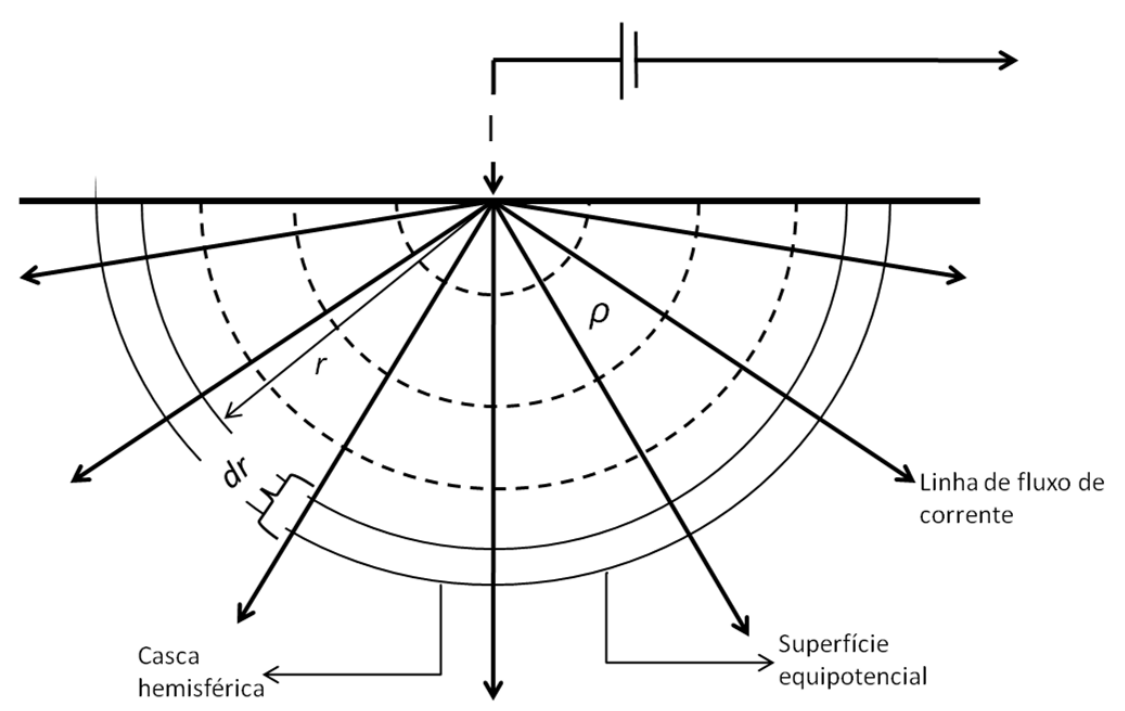

Figura 2: Fonte de corrente pontual em um meio homogêneo isotrópico.

Dessa forma é formada a partir do eletrodo uma casca hemisférica de radio $r$ e espessura $d r$. Por simetria, a corrente em qualquer ponto da casca vai estar a mesma distância $r$ da fonte de corrente (o eletrodo). Se a corrente total passando do eletrodo para o meio é $I$, a diferença infinitesimal de potencial elétrico entre as faces da casca pode ser escrita, segundo 2.4, como:

$$
d V=-\frac{I \rho d r}{2 \pi r^{2}}
$$

Integrando a equação acima temos o potencial a uma distância $r$ da fonte de corrente dado por:

$$
V(r)=\frac{I \rho}{2 \pi} \frac{1}{r}+C
$$

onde $C$ é uma constante arbitrária. Se $V$ é tido como zero em $r=\infty$, então $C=0$, dessa forma temos: 


$$
V(r)=\frac{I \rho}{2 \pi} \frac{1}{r}
$$

A equação 2.9 é a equação principal para os métodos elétricos.

\section{Medidas em Campo}

Na prática precisamos de dois eletrodos de corrente para fechar o circuito. Então o próximo passo é determinar o fluxo de corrente em um meio homogêneo e isotrópico com dois eletrodos de corrente. Nesse caso a corrente deve fluir do eletrodo de corrente positivo (a fonte) para o negativo (o sorvedouro). O potencial em qualquer ponto $P$ na superfície pode ser calculado utilizando a equação 2.9. Para dois eletrodos de corrente $A$ e $B$, o potencial em $P$ será:

$$
V_{P}=\frac{i \rho}{2 \pi r_{A}}+\left(-\frac{i \rho}{2 \pi r_{B}}\right)
$$

onde $r_{A}$ e $r_{B}$ são respectivamente a distância do ponto $P$ do eletrodo A e do eletrodo $\mathrm{B}$.

Do mesmo modo que são necessários dois eletrodos de corrente para fechar o circuito de injeção de corrente, são necessários dois eletrodos de potencial para fechar o circuito de medida de potencial. A Figura 3 mostra um arranjo genérico com quatro eletrodos. Nele estão os dois eletrodos de corrente, A e B (eletrodos externos), e dois eletrodos de potencial, M e N (eletrodos internos). Usando a equação 2.10 podemos calcular o potencial em M e N:

$$
V_{M}=\frac{I \rho}{2 \pi}\left(\frac{1}{\overline{A M}}-\frac{1}{\overline{B M}}\right)
$$

e

$$
V_{N}=\frac{I \rho}{2 \pi}\left(\frac{1}{\overline{A N}}-\frac{1}{\overline{B N}}\right)
$$

e assim obter a diferença de potencial, $d V$, entre eles:

$$
\Delta V_{M N}=\frac{I \rho}{2 \pi}\left(\frac{1}{\overline{A M}}-\frac{1}{\overline{B M}}-\frac{1}{\overline{A N}}+\frac{1}{\overline{B N}}\right)
$$


No método da resistividade elétrica a corrente é injetada no solo, a diferença de potencial é medida e a resistividade é determinada. Uma vez que a resistividade é o parâmetro a ser determinado, resolvemos a equação 2.13 para obter $\rho$ que é dado por:

$$
\rho=K \cdot \frac{\Delta V}{I}
$$

onde $K$ é a constante geométrica, que é dada da seguinte forma:

$$
K=2 \pi\left(\frac{1}{\overline{A M}}-\frac{1}{\overline{B M}}-\frac{1}{\overline{A N}}+\frac{1}{\overline{B N}}\right)^{-1}
$$

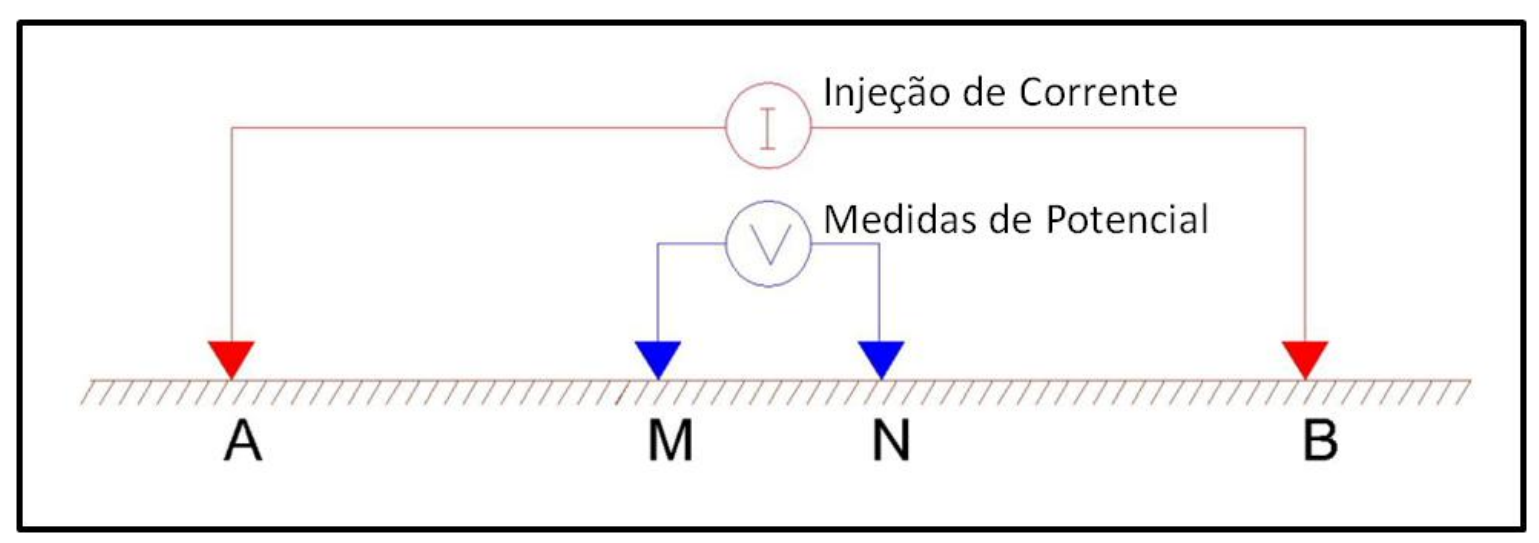

Figura 3: Arranjo com quatro eletrodos. Dois externos de injeção de corrente e dois centrais para medidas de potencial elétrico.

\section{Resistividade Aparente}

Quando calculamos a equação 2.14 assumimos uma subsuperfície homogênea e isotrópica. Porém a Terra não é homogênea, e dessa forma o valor da resistividade calculada, pela equação 2.14, provavelmente não é igual a do material que os eletrodos estão inseridos. 0 termo adequado para a resistividade calculada pela equação 2.14 , é resistividade aparente. 0 termo resistividade aparente $\left(\rho_{a}\right)$ vem do fato que o potencial medido pelos eletrodos $\mathrm{MN}$ está relacionado à passagem da corrente injetada em $A B$ em um meio heterogêneo. $O$ fluxo de corrente fez um caminho pelo subsolo no qual passa por diversas camadas com resistividades diferentes. O potencial medido então 
não é devido à passagem da corrente por um único meio de resistividade $\rho$, mas sim é equivalente a passagem da corrente por um meio de resistividade $\rho_{a}$. No qual a resistividade resultante seria equivalente a uma média ponderada de todas as camadas pela qual a corrente passou. Por isso o termo resistividade aparente é usado, porque a resistividade obtida não está diretamente ligada a uma camada, mas sim a um conjunto de camadas pelo qual a corrente injetada passou. Sendo assim a equação 2.14 fica sendo:

$$
\rho_{a}=K \cdot \frac{\Delta V}{I}
$$

A Figura 4 mostra como um meio heterogêneo pode distorcer o fluxo de corrente em comparação a um meio homogêneo. Nela podemos ver as diferenças no fluxo de corrente conforme o aumento do espaçamento entre os eletrodos num meio heterogêneo. Com um espaçamento pequeno em relação a espessura da camada, o fluxo se comporta como em um meio homogêneo. Porém conforme o espaçamento aumenta, a influência da segunda camada no fluxo de corrente faz com que ele se distorça. E quanto maior esse espaçamento, maior é a influência da segunda camada, ou seja, maior é o caminho que a corrente irá percorrer. E com isso maiores são as distorções do fluxo. O levantamento eletrorresistivo consiste então em explorar essa idéia de distorção do fluxo de corrente no substrato. Com a mudança na posição dos eletrodos é possível explorar as camadas inferiores do substrato (como na Figura 4) ou explorar as variações laterais de resistividade.

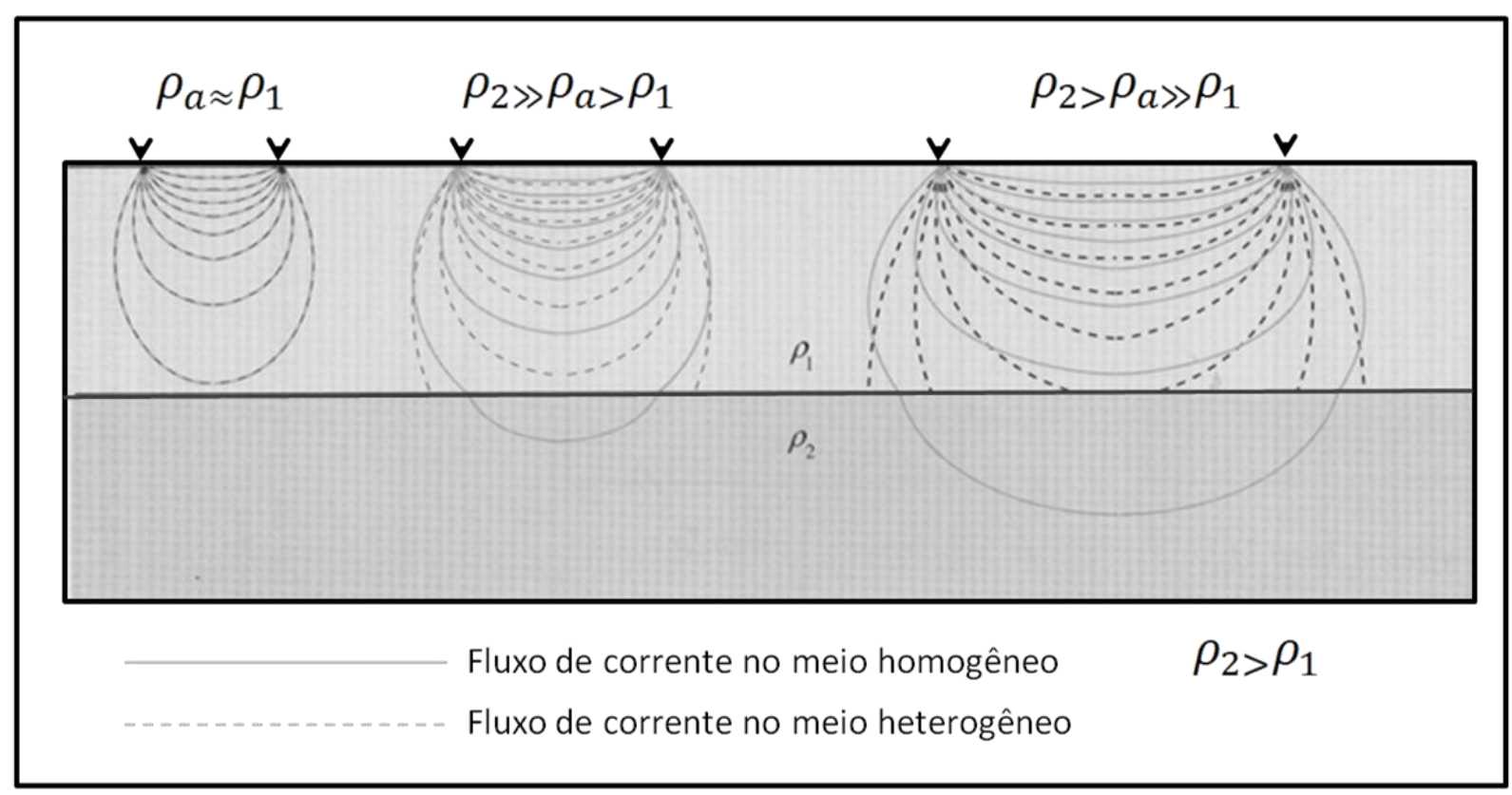

Figura 4: Distorções do fluxo de corrente num meio heterogêneo. (Adptado de Burguer et. al.,1992) 


\section{Técnicas de Investigação}

Os levantamentos eletrorresistivos podem ser feitos visando três objetivos diferentes: determinar a variação da resistividade em função da profundidade (sondagem elétrica vertical), a variação lateral da resistividade (caminhamento elétrico) ou estudos da variação da resistividade dentro de poços (perfilagem elétrica). A diferença entre essas técnicas está no procedimento de campo usado para se obter a resistividade. Ou seja, a diferença está na disposição dos eletrodos na superfície do terreno ou no interior de furos de sondagens e na maneira como o trabalho é desenvolvido para se obter os dados de campo.

A sondagem elétrica vertical (SEV) é usada em situações cujo objetivo é investigar em profundidade os diferentes tipos geológicos. Determinando dessa forma as espessuras e resistividades das camadas sobrepostas. A investigação é tida como sendo a partir de um único ponto na superfície do terreno, que é o centro do arranjo. Isso quer dizer que os valores medidos são tidos como sendo abaixo desse ponto. Um esquema da SEV pode ser visto na Figura 5 . Nele pode-se ver como a investigação das camadas inferiores é feita aumentando a distância dos eletrodos de corrente em relação ao centro do arranjo. A Sondagem Elétrica Vertical é uma ferramenta importante para a geofísica a quase um século. Desenvolvida no início do século XX, ainda é amplamente utilizada no mundo todo por ser uma técnica relativamente simples, robusta e que gera resultados preliminares já no instante da medida. A própria curva de resistividade aparente já dá indícios do modelo geoelétrico na área de estudo.

A técnica do caminhamento elétrico (CE) por sua vez aplica-se principalmente em pesquisas que visam determinar descontinuidades laterais nos materiais geológicos. Tais descontinuidades podem ser: diques, sills, contatos geológicos, fraturamentos e/ou falhamentos ou corpos mineralizados. O caminhamento elétrico também é muito utilizado em estudos ambientais para mapear plumas de contaminação. Um esquema de como funciona o CE está na Figura 6 . Ao contrário da SEV, o caminhamento não tem apenas um ponto associado em superfície, mas sim, uma série de pontos que formam uma linha em superfície.

A perfilagem elétrica é uma técnica utilizada e desenvolvida no interior de furos de sondagem. O objetivo principal é estudar a variação da resistividade in situ. É principalmente utilizada em hidrogeologia, mineração e na prospecção de petróleo. Um esquemático da perfilagem elétrica está na Figura 7. Nela todos os eletrodos ou parte deles estão em uma sonda que desce por um furo de sondagem. Com isso as medidas são feitas nas laterais do poço. É ideal para se 
determinar a interface de níveis arenosos/argilosos, diferenças de permeabilidade ou diferenças de concentração de algum elemento.

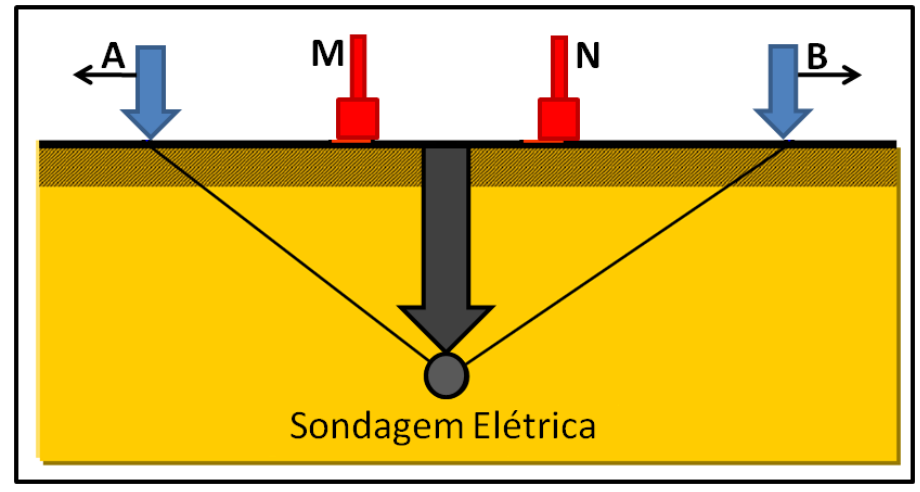

Figura 5: Sondagem Elétrica Vertical.

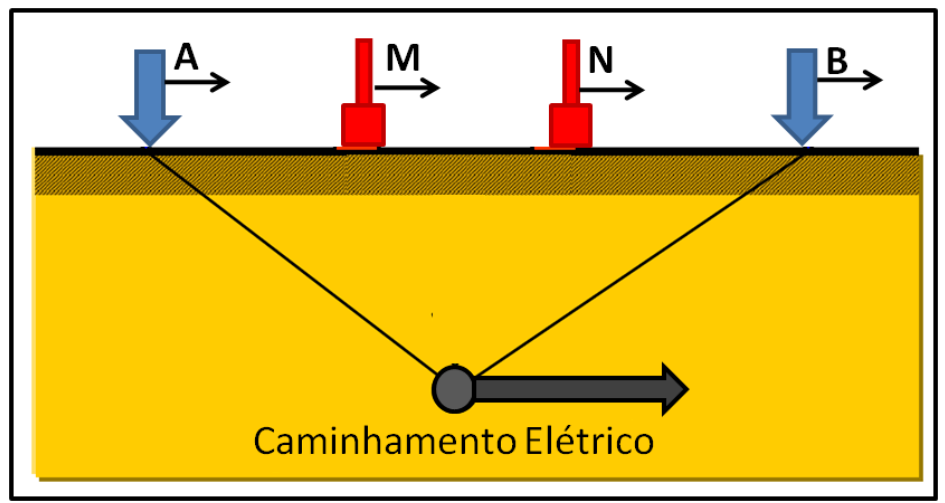

Figura 6: Caminhamento Eletrico.

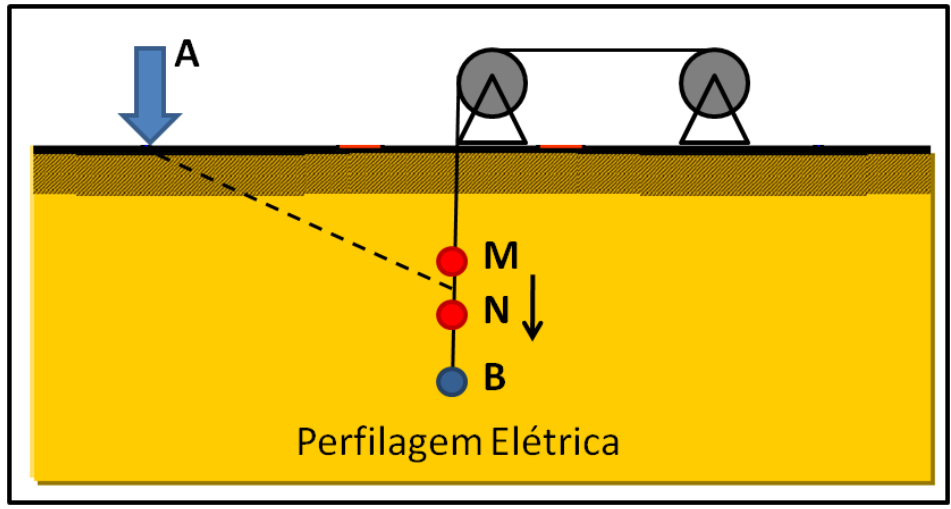

Figura 7: Perfilagem Elétrica. 


\section{Arranjo de Eletrodos}

Nessa pesquisa foi empregada a técnica da sondagem elétrica vertical, que lida com a variação da resistividade em função da profundidade. Então dessa forma será abordada apenas as configurações de eletrodos usados nessa técnica. Os principais arranjos usados na sondagem elétrica vertical são os arranjos Wenner e Schlumberger. O arranjo Wenner é principalmente usado nos Estados Unidos, Canadá e Inglaterra. Já o arranjo Schlumberger é o mais utilizado na Europa (em especial na França), na Rússia, nos países que integravam o antigo bloco soviético e no Brasil. Ambos os arranjos surgiram no início do século XX. O arranjo Schlumberger foi desenvolvido por Conrad Schlumberger na França. Enquanto que na mesma época Frank Wenner desenvolveu nos EUA o seu arranjo homônimo.

Ambos os arranjos utilizam quatro eletrodos, dois de corrente e dois de potencial. Os eletrodos de corrente ficam nos extremos do arranjo e vão se distanciando em relação ao centro. Dessa forma investigam-se as camadas mais profundas. Os dois arranjos diferem entre si no modo como os eletrodos são arranjados em superfície. No caso do arranjo Wenner a distância entre os eletrodos é sempre a mesma (normalmente essa distância é dita $a$ ), e a cada mudança, todos os eletrodos são mudados. Na Figura 8 tem-se um esquema do funcionamento do arranjo Wenner. No caso do arranjo Schlumberger, os eletrodos de potencial ficam muito mais próximos do centro, e não mudam a cada medida. Só são mudados quando o sinal medido entre os eletrodos de potencial fica abaixo do ruído local ou da precisão do equipamento usado. Um esquema simplificado do arranjo Schlumberger está na Figura 9. O levantamento de campo com esse arranjo acaba sendo mais rápido se comparado com o arranjo Wenner, uma vez que apenas os eletrodos de corrente são mudados a cada medida. Ele também sofre menos influências laterais, menos influências devido a irregularidades na superfície do terreno e ruídos produzidos por fontes artificiais. Neste trabalho o arranjo utilizado é o Schlumberger, que é o mais utilizado na escola brasileira de geofísica, melhor se adéqua aos nossos interesses, portanto, este arranjo foi empregado nesta pesquisa. Informações mais detalhadas sobre o método da eletrorresistividade e as técnicas de aquisição dos dados podem ser obtidas em Telford et. al. (1990), Burguer et. al. (2006) e Parasnis (1962). 


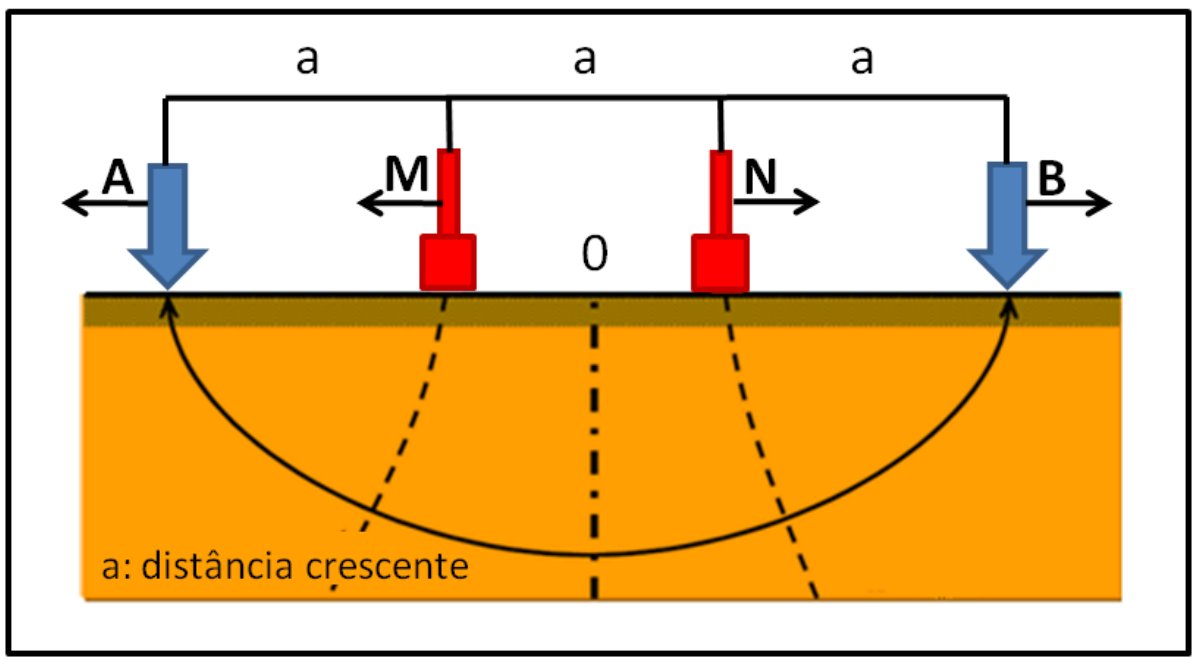

Figura 8: Arranjo Wenner.

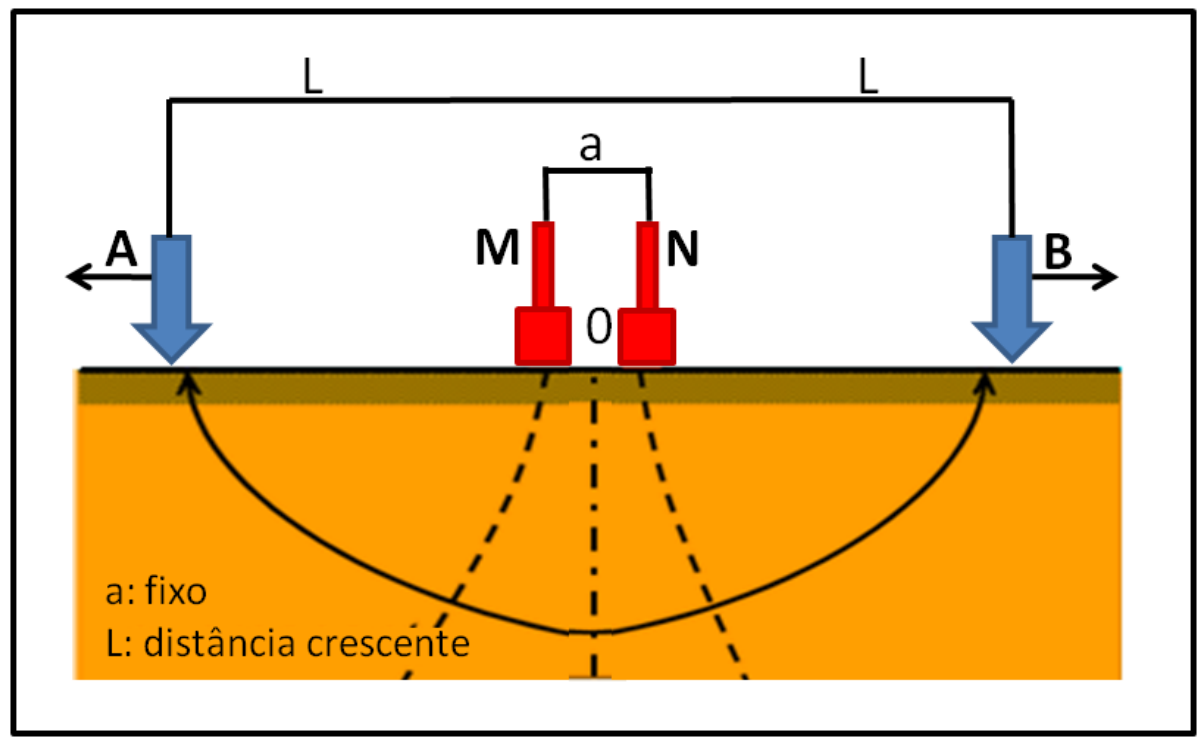

Figura 9: Arranjo Schlumberger 


\section{Método Eletromagnético Domínio do Tempo (TDEM)}

O método TDEM surgiu na União Soviética nos anos 60 do século XX. Mas seu uso no ocidente começou somente a partir de 1972. Ele surgiu da necessidade de investigar alvos em profundidade e em locais com resistividade muito baixa. Nestas condições, os métodos eletromagnéticos no domínio da freqüência convencionais são incapazes de executar um levantamento com boa resolução. O TDEM é amplamente usado em estudos de mineração, devido a sua grande capacidade de penetração e resolução. O desenvolvimento do método está relacionado aos avanços na área de eletrônica, o que proporcionou o desenvolvimento de equipamentos avançados para as medidas de precisão e na área de informática para o tratamento de dados que necessita de softwares com cálculos avançados.

Um problema comum entre os métodos eletromagnéticos no domínio da freqüência é o fato que o campo magnético secundário (referente aos materiais no subsolo) é medido na presença do campo magnético primário (gerado pela fonte do equipamento). Sendo o campo primário muito maior que o secundário, a correta remoção dele é sempre complicada. Essa eliminação complicada pode gerar ruídos nos dados e com isso uma perda de precisão. Uma maneira de evitar o enorme sinal do campo primário é usar um campo pulsado ao invés de um contínuo. E assim medir o campo secundário enquanto o campo primário está desligado.

O método TDEM funciona dessa maneira, usa o sinal de uma fonte transiente ao invés de uma contínua. É usado um loop transmissor e uma bobina receptora. A idéia básica é que em um circuito (um grande loop transmissor) transita uma corrente contínua que gera um fluxo magnético constante. O fluxo magnético atravessa qualquer condutor em subsuperfície, mas não gera corrente nesse condutor, uma vez que esse fluxo é constante. Se a corrente contínua é de repente desligada, o fluxo cai do seu valor inicial para zero, e durante um curto período de tempo o fluxo varia no tempo. Dessa forma são geradas correntes secundárias no condutor, de acordo com a lei de Neumann, conforme mostrado na Figura 10. O campo secundário por sua vez decai com o tempo conforme as correntes são gradualmente dissipadas no substrato. Esse campo dependente do tempo por sua vez induz uma força eletromotriz (f.e.m.) transiente num circuito receptor (bobina receptora) no qual ele está agindo. Como a dissipação do campo secundário varia conforme a resistência elétrica do condutor em subsuperfície é possível obter as propriedades geoelétricas dos materiais abaixo do arranjo. 


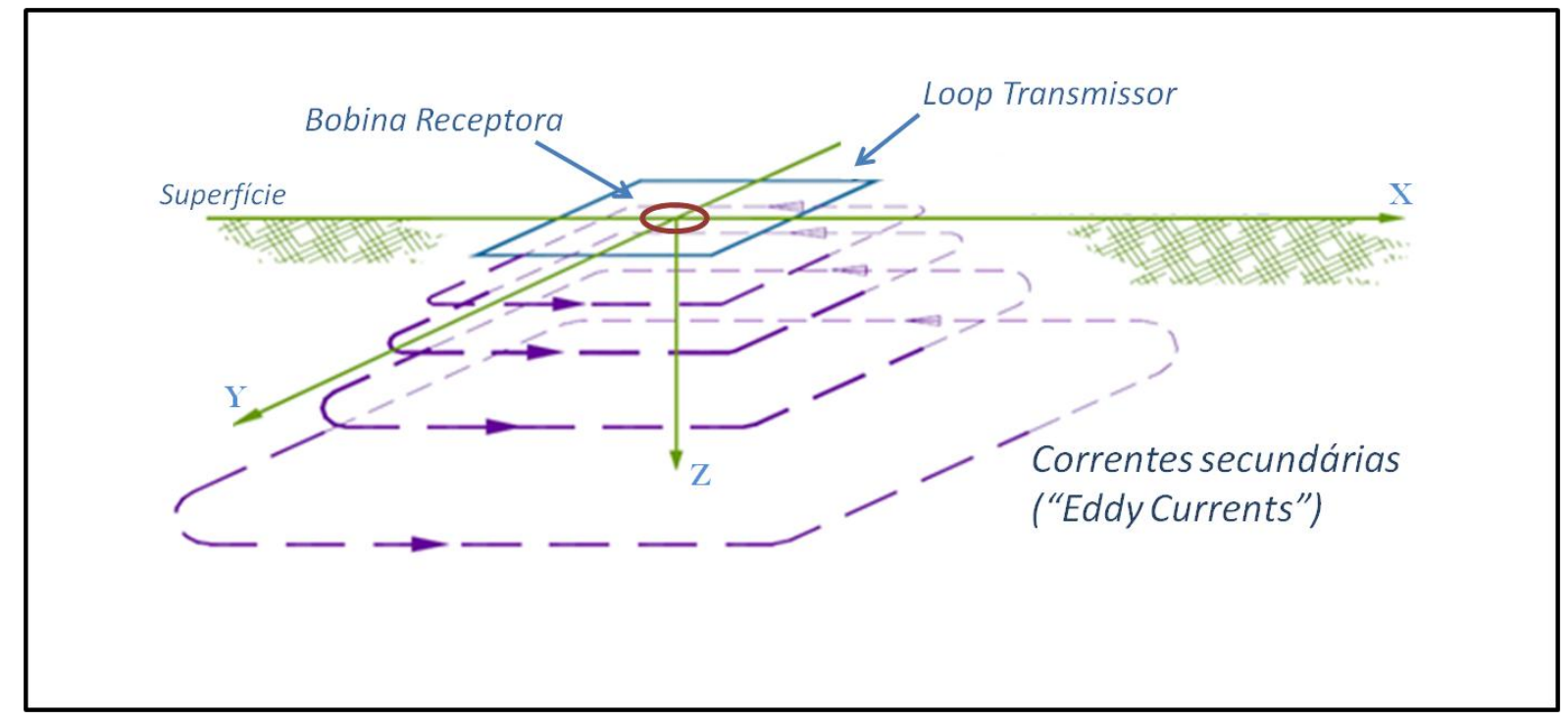

Figura 10: Correntes secundárias geradas no subsolo. O padrão de propagação das correntes no substrato é na forma de "Smoke RIngs" (anéis de fumaça). Adaptado de (McNeill, 1994).

Na prática, a corrente primária juntamente com o fluxo associado a ela não podem ser desligados instantaneamente. O que acaba acontecendo é que o fluxo sai do seu valor constante $B_{0}$ até zero linearmente com o tempo em um intervalo de tempo $\tau$, na ordem de microsegundos. A taxa de variação do fluxo, $B_{0} / \tau$, e qualquer força eletromotriz devido a e ele, vai ser proporcional a $B_{0} \mathrm{e}$ dessa forma proporcional a corrente primária. Conseqüentemente o campo secundário que age no circuito receptor e a f.e.m. induzida nele, também vai ser proporcional a corrente primária no circuito transmissor. A Figura 11 ilustra todo esse procedimento, mostrando como acontece em cada um dos eventos. 


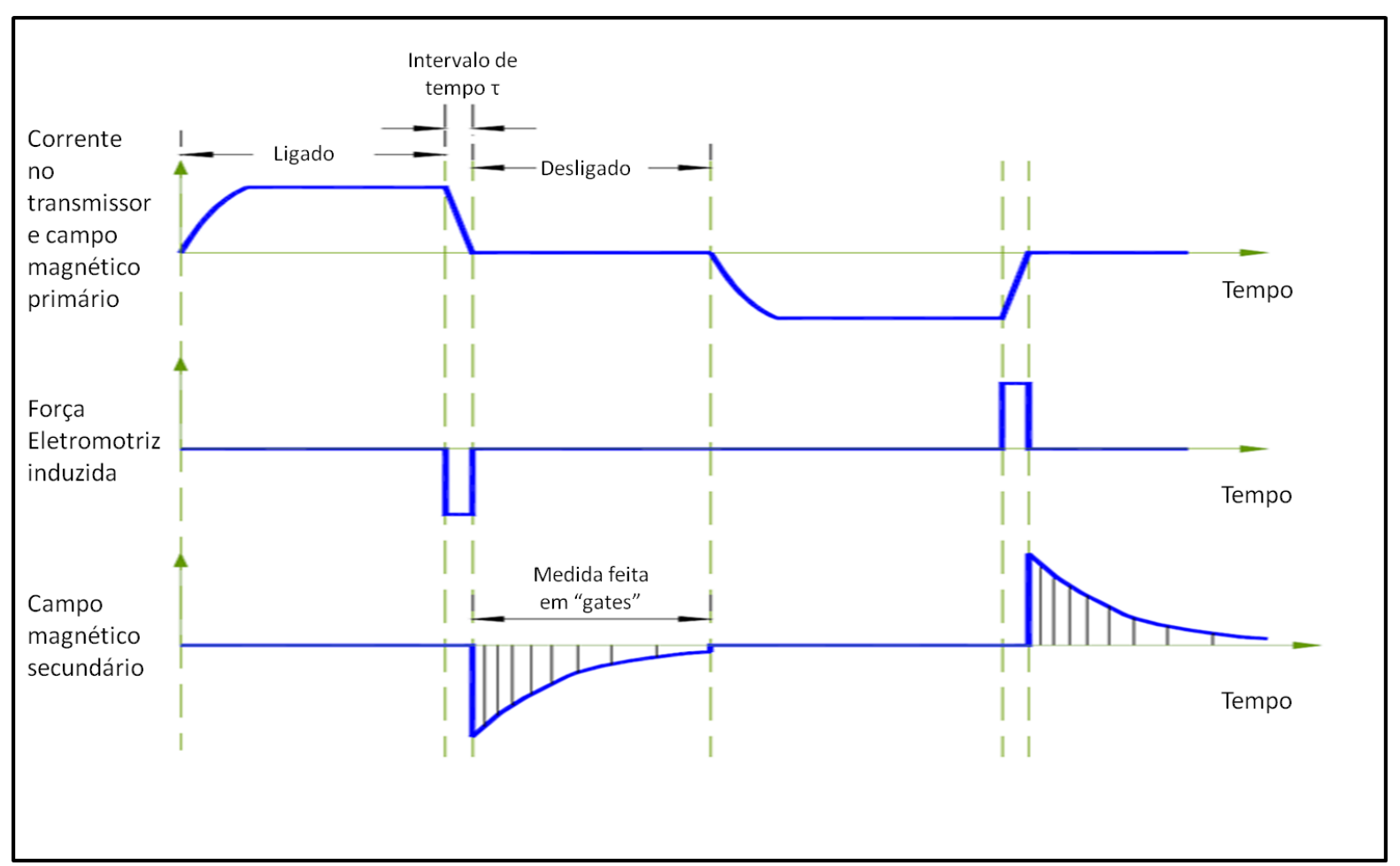

Figura 11: Representação da seqüência de eventos num levantamento TDEM.

\section{Formulação Básica}

Seguindo a dedução mostrada em Kirsch (2006), um campo eletromagnético é definido por cinco funções vetoriais: $E$ (intensidade do campo elétrico $(\mathrm{V} / \mathrm{m})$ ), B (indução magnética (weber $/ \mathrm{m}^{2}=$ tesla, T)), D (densidade de fluxo elétrico $\left(\right.$ columb/ $\left.\mathrm{m}^{2}\right)$ ), H (intensidade do campo magnético (ampére/metro, $A / m)$ ) e $\boldsymbol{j}$ (densidade de corrente elétrica $\left(A / m^{2}\right)$ ). A interação entre esses elementos é governada pelas equações de Maxwell dadas por:

$$
\begin{gathered}
\nabla \times \boldsymbol{E}+\frac{\partial \boldsymbol{B}}{\partial t}=0 \\
\nabla \times \boldsymbol{H}-\frac{\partial \boldsymbol{D}}{\partial t}=\boldsymbol{j} \\
\nabla \cdot \boldsymbol{B}=0 \\
\nabla \cdot \boldsymbol{D}=q
\end{gathered}
$$

onde $q$ é a densidade de carga $\left(\mathrm{C} / \mathrm{m}^{3}\right)$. 
O emprego da transformada de Fourier nas equações 2.17 e 2.18 (fazendo uso das relações constitutivas do meio $\boldsymbol{J}=\sigma \boldsymbol{E}, \boldsymbol{D}=\varepsilon \boldsymbol{E}, \boldsymbol{B}=\mu \boldsymbol{H}$ ) e com um pouco de álgebra obtém-se as equações de Maxwell no domínio da freqüência, dadas por:

$$
\begin{gathered}
\nabla \times \boldsymbol{E}+i \omega \mu_{0} \boldsymbol{H}=0 \\
\nabla \times \boldsymbol{H}-(\sigma+i \varepsilon \omega) \boldsymbol{E}=0
\end{gathered}
$$

onde $\varepsilon$ é a permissividade dielétrica, $\sigma$ é a condutividade elétrica, $\omega$ é a freqüência angular e $\mu_{0}$ é a permeabilidade magnética (no caso adota-se a mesma que a do vácuo). Por conveniência adotamos $\hat{z}=i \omega \mu_{0}$ e $\hat{y}=\sigma+i \varepsilon \omega$.

As equações de Maxwell homogêneas 2.21 e 2.22 se aplicam somente para regiões livres de cargas. Para regiões contendo cargas elas são substituídas pelas equações não homogêneas:

$$
\begin{gathered}
\nabla \times \boldsymbol{E}+\hat{z} \boldsymbol{H}=-\boldsymbol{J}_{m}^{S} \\
\nabla \times \boldsymbol{H}-\hat{y} \boldsymbol{E}=\boldsymbol{J}_{e}^{S}
\end{gathered}
$$

onde $\boldsymbol{J}_{m}^{S}$ é a corrente de fonte magnética e $\boldsymbol{J}_{e}^{S}$ é a corrente de fonte elétrica.

As equações não homogêneas no domínio da freqüência 2.23 e 2.24 podem ser resolvidas para regiões homogêneas se $\boldsymbol{J}_{m}^{S}$ e $\boldsymbol{J}_{e}^{S}$ podem ser definidas. Expressando $\mathbf{E}$ e $\mathbf{H}$ em termos dos potenciais de Schelkunoff $\mathbf{A}$ e $\mathbf{F}$ facilita a derivação de $\mathbf{E}$ e $\mathbf{H}$ por diferenciação. A solução das equações fica mais fácil porque os potenciais são paralelos aos campos geradores, ao contrário dos próprios campos.

O método TDEM usa somente fonte magnética $\left(J_{m}^{S}\right)$ transmitindo um campo elétrico transversal. Isso simplifica a formulação, pois somente o potencial $\mathbf{F}$ é necessário para o cálculo. Dessa forma o potencial de Schelkunoff F é definido como:

$$
\boldsymbol{E}_{m}=-\nabla \times \boldsymbol{F}
$$

onde $\boldsymbol{E}_{m}$ é o campo elétrico gerado pela fonte magnética.

Usando esta relação na equação 2.23 podemos derivar a equação não homogênea de Helmholtz dada por:

$$
\nabla^{2} \boldsymbol{F}+k^{2} \boldsymbol{F}=-\boldsymbol{J}_{m}^{S}
$$

onde o número de onda $k$ é definido como: 


$$
k^{2}=\mu_{0} \varepsilon \omega^{2}-i \mu_{0} \sigma \omega
$$

ou seja

$$
k^{2}=-\hat{z} \hat{y}
$$

Para materiais geológicos e freqüências menores que $10^{5} \mathrm{~Hz}$, a corrente de deslocamento se torna desprezível $\left(k^{2} \approx-i \mu_{0} \sigma \omega\right)$. Esta é a chamada aproximação quasi-estática.

Os campos elétrico e magnético totais originados pela fonte magnética podem agora ser derivados usando o potencial $\mathbf{F}$, tais como:

$$
\begin{gathered}
\boldsymbol{E}_{m}=-\nabla \times \boldsymbol{F} \\
\boldsymbol{H}_{m}=-\hat{y} \boldsymbol{F}+\frac{1}{\hat{z}} \nabla(\nabla \cdot \boldsymbol{F})
\end{gathered}
$$

Assumindo uma terra estratificada unidimensional, $\mathbf{F}$ consiste em apenas uma componente, ou seja, a componente $z$ :

$$
\boldsymbol{F}=F_{z} \boldsymbol{u}_{z} ; T E_{z}
$$

onde $F_{z}$ é uma função escalar de $x, y$ e $z$, enquanto que $\boldsymbol{u}_{z}$ é um vetor unitário na direção $z$. $T E_{z}$ representa o campo elétrico transverso, o campo que propaga no plano $x y$. Substituindo a equação 2.31 em 2.29 e 2.30 temos as expressões para as componentes dos campos, dadas por:

$$
\begin{array}{ll}
H_{x}=\frac{1}{\hat{z}} \frac{\partial^{2} F_{z}}{\partial x \partial z} & E_{x}=-\frac{\partial F_{z}}{\partial y} \\
H_{y}=\frac{1}{\hat{z}} \frac{\partial^{2} F_{z}}{\partial x \partial z} & E_{y}=\frac{\partial F_{z}}{\partial x} \\
H_{z}=\frac{1}{\hat{z}}\left(\frac{\partial^{2}}{\partial z^{2}}+k^{2}\right) F_{z} & E_{z}=0
\end{array}
$$

O campo transmitido no método TDEM é um campo elétrico transversal produzido por um loop transmissor. Dessa forma precisamos calcular o campo magnético vertical no centro do loop. Um transmissor circular ou quadrado pode ser calculado como uma integração de dipolos magnéticos verticais sobre sua área. O potencial de Schelkunoff, nesse caso pode ser entendido como um dipolo magnético vertical, dado por:

$$
F(r, z)=\frac{\hat{z}_{0} m}{4 \pi} \int_{0}^{\infty}\left[e^{-u_{0}|z+h|}+R_{T E} e^{u_{0}(z+h)}\right] \frac{\lambda}{u_{0}} J_{0}(\lambda r) d \lambda
$$


onde $m$ é o momento magnético do dipolo, $J_{0}$ é sendo a função de Bessel de ordem zero, $\lambda=\sqrt{k_{x}^{2}+k_{y}^{2}}$ onde $k_{x}$ e $k_{y}$ são as freqüências nas direções $\mathrm{x}$ e y, $u_{n}=\sqrt{\lambda^{2}+k_{n}^{2}}$ onde $k_{n}^{2}$ é o número de onda na $n$-ésima camada, que segundo a equação 2.27 , na aproximação quasi-estática é dado por $k^{2}=-i \mu_{0} \sigma_{n} \omega, r=\sqrt{x^{2}+y^{2}}$ onde $r$ é a distância radial da fonte ao receptor e $\mathrm{R}_{\mathrm{TE}}$ é chamado de coeficiente de reflexão e seu valor expressa como o substrato modifica o campo primário.

Podemos integrar a equação 2.33 sobre um loop circular de raio $(a)$ e uma corrente $(I)$, resultando:

$$
F(r, z)=\frac{\hat{z}_{0} I a}{2} \int_{0}^{\infty} \frac{1}{u_{0}}\left[e^{-u_{0}|z+h|}+R_{T E} e^{u_{0}(z+h)}\right] J_{1}(\lambda a) J_{0}(\lambda r) d \lambda
$$

onde $J_{1}$ é a função de Bessel de primeira ordem. Substituindo 2.34 na equação 2.30 e simplificando para a situação em que o receptor está no centro do loop (configuração loop central) temos para o campo magnético vertical que

$$
H_{z}=\frac{I a}{2} \int_{0}^{\infty}\left[e^{-u_{0}|z+h|}+R_{T E} e^{u_{0}(z+h)}\right] \frac{\lambda^{2}}{u_{0}} J_{1}(\lambda a) d \lambda
$$

A equação 2.35 (integral de Hankel) é expressa no domínio da freqüência, uma vez que $R_{T E}$ é uma função da freqüência. A resposta transiente, no domínio do tempo, é obtida pela transformada inversa de Laplace ou de Fourier.

A integral de Hankel não pode ser resolvida de forma analítica, por causa da complexidade da função de Bessel e da integral em si. Porém, para a configuração de loop central, na superfície de um substrato homogêneo $R_{T E}$ se torna

$$
R_{T E}=\frac{\lambda-u}{\lambda+u}
$$

e dessa forma a equação 2.35 se reduz para:

$$
H_{z}=I a \int_{0}^{\infty} \frac{\lambda^{2}}{\lambda-u} J_{1}(\lambda a) d \lambda
$$

Determinando a integral e aplicando a transformada inversa de Laplace pode-se resolver 2.37 para o campo $\mathrm{B}$, usando a simples relação $\boldsymbol{B}=\mu_{0} \boldsymbol{H}$, resultando:

$$
B_{z}=\frac{\mu_{0 I}}{2 a}\left[\frac{3}{\pi^{1 / 2} \theta a} e^{-\theta^{2} a^{2}}+\left(1-\frac{3}{2 \theta^{2} a^{2}}\right) \operatorname{erf}(\theta a)\right]
$$


onde $\theta=\sqrt{\mu_{0} \sigma / 4 t}$ e $\operatorname{erf}(\theta a)$ é a função erro. $B_{z}$ pode ser determinado para $t \rightarrow 0$ com $B_{z}=$ $\mu_{0 I} / 2 a$. O que seria o tamanho do campo primário no espaço, ou seja, a intensidade magnética antes da corrente ser desligada.

A derivada no tempo, ou o impulso, $\partial B_{z} / \partial t$ pode então ser dada da seguinte forma:

$$
\frac{\partial B_{z}}{\partial t}=-\frac{I}{\sigma a^{3}}\left[3 \operatorname{erf}(\theta a)-\frac{2}{\pi^{\frac{1}{2}}} \theta a\left(3+2 \theta^{2} a^{2}\right) e^{-\theta^{2} a^{2}}\right]
$$

A resposta do impulso, $\partial B_{z} / \partial t$ (2.39), é o que de fato medimos em campo. Porém por causa de limitações instrumentais não é possível medir a resposta do campo secundário logo após o desligamento da corrente (antes de 100 micro-segundos). Dessa forma só é possível recuperar a resposta do meio depois de um certo tempo transcorrido do desligamento. O que é chamado de estágio posterior (i.e., late time). Para esses tempos tardios o impulso pode ser aproximado por:

$$
\frac{\partial B_{z}}{\partial t} \approx \frac{I \sigma^{3 / 2} \mu_{0}^{5 / 2} a^{2}}{20 \pi^{1 / 2}} t^{-5 / 2}
$$

Dessa forma podemos ver que a derivada temporal de B tem um decaimento proporcional a $t^{-5 / 2}$. Porém a curva do decaimento do campo magnético não é muito informativa. Para melhor visualização é usada a resistividade aparente, que para os tempos tardios é dada por:

$$
\rho_{a}=\left(\frac{I a^{2}}{20 \partial B_{z} / \partial t}\right)^{1 / 2} \frac{\mu_{0}^{5 / 3}}{\pi^{1 / 3}} t^{-5 / 3}
$$

\section{Resistividade Aparente}

Assim como na sondagem elétrica vertical a sondagem TDEM faz uso do conceito de resistividade aparente. No caso da SEV a idéia era que a corrente elétrica passando por diversas camadas amostra um terreno de resistividade equivalente a uma média ponderada de todas as camadas. No caso do TDEM a idéia é parecida, mas no caso a área amostrada vai ser referente ao volume amostrado pelos smoke rings (visto na Figura 10) das correntes secundárias no subsolo. Essas correntes vão transitar no formato de anéis em subsuperfície, dessa forma a resistividade aparente vai ser correspondente a uma média das resistividades das estruturas no subsolo. As linhas de correntes secundárias podem ser distorcidas de forma parecida as linhas de corrente na Figura 4 , 
mas em vez das correntes serem devidas a injeção de corrente em superfície seriam devidas a indução de corrente por um loop em superfície. Dessa forma as curvas de resistividade aparente da SEV e da sondagem TDEM são bem parecidas, com métodos de interpretação relativamente próximos.

\section{Procedimentos de Campo}

Os procedimentos para aquisição de dados TDEM assim como nos métodos elétricos são muito variados. A configuração do tamanho e posição do loop transmissor ( $T x$ ) e da bobina receptora ( $\mathrm{Rx}$ ) depende de cada objetivo. O método TDEM é muito versátil, possuindo formas de levantamento terrestre, aérea e aquática. Os mais usados são os procedimentos terrestre e aéreo. No caso deste trabalho vamos usar somente aquisição terrestre, dessa forma seguiremos discutindo apenas essas formas de aquisição. As mais comuns são as seguintes:

- Single Loop: muito utilizada na antiga União Soviética, essa configuração utiliza um único loop como transmissor e receptor (Figura 12a). Enquanto a corrente está passando ele age como o transmissor. Uma vez que a corrente está desligada, os terminais do loop são conectados ao receptor e dessa forma a resposta do campo secundário pode ser medida

- Loops Transmissor/Receptor Coincidentes: esse arranjo tem a mesma geometria e resposta do arranjo Single Loop, porém o loop transmissor e receptor são loops separados dispostos numa posição coincidente (Figura 12b).

- Loops Transmissor/Receptor Separados: essa configuração é bem similar a configuração Slingram com o loop transmissor e receptor separados por uma distância fixa (por exemplo, $100 \mathrm{~m}$ ). Os loops nesse caso têm a ordem de algumas dezenas de metros de lado (Figura 12c).

- Loop-Loop: Uma variante da técnica de loops separados, ela consiste em um dipolo receptor pequeno colocado a uma distância fixa do loop transmissor (Figura 12d). Nesse caso o dipolo transmissor deve ser uma bobina com muitas espiras para compensar o pequeno diâmetro.

- Off-set: é uma variação do arranjo loop-loop, porém a bobina receptora fica alinhada com os cantos do loop transmissor ao invés do lado dele (Figura 12e). Também é usado para quando o loop transmissor é muito pequeno (menor que $40 \mathrm{~m}$ de lado).

- Dual-Loop: utiliza dois loops adjacentes conectados em paralelo para um melhor acoplamento com condutores verticais (Nabighian, M.N. \& Macnae, J.C., 1991). Nessa 
configuração também há uma grande redução de ruído proveniente de fontes de interferência elétrica. Uma vez que o ruído gerado por essas fontes são quase que opostos nos dois loops, se estiverem em um terreno homogêneo. Em áreas com variação lateral de resistividade essa redução não é significante. $O$ arranjo pode ser feito com apenas um cabo (Figura 12f) ou com dois cabos separados (Figura 12g).

- Caminhamento TDEM com transmissor e receptor móveis: essa configuração permite uma aquisição 2D ou 3D. Ela é feita com a sobreposição de uma série de sondagens Single Loop ou Loop Central. Se o objetivo for um levantamento 2D uma serie de sondagens são feitas ao longo de uma linha escolhida (Figura 12h). As sondagens devem ser feitas idealmente com um espaçamento de metade do tamanho do lado do loop transmissor. Para que os centros do loop transmissor nas duas sondagens fiquem a uma distância equivalente ao tamanho do lado do transmissor.

- Caminhamento TDEM com transmissor fixo: esse levantamento consiste em colocar um loop transmissor grande, que envolva toda ou grande parte da área de estudo. A bobina receptora, pequena em relação ao loop transmissor, é então movida ao longo da área na forma de perfis 2D (perpendiculares ao transmissor) ou mesmo numa malha 3D (Figura 12i).

- Perfilagem TDEM: a perfilagem TDEM consiste em montar um loop transmissor na superfície e descer por um poço de sondagem uma bobina receptora. Dessa forma é possível medir o transiente em várias profundidades.

- Loop Central: essa configuração é uma variante do arranjo de loops coincidentes, mas ao contrário dela o loop receptor tem um tamanho muito menor que o transmissor. Nessa configuração uma bobina receptora com muitas espiras é colocada no centro do loop transmissor, como mostrado na Figura 12j. A diferença de tamanho é um fator chave nesse tipo de configuração. Para uma bobina receptora de $1 \mathrm{~m}$ de diâmetro o loop transmissor não deve ter menos que $40 \mathrm{~m}$ de lado. A relação sinal ruído nessa configuração é muito boa e a logística de campo também é bem prática. Também é um arranjo bem difundido tanto na academia quando no setor de exploração mineral. Por esses motivos esse arranjo foi o escolhido para ser utilizado nessa pesquisa.

Informações mais detalhadas sobre o método eletromagnético no domínio do tempo e as técnicas de aquisição dos dados podem ser obtidas em Telford et. al. (1990), Burguer et. al. (2006) e Parasnis (1962). 


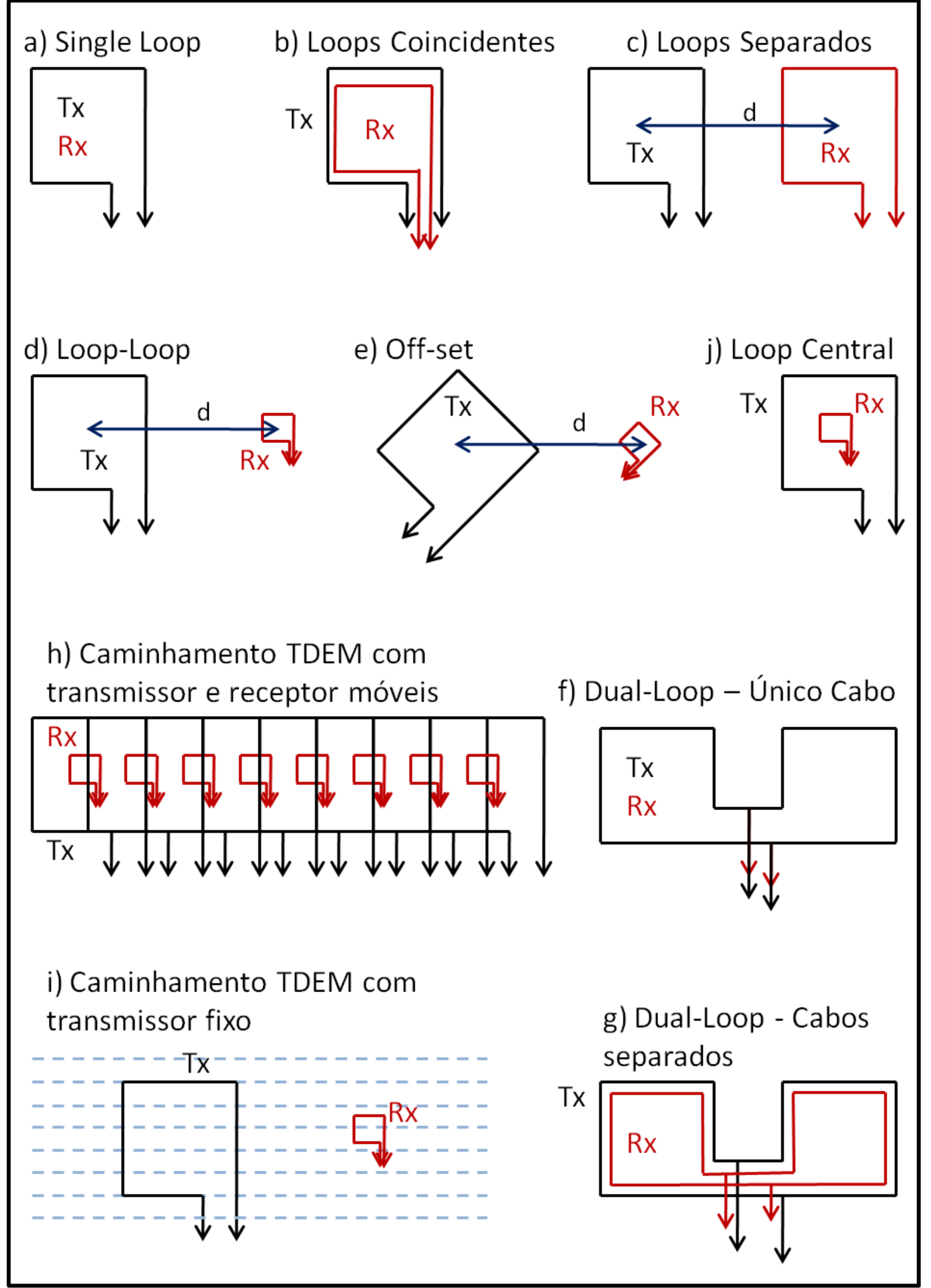

Figura 12: Representação dos diversos tipos de arranjos TDEM. Na figura "Tx" representa os loops transmissores e "Rx" os loops receptores ou bobinas receptoras. 


\section{Fontes de Ruído}

Ao contrário de outros métodos eletromagnéticos, o TDEM sofre pouca influência de ruídos originados por fontes naturais. As maiores fontes de ruído para o TDEM de fato são artefatos feitos pelo homem. Sørensen et al. (2000) divide as fontes de ruído para o TDEM na forma de dois tipos diferentes de acoplamento: o galvânico e o capacitivo.

O acoplamento galvânico acontece quando um condutor (normalmente não natural) está em contato galvânico com o solo (por exemplo, linhas de transmissão de energia com torres aterradas). Quando o transmissor TDEM é ligado induz corrente nas camadas do subsolo. Uma vez que a fonte de ruído está em contato com o subsolo o TDEM acaba induzindo correntes na fonte de interferência também. Isso forma um circuito LR (indutor/resistor) que apresenta um decaimento do campo de forma exponencial com o tempo. Isso faz com que os dados obtidos no final tenham uma interpretação errônea de camadas de baixa resistividade. Esse tipo de ruído não pode ser removido dos dados. Mas o maior agravante desse efeito é que ele só é identificado na comparação da sondagem em questão com sondagens relativamente próximas (Figura 13a).

No acoplamento capacitivo a fonte de ruído é algum material metálico envolto por um isolante, como por exemplo, um cabo elétrico. Nesse caso o condutor (o fio metálico) junto com o envoltório isolante (isolamento do cabo) acabam formando no subsolo um capacitor, transformando a área num circuito RLC (resistor/indutor/capacitor). O transmissor então carrega o capacitor através da indução e ele por sua vez decai de forma oscilante. Esse decaimento oscilante do "capacitor" gera nos dados uma perturbação claramente visível. Não há forma de retirar esse tipo de ruído, porém fica evidente a perturbação na curva e ela pode ser descartada. (Figura 13b). 


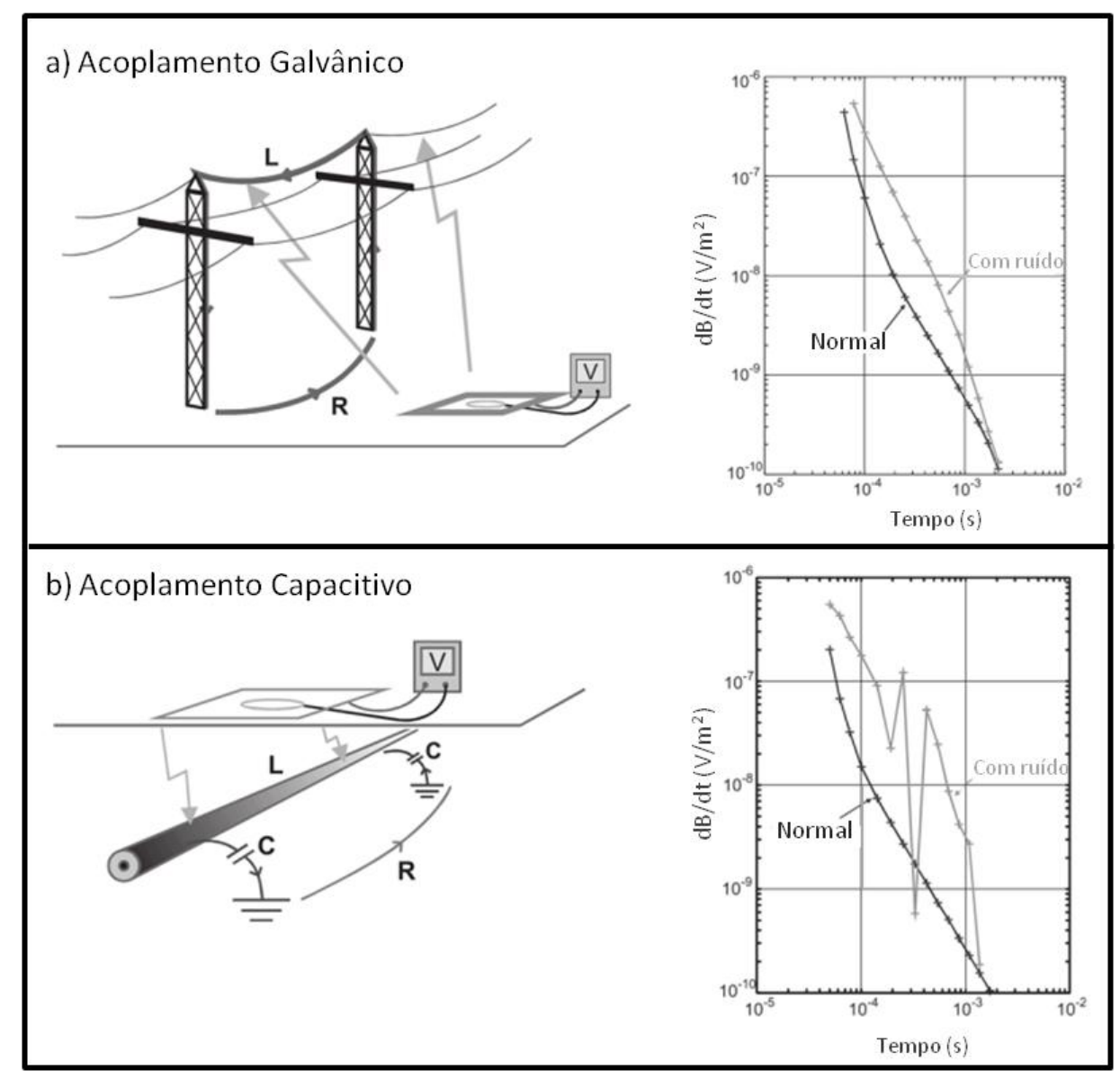

Figura 13: Fontes de ruídos no método TDEM. Em "a" temos o acoplamento galvânico e em "b" o acoplamento capacitivo. 


\section{Modelagem Numérica}

Um aspecto importante das geociências é conseguir simular a resposta física de um meio conhecido. Ou seja, tendo um modelo que representa uma situação física conseguir simular a partir de cálculos a resposta desse meio em relação a alguma propriedade física. Esse tipo de cálculo é conhecido como modelagem física. No caso da geofísica o intuito é simular um meio geológico e obter qual seria a resposta desse meio em termos de propriedades físicas. Esse tipo de ferramenta é muito útil em diversos estudos científicos, bem como a certificação de teorias. Esse tipo de cálculo também é indispensável quando se trabalha com inversão de dados geofísicos. No caso da sondagem elétrica e sondagem TDEM a teoria para a modelagem está desenvolvida e foram usadas nesse trabalho. A formulação usada será discutida a seguir.

\section{Modelagem SEV}

A sondagem elétrica vertical tem como objetivos estudar a variação vertical da resistividade elétrica do subsolo. Por isso é tida como um levantamento $1 D$, já que a resistividade, que é a propriedade estudada, varia apenas com a profundidade. Tendo em vista essa idéia, vamos definir como será o modelo representativo do subsolo e do levantamento. A subsuperfície é dividida em camadas planas e paralelas que possuem espessura e resistividade próprias. 0 embasamento geoelétrico (no caso a última camada) possui apenas uma resistividade associada. Pois assume-se que esta camada se estende até o infinito. A fonte de corrente vai estar na superfície e a corrente gerada é continua. Essa aproximação por camadas é uma esquematização do substrato que logicamente é mais complexo. Mas ela é amplamente usada e é muito representativa. Na Figura 14 está a representação do modelo geoelétrico descrito. 


\section{Modelo de $\mathrm{N}$ camadas}

\section{Superfície}

\begin{tabular}{lll}
\hline Camada 1 & $\sigma_{1}$ & $\downarrow^{h 1}$ \\
\hline
\end{tabular}
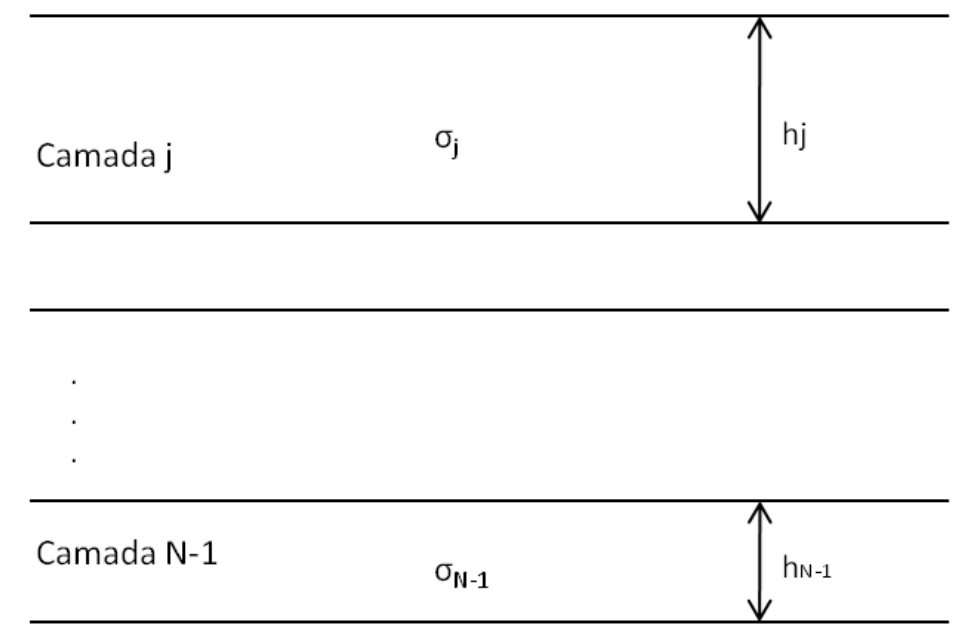

Camada N

(embasamento geoelétrico)

Figura 14: Representação do modelo geoelétrico do subsolo para a modelagem da sondagem elétrica vertical.

\section{Distribuição do Potencial Elétrico na Superfície de Um Meio Estratificado}

A derivação do potencial elétrico na superfície para o caso de camadas plano paralelas foi proposta por Stefanescu et. al. (1930). Ela começa com a Lei de Ohm para o fluxo de corrente elétrica em meio continuo, dada por:

$$
\boldsymbol{E}=\rho j
$$

e mostra como o fluxo de corrente se relaciona com o campo elétrico $\boldsymbol{E}$. 
O potencial eletrico $V$ nas condições de corrente continua satisfaz a equação de Laplace e então pode ser escrito como:

$$
\frac{\partial^{2} V}{\partial x^{2}}+\frac{\partial^{2} V}{\partial y^{2}}+\frac{\partial^{2} V}{\partial z^{2}}=0
$$

Porém no caso das condições descritas para esse problema o potencial $V$ tem simetria cilíndrica em relação ao eixo vertical. Dessa forma vamos usar a equação de Laplace para coordenadas cilíndricas. Nesse caso a expressão para $V$ fica sendo:

$$
\frac{\partial^{2} V}{\partial r^{2}}+\frac{1}{r} \frac{\partial V}{\partial r}+\frac{\partial^{2} V}{\partial z^{2}}+\frac{1}{r^{2}} \frac{\partial^{2} V}{\partial \theta^{2}}=0
$$

Já que a solução é para ser simétrica com respeito a coordenada vertical, então a primeira e a segunda derivada do potencial em relação a $\theta$ deve ser zero. Dessa forma a equação 3.3 é simplificada:

$$
\frac{\partial^{2} V}{\partial r^{2}}+\frac{1}{r} \frac{\partial V}{\partial r}+\frac{\partial^{2} V}{\partial z^{2}}=0
$$

Uma forma de resolver equações diferenciais parciais como a 3.4 é pela forma de separação de variáveis. Esse método consiste em primeiro obter soluções particulares e depois obter uma solução geral pela combinação linear delas. Dessa forma assume-se que existem soluções para 3.4 na seguinte forma:

$$
\frac{1}{U} \frac{d^{2} U}{d r^{2}}+\frac{1}{U r} \frac{d U}{d r}+\frac{1}{W} \frac{d^{2} W}{d z^{2}}=0
$$

essa equação é satisfeita se

$$
\frac{1}{U} \frac{d^{2} U}{d r^{2}}+\frac{1}{U r} \frac{d U}{d r}=-\lambda^{2}
$$

e

$$
\frac{1}{W} \frac{d^{2} W}{d z^{2}}=\lambda^{2}
$$

onde $\lambda$ é uma constante real arbitraria.

As soluções da equação 3.7 são:

$$
W=C e^{-\lambda z} e W=C e^{+\lambda z}
$$


Já a solução da equação 3.6 é mais complicada. Equações como ela levaram a criação de uma serie especial de funções, chamadas de funções de Bessel. No caso particular da equação 3.6, a solução pode ser escrita como

$$
U=C J_{0}(\lambda r)
$$

onde $J_{0}$ é a função de Bessel de ordem zero.

Combinando as equações 3.8 e 3.9 temos as soluções particulares de 3.4 dadas por:

$$
V=C e^{-\lambda z} J_{0}(\lambda r) e V=C e^{+\lambda z} J_{0}(\lambda r)
$$

onde $C$ e $\lambda$ são constantes arbitrárias.

Dessa forma qualquer combinação linear das soluções também é solução. Então fazendo $\lambda$ ter qualquer valor possível entre zero e infinito e permitindo as duas constantes $C$ variar em dependência a $\lambda$, temos a solução geral de 3.4 :

$$
V=\int_{0}^{\infty}\left[\Phi(\lambda) e^{-\lambda z}+\psi(\lambda) e^{+\lambda z}\right] J_{0}(\lambda r) d \lambda
$$

Nessa equação tanto $\Phi(\lambda)$ quanto $\psi(\lambda)$ são funções arbitrárias de $\lambda$. As formas especiais que essas funções assumem em cada problema específico é controlada pelas condições de fronteira. A equação 3.11 é dita geral no sentido de conter todas as soluções de todos os problemas possíveis.

Sobreposto ao potencial da equação 3.11 existe o potencial elétrico primário, $V_{p}$, devido à fonte de corrente. Esse potencial é dado na forma de:

$$
V=\frac{\rho_{1} I}{2 \pi \sqrt{r^{2}+z^{2}}}
$$

onde $\rho_{1}$ é a resistividade da terra homogênea e $I$ a intensidade da corrente. Essa equação por sua vez pode ser escrita numa forma similar aquela da equação 3.11 usando a integral de Lipschitz:

$$
\int_{0}^{\infty} e^{-\lambda z} J_{0}(\lambda r) d \lambda=\frac{1}{\sqrt{r^{2}+z^{2}}}
$$

Dessa forma a equação 3.12 pode ser escrita na forma de

$$
V=\frac{\rho_{1} I}{2 \pi} \int_{0}^{\infty} e^{-\lambda z} J_{0}(\lambda r) d \lambda
$$


e assim a solução geral de 3.11 é escrita na forma de

$$
V=\frac{\rho_{1} I}{2 \pi} \int_{0}^{\infty}\left[e^{-\lambda z}+\Theta(\lambda) e^{-\lambda z}+X(\lambda) e^{+\lambda z}\right] J_{0}(\lambda r) d \lambda
$$

onde $\Theta(\lambda)$ e $X(\lambda)$ são funções arbitrárias de $\lambda$.

As soluções na forma de 3.15 são válidas em todas as camadas em subsuperfície. Mas as funções $\Theta(\lambda)$ e $X(\lambda)$ não são necessariamente as mesmas em todas as diferentes camadas. No caso de um ponto de corrente na superfície de uma terra com camadas horizontais é necessário escrever expressões separadas para cada camada do subsolo como

$$
V_{i}=\frac{\rho_{1} I}{2 \pi} \int_{0}^{\infty}\left[e^{-\lambda z}+\Theta_{i}(\lambda) e^{-\lambda z}+X_{i}(\lambda) e^{+\lambda z}\right] J_{0}(\lambda r) d \lambda
$$

onde $i$ se refere a cada camada em subsuperfície.

\section{Condições de Contorno}

Para o caso de um campo potencial devido a uma fonte de corrente na superfície de uma terra estratificada em camadas plano-paralelas as seguintes condições de contorno devem ser satisfeitas:

1. Em cada interface das camadas em subsuperfície o potencial deve ser contínuo;

2. Em cada interface das camadas em subsuperfície a componente vertical da densidade de corrente precisa ser contínua;

3. Na superfície tanto a componente vertical quanto o campo elétrico devem ser zero, exceto numa vizinhança infinitesimal da fonte de corrente. Isso é porque não há corrente em direção ao ar (que possui resistividade aproximada para infinito);

4. Próximo a fonte de corrente o potencial deve se aproximar do infinito conforme $\rho_{1} I / 2 \pi \sqrt{r^{2}+z^{2}}$.

5. Em uma profundidade infinita o potencial é aproximadamente zero. 
De acordo com a condição 1 na profundidade do i-ésimo plano de fronteira, $d_{i}$, as expressões para o potencial na camada $i$ e $(i+1)$ devem ser as mesmas. Isso leva a seguinte equação:

$$
\begin{aligned}
\int_{0}^{\infty}\left[e^{-\lambda d_{i}}\right. & \left.+\Theta_{\mathrm{i}}(\lambda) e^{-\lambda d_{i}}+X_{i}(\lambda) e^{+\lambda d_{i}}\right] J_{0}(\lambda r) d \lambda \\
& =\int_{0}^{\infty}\left[e^{-\lambda d_{i}}+\Theta_{\mathrm{i}+1}(\lambda) e^{-\lambda d_{i}}+X_{i+1}(\lambda) e^{+\lambda d_{i}}\right] J_{0}(\lambda r) d \lambda
\end{aligned}
$$

essa equação só é satisfeita para todos os valores de $r$ se os integrandos dos dois lados forem iguais. Dessa forma temos:

$$
\Theta_{\mathrm{i}}(\lambda) e^{-\lambda d_{i}}+X_{i}(\lambda) e^{+\lambda d_{i}}=\Theta_{\mathrm{i}+1}(\lambda) e^{-\lambda d_{i}}+X_{i+1}(\lambda) e^{+\lambda d_{i}}
$$

Sobre a condição de fronteira 2 podemos inferí-la pois a componente vertical da densidade de corrente é igual a derivada do potencial em relação a $z$ dividida pela resistividade da camada em questão. Usando a expressão do potencial em 3.16 temos então a seguinte equação:

$$
\begin{aligned}
\frac{1}{\rho_{i}} \int_{0}^{\infty}[\{1 & \left.\left.+\Theta_{\mathrm{i}}(\lambda)\right\} e^{-\lambda d_{i}}-X_{i}(\lambda) e^{+\lambda d_{i}}\right] J_{0}(\lambda r) \lambda d \lambda \\
& =\frac{1}{\rho_{i+1}} \int_{0}^{\infty}\left[\left\{1+\Theta_{\mathrm{i}+1}(\lambda)\right\} e^{-\lambda d_{i}}-X_{i+1}(\lambda) e^{+\lambda d_{i}}\right] J_{0}(\lambda r) \lambda d \lambda
\end{aligned}
$$

Assim como em 3.17 a equação 3.19 só pode ser satisfeita para todos os valores de $r$ se os integrandos dos dois lados forem iguais. Então temos também que:

$$
\frac{1}{\rho_{i}} \int_{0}^{\infty}\left[\left\{1+\Theta_{\mathrm{i}}(\lambda)\right\} e^{-\lambda d_{i}}-X_{i}(\lambda) e^{+\lambda d_{i}}\right]=\frac{1}{\rho_{i+1}} \int_{0}^{\infty}\left[\left\{1+\Theta_{\mathrm{i}+1}(\lambda)\right\} e^{-\lambda d_{i}}-X_{i+1}(\lambda) e^{+\lambda d_{i}}\right]
$$

Para satisfazer a condição 3 devemos primeiro diferenciar o potencial na primeira camada em relação a $z$. E a seguir substituir $z=0$ para obter:

$$
\int_{0}^{\infty}\left[-1-\Theta_{1}(\lambda)+X_{1}(\lambda)\right] J_{0}(\lambda r) \lambda d \lambda=0
$$

nesse ponto não é preciso se preocupar com o primeiro termo do integrando dessa equação. Esse termo define o campo que existiria num meio homogêneo, que nos referimos como campo primário. 
Esse campo primário automaticamente satisfaz a condição de contorno. Mas deve-se ter atenção em relação aos dois últimos termos do integrando, que juntos definem o Campo Perturbado (campo devido às heterogeneidades do meio). A componente vertical da intensidade do Campo Perturbado deve ser zero na superfície para todos os valores de $r$. Incluindo na origem, onde o ponto de corrente está localizado. Essa condição só é satisfeita se os dois últimos termos do integrando juntos forem zero. Então isso leva a seguinte equação:

$$
\Theta_{1}(\lambda)=X_{1}(\lambda)
$$

A condição 4 é automaticamente satisfeita pela expressão do potencial primário. A única coisa que se deve ter cuidado é ter certeza que o Potencial Perturbado deve se manter finito na origem. E não deve influenciar como o potencial total se aproxima do infinito. Mais adiante no texto será mostrado que a equação 3.22 se mantém finita no intervalo de integração e se aproxima de zero com $\lambda \rightarrow \infty$. Dessa forma a equação 3.16 se aproxima do infinito conforme definido pela condição 3.

A condição 5 por sua vez exige que para a última camada ( $n$-ésima camada) a função $X$ seja igual a zero. Porque de outra forma o fator $e^{+\lambda z}$ faria o potencial ir para o infinito numa profundidade infinita, o que obviamente não faz sentido. Essa consideração então leva a seguinte equação:

$$
X_{n}(\lambda)=0
$$

Com as condições de fronteira definidas para o problema em questão a fórmula do potencial na superfície pode ser mais uma vez simplificada. Uma vez que o potencial só será calculado na superfície só os termos $\Theta_{1}(\lambda)$ e $X_{1}(\lambda)$ serão usados. Com a condição de fronteira 3 , temos que $\Theta_{1}(\lambda)$ tem que ser igual a $X_{1}(\lambda)$, então podemos colocar o último termo de dentro da integral em função de $\Theta_{1}(\lambda)$. E como o potencial será calculado na superfície $(z=0)$, os termos exponenciais se tornam iguais a um. Dessa forma a função para o potencial na superfície fica sendo:

$$
V=\frac{\rho_{1} I}{2 \pi} \int_{0}^{\infty}\left[1+2 \Theta_{1}(\lambda)\right] J_{0}(\lambda r) d \lambda
$$




\section{Função Kernel}

Pode-se também definir uma função $K(\lambda)$ tal que:

$$
K(\lambda)=1+2 \Theta_{1}(\lambda)
$$

e assim a equação 3.24 ficar sendo:

$$
V=\frac{\rho_{1} I}{2 \pi} \int_{0}^{\infty} K(\lambda) J_{0}(\lambda r) d \lambda
$$

A função $K(\lambda)$ foi primeiramente introduzida na teoria de sondagem elétrica por Slichter (1933). Na literatura tanto $\Theta_{1}(\lambda)$ quanto $K(\lambda)$ são referidas como as funções Kernel da equação do potencial. Koefoed (1979) chama $\Theta_{1}(\lambda)$ de Kernel de Stefanescu e $K(\lambda)$ de Kernel de Slichter. Essas funções Kernel podem se relacionar com os parâmetros do modelo $h$ e $\rho$ através de relações de recorrência. E uma das formas de calcular essas relações de recorrência é devido a Pekeris (1940).

O cálculo para as relações de recorrência começa somando $e^{-\lambda d_{1}}$ nos dois membros da equação 3.18 da condição de contorno. A seguir dividem-se os membros dessa equação pelos membros correspondentes da equação 3.20. Assim tem-se que:

$$
\rho_{i} \frac{1+\Theta_{\mathrm{i}}(\lambda)+X_{i}(\lambda) e^{+2 \lambda d_{i}}}{1+\Theta_{\mathrm{i}}(\lambda)-X_{i}(\lambda) e^{+2 \lambda d_{i}}}=\rho_{i+1} \frac{1+\Theta_{\mathrm{i}+1}(\lambda)+X_{i+1}(\lambda) e^{+2 \lambda d_{i}}}{1+\Theta_{\mathrm{i}+1}(\lambda)-X_{i+1}(\lambda) e^{+2 \lambda d_{i}}}
$$

Uma nova função $K_{i}$ então pode ser definida para cada camada:

$$
K_{i}(\lambda)=\frac{1+\Theta_{\mathrm{i}}(\lambda)+X_{i}(\lambda) e^{+2 \lambda d_{i-1}}}{1+\Theta_{\mathrm{i}}(\lambda)-X_{i}(\lambda) e^{+2 \lambda d_{i-1}}}
$$

para a camada superior, onde $d_{i-1}$ é zero e $\Theta_{i}(\lambda)=X_{i}(\lambda)$, a função $K_{i}$ assume a forma de

$$
K_{1}(\lambda)=1+2 \Theta_{1}(\lambda)
$$

Pela definição da função $K_{i}$ (equação 3.28) o lado direito da equação 3.27 é igual a $\rho_{i+1} K_{i+1}$. Para obter então a relação entre o lado esquerdo da equação 3.27 com $K_{i}$, dividimos o numerador e o denominador do lado direito da equação 3.28 por $X_{1}(\lambda)$ e resolvemos essa equação para $\left[1+\Theta_{i}(\lambda)\right] / X_{i}(\lambda)$. Assim temos:

$$
\frac{\left(1+\Theta_{\mathrm{i}}\right)}{X_{i}}=e^{+2 \lambda d_{i-1}} \frac{\left(K_{i}+1\right)}{\left(K_{i}-1\right)}
$$


Agora se divide o numerador e o denominador do lado esquerdo da equação 3.27 por $X_{i}(\lambda)$ e a seguir substitui-se nele a expressão de acordo com 3.30. Dessa forma a equação 3.27 fica sendo:

$$
\rho_{i} \frac{\left(K_{i}+1\right) e^{2 \lambda d_{i-1}}+\left(K_{i}-1\right) e^{2 \lambda d_{i}}}{\left(K_{i}+1\right) e^{2 \lambda d_{i-1}}-\left(K_{i}-1\right) e^{2 \lambda d_{i}}}=\rho_{i+1} K_{i+1}
$$

Dividindo agora o numerador e o denominador do lado esquerdo dessa equação por $e^{2 \lambda d_{i-1}}$. Temos

$$
K_{i+1}=p_{i} \frac{K_{i}\left(e^{2 \lambda h_{i}}+1\right)-\left(e^{2 \lambda h_{i}}-1\right)}{\left(e^{2 \lambda h_{i}}+1\right)-K_{i}\left(e^{2 \lambda h_{i}}-1\right)}
$$

onde $h_{i}$ é a espessura da camada $i\left(d_{i}-d_{i-1}\right)$ e $p_{i}=\rho_{i} / \rho_{i+1}$.

Pela definição de tangente hiperbólica

$$
\frac{\left(e^{2 \lambda h_{i}}-1\right)}{\left(e^{2 \lambda h_{i}}+1\right)}=\tanh \left(\lambda h_{i}\right)
$$

a equação 3.32 fica igual a

$$
K_{i+1}=p_{i} \frac{K_{i}-\tanh \left(\lambda h_{i}\right)}{1-K_{i} \tanh \left(\lambda h_{i}\right)}
$$

resolvendo então essa equação para $K_{i}$ obtemos

$$
K_{i}=\frac{K_{i+1}+p_{i} \tanh \left(\lambda h_{i}\right)}{p_{i}+K_{i+1} \tanh \left(\lambda h_{i}\right)}
$$

A equação 3.35 então pode ser usada para calcular o Kernel de Slichter na superfície, isso quando os parâmetros da distribuição de camadas são conhecidos. Para fazer isso primeiro é necessário achar a expressão para a função $K$ do embasamento. Para depois calcular de forma recursiva as funções $K$ das camadas superiores até chegar à superfície. A expressão então para o embasamento pode ser obtida pela definição da função $K$ (equação 3.28). Sendo ela combinada com a condição de fronteira 5 que define que $X_{i}(\lambda)$ é zero no embasamento (equação 3.23) temos:

$$
K_{n}=1
$$




\section{Transformada da Resistividade}

Koefoed (1970) introduziu na literatura o conceito de transformada da resistividade, denominada $T_{i}$ e definida pela seguinte equação:

$$
T_{i}=\rho_{i} K_{i}
$$

onde o índice $i$ tem o mesmo sentido que o índice do Kernel de Slicher nas relações recursivas de Pekeris. E as relações recursivas expressas para a transformada da resistividade são

$$
T_{i}=\frac{\left(T_{i+1}+\rho_{i} \tanh \left(\lambda h_{i}\right)\right)}{\left(\rho_{i}+T_{i+1} \tanh \left(\lambda h_{i}\right) / \rho_{i}\right)}
$$

e no sentido reverso

$$
T_{i+1}=\frac{\left(T_{i}+\rho_{i} \tanh \left(\lambda h_{i}\right)\right)}{\left(\rho_{i}+T_{i} \tanh \left(\lambda h_{i}\right) / \rho_{i}\right)}
$$

A transformada da resistividade tem a mesma dimensão física da resistividade, é uma função variável com os parâmetros geoelétricos e $\operatorname{com} \lambda$, que tem a dimensão de distância. Esse conceito de transformada da resistividade vai ser muito importante mais a frente na modelagem numérica da sondagem elétrica vertical.

\section{A Função Resistividade Aparente}

Como já discutido no capítulo anterior, a resistividade aparente é um conceito muito importante nos métodos elétricos e eletromagnéticos. Agora vamos deduzir a equação para a resistividade aparente a partir da equação do potencial elétrico na superfície. Inserindo as variáveis $s$ e $b$ nas equações 2.14 e 2.15 do capítulo anterior temos que a equação da resistividade aparente pode ser expressa como:

$$
\rho_{a}=\frac{(\Delta V / I) 2 \pi s\left(s^{2}-b^{2}\right)}{4 b s}
$$


onde $s$ é igual a metade da distância entre os eletrodos de corrente (A e B) e $b$ metade da distância dos eletrodos de potencial ( $\mathrm{M}$ e $\mathrm{N}$ ).

Para o arranjo Schlumberger a distância entre os eletrodos de potencial é considerada infinitesimal. Dessa forma o fator geométrico em $3.40\left(\left(s^{2}-b^{2}\right) / 4 b s\right)$ fica reduzido a $(s / 4 b)$. Além disso, com a suposição que a distância entre os eletrodos de potencial é infinitesimal é possível aproximar a intensidade do campo elétrico na superfície como sendo constante entre os eletrodos de potencial. Dessa forma o quociente $\Delta V / 2 \mathrm{~b}$ é substituído por um quociente diferencial da seguinte forma:

$$
\Delta V / 2 b \rightarrow-2(\partial V / \partial r)_{r=s}
$$

e substituindo 3.41 em 3.40 tem-se

$$
\rho_{a}=-\frac{2 \pi s^{2}}{I}(\partial V / \partial r)_{r=s}
$$

onde $V$ deve ser substituído de acordo com a equação 3.24. E usando a integral de Lipschitz (equação 3.13) podemos escrever a equação 3.24 de uma forma mais conveniente:

$$
V=\frac{\rho_{1} I}{2 \pi r}+\frac{\rho_{1} I}{2 \pi} 2 \int_{0}^{\infty} \Theta_{1}(\lambda) J_{0}(\lambda r) d \lambda
$$

Substituindo então essa equação em 3.42 e fazendo a diferenciação temos:

$$
\rho_{a}=\rho_{1}+2 \rho_{1} s^{2} \int_{0}^{\infty} \Theta_{1}(\lambda) J_{1}(\lambda s) \lambda d \lambda
$$

mas usando as equações 3.25 e 3.37 podemos escrever essa equação de forma mais conveniente, dada por:

$$
\rho_{a}=\rho_{1}+s^{2} \int_{0}^{\infty}\left[T(\lambda)-\rho_{1}\right] J_{1}(\lambda s) \lambda d \lambda
$$

ou mesmo

$$
\rho_{a}=\rho_{1}+s^{2}\left(\int_{0}^{\infty} T(\lambda) J_{1}(\lambda s) \lambda d \lambda-\rho_{1} \int_{0}^{\infty} J_{1}(\lambda s) \lambda d \lambda\right)
$$


A equação 3.45 pode ficar ainda mais simples se usarmos uma propriedade das funções de Bessel que diz que

$$
\int_{0}^{\infty} J_{1}(\lambda s) \lambda d \lambda=\frac{1}{s^{2}}
$$

e assim podemos escrever que

$$
\rho_{a}=\rho_{1}+s^{2} \int_{0}^{\infty} T(\lambda) J_{1}(\lambda s) \lambda d \lambda-\frac{\rho_{1} s^{2}}{s^{2}}
$$

e simplificando temos a função da resistividade aparente para o caso do arranjo Schlumberger:

$$
\rho_{a}(s)=s^{2} \int_{0}^{\infty} T(\lambda) J_{1}(\lambda s) \lambda d \lambda
$$

onde $s$ é a metade da distância entre os eletrodos de corrente, ou seja, $A B / 2$.

\section{Modelagem Numérica por Filtragem Linear}

O método da filtragem linear aplicado aos métodos elétricos foi elaborado por Gosh (1971a, 1971b). Esse método permitiu o cálculo da resistividade aparente com pouco custo computacional, essencial na época. Consistia em resolver a integral da função de resistividade aparente por uma convolução. A função transformada da resistividade era convolvida com um conjunto de filtros previamente calculados e o resultado dessa convolução era a resistividade aparente. Logo depois Johansen (1975) aprimorou a técnica utilizando um conjunto de filtros mais longo e com isso aumentou consideravelmente a precisão do cálculo. É essa formulação de Johansen que utilizamos no trabalho.

Ela começa introduzindo novas variáveis, $x$ e $y$, na equação 3.49:

$$
x=\ln (s) \text { e } y=\ln (1 / \lambda)
$$

que torna a resistividade aparente igual a 


$$
\rho_{a}(x)=\int_{-\infty}^{\infty} T(y) b(x-y) d y
$$

onde

$$
b(x)=J_{1}\left(e^{x}\right) e^{2 x}
$$

Pode-se notar que a integral de convolução 3.51 possui a seguinte propriedade para qualquer deslocamento $S$

$$
\rho_{a}(x)=\int_{-\infty}^{\infty} T(y+S) b(x-y-S) d y
$$

Agora se considera $F, G$ e $H$ sendo as transformadas de Fourier de $\rho_{a}, T$ e $b$ respectivamente. Dessa forma podemos considerar a equação 3.51 igual a

$$
F(f)=G(f) \cdot H(f)
$$

Uma vez que toda informação sobre a seqüência de camadas está em $T$ somente, $H(f)=F(f) / G(f)$ é o mesmo para qualquer modelo geoelétrico. A função $b(x)$ possui oscilações bruscas para valores altos de $x$, fazendo com que $H$ só exista realmente num sentido generalizado. Por isso uma aproximação indireta (Gosh, 1971) para determinar $H$ é usada. Utilizando as seguintes funções, que satisfazem 3.51:

$$
\begin{array}{r}
\rho(x)=e^{3 x} /\left(1+e^{2 x}\right)^{\frac{5}{2}} \\
T(y)=\frac{e^{-y} e^{-e^{y}}}{3}
\end{array}
$$

suas transformadas de Fourier são calculadas por integração numérica e o modulo $Q(f)$ e a fase $\Phi(f)$ do quociente $F / G$ determinam $H$.

Para um dado intervalo de amostragem $\Delta x$ a freqüência de Nyquist é $f_{N}=1 / 2 \Delta x$ e a função sinc correspondente é dada por

$$
C(x)=\frac{1}{f_{N}} \int_{0}^{f_{N}} Q(f) \cos \left(\Phi(f)+2 \pi f_{x}\right) d f
$$

Como observado por Koefoed (1972) é conveniente amostrar $C(x)$ em posições deslocadas para a esquerda, pelo fator de 


$$
S=\left(\frac{\Delta x}{\pi}\right) \Phi\left(f_{N}\right)
$$

porque isso faz com que os pontos de amostragem coincidam assimptoticamente com os nós de $C(x)$, dessa forma pode-se reduzir o tamanho do filtro.

A resistividade aparente $\rho_{a}$ nos pontos de amostragem $x_{i}=i \Delta x$ são então dados aproximadamente por

$$
\rho_{a}(i \Delta x) \sim \sum_{j=j_{\min }}^{j_{\max }} T((i-j) \Delta x+S) C(j \Delta x-S)
$$

onde $j_{\min }$ e $j_{\max }$ são escolhidos para que os coeficientes do filtro com menores ou maiores índices possam ser negligenciados.

A transformada da resistividade $T$ para uma terra estratificada com $N$ camadas (Figura 15) como já dito pode se calculada recursivamente. Para uma camada $\left(\rho_{N-1}, h_{N-1}\right)$ acima do embasamento geoelétrico, $\rho_{N}$, a transformada pode ser calculada, usando a formulação exponencial como:

$$
T_{N-1}(\lambda)=\rho_{N-1} \frac{1-k_{N-1} e^{-2 h_{N-1} \lambda}}{1+k_{N-1} e^{-2 h_{N-1} \lambda}}
$$

onde

$$
k_{N-1}=\frac{\left(\rho_{N-1}-\rho_{N}\right)}{\left(\rho_{N-1}+\rho_{N}\right)}
$$




\section{Modelo de $\mathrm{N}$ camadas}
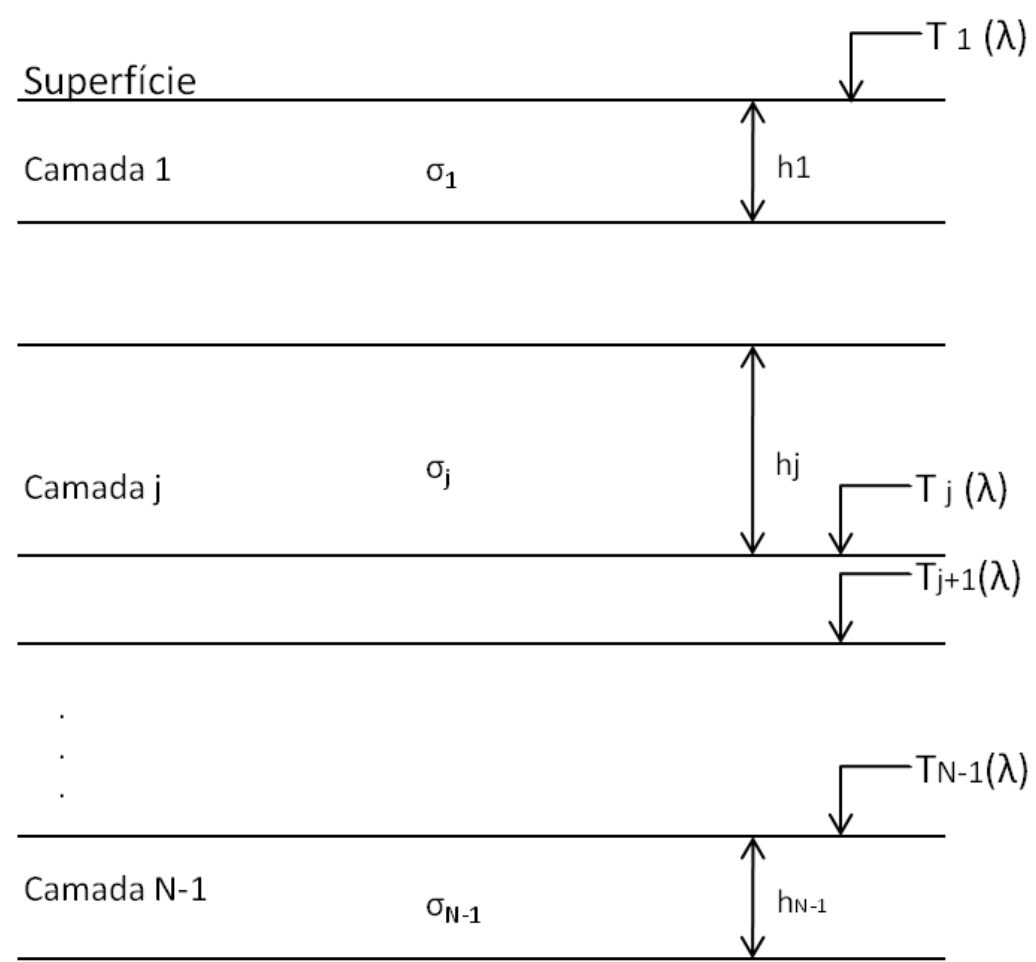

Camada $\mathrm{N} \quad \sigma_{\mathrm{N}}$

(embasamento geoelétrico)

Figura 15: Representação da transformada da resistividade $T$ para uma terra estratificada com $N$ camadas.

A transformada $T_{j}$ para a camada $\left(\rho_{j}, h_{j}\right)$ no topo da seqüência de camadas $\left(\rho_{j+1}, \ldots, \rho_{N} ; h_{j+1}, \ldots, h_{N-1}\right)$ é dada por:

$$
T_{j}(\lambda)=\frac{W_{j}(\lambda)+T_{j+1}(\lambda)}{1+W_{j}(\lambda) T_{j+1}(\lambda) / \rho_{j}^{2}}
$$

onde

$$
W_{j}(\lambda)=\rho_{j} \frac{1-e^{-2 h_{j} \lambda}}{1+e^{-2 h_{j} \lambda}}
$$

e

$$
j=N-2, N-3, \cdots, 2,1
$$

pela operação recursiva chega-se que $T=T_{1}(\lambda)$. 
Tendo o cálculo da transformada da resistividade precisamos agora calcular a convolução com os filtros. Para conveniência substitui-se na equação $3.58 T^{(i-j)}$ e $C^{(j)}$ para $T((i-j) \Delta x+S)$ e $C(j \Delta x-S)$. E divide-se o somatório em três partes:

$$
\rho_{a}(i)=\left\{\sum_{j=-\infty}^{j_{1}}+\sum_{j_{1}+1}^{j_{2}-1}+\sum_{j=j_{2}}^{\infty}\right\} T^{(i-j)} C^{(j)}
$$

com

$$
i=0,1,2, \ldots
$$

É necessário então definir um $j_{1}$ e um $j_{2}$ para que façam com que $T$ se aproxime assimptoticamente dos valores de $\rho_{N}$ e $\rho_{1}$ no primeiro e no segundo termo de 3.63 respectivamente. Para que então a resistividade aparente possa ser calculada pela seguinte expressão:

$$
\rho_{a}(i) \approx \rho_{N} C_{*}^{j_{1}}+\sum_{j_{1}+1}^{j_{2}-1} T^{(i-j)} C^{(j)}+\rho_{1} C_{*}^{j_{2}}
$$

onde

$$
C_{*}^{j_{1}}=\sum_{j=-\infty}^{j_{1}} C^{(j)} \text { e } C_{*}^{j_{2}}=\sum_{j=j_{2}}^{\infty} C^{(j)}
$$

No caso de Johansen (1975) os limites do filtro foram definidos como sendo $j_{1}=-100$ e $j_{2}=40$. Assim o conjunto de filtros usado possui 141 coeficientes que são apresentados no Apêndice 1. O autor usa um intervalo de amostragem de $\Delta x=(\ln (10)) / 10$ que é mais que o suficiente, pois normalmente numa sondagem Schlumberger são feitos menos que oito pontos por década. O desvio $S$ calculado para uma melhor resolução é -1,7239458. A precisão do cálculo para esse filtro também é ótima sendo na ordem de $10^{-2}$. Foi elaborada então uma rotina em Matlab para o cálculo da modelagem da sondagem elétrica vertical Schlumberger. Para um modelo geoeletrico como o mostrado na Figura 16a a resposta calculada pode ser vista na Figura 16b. 


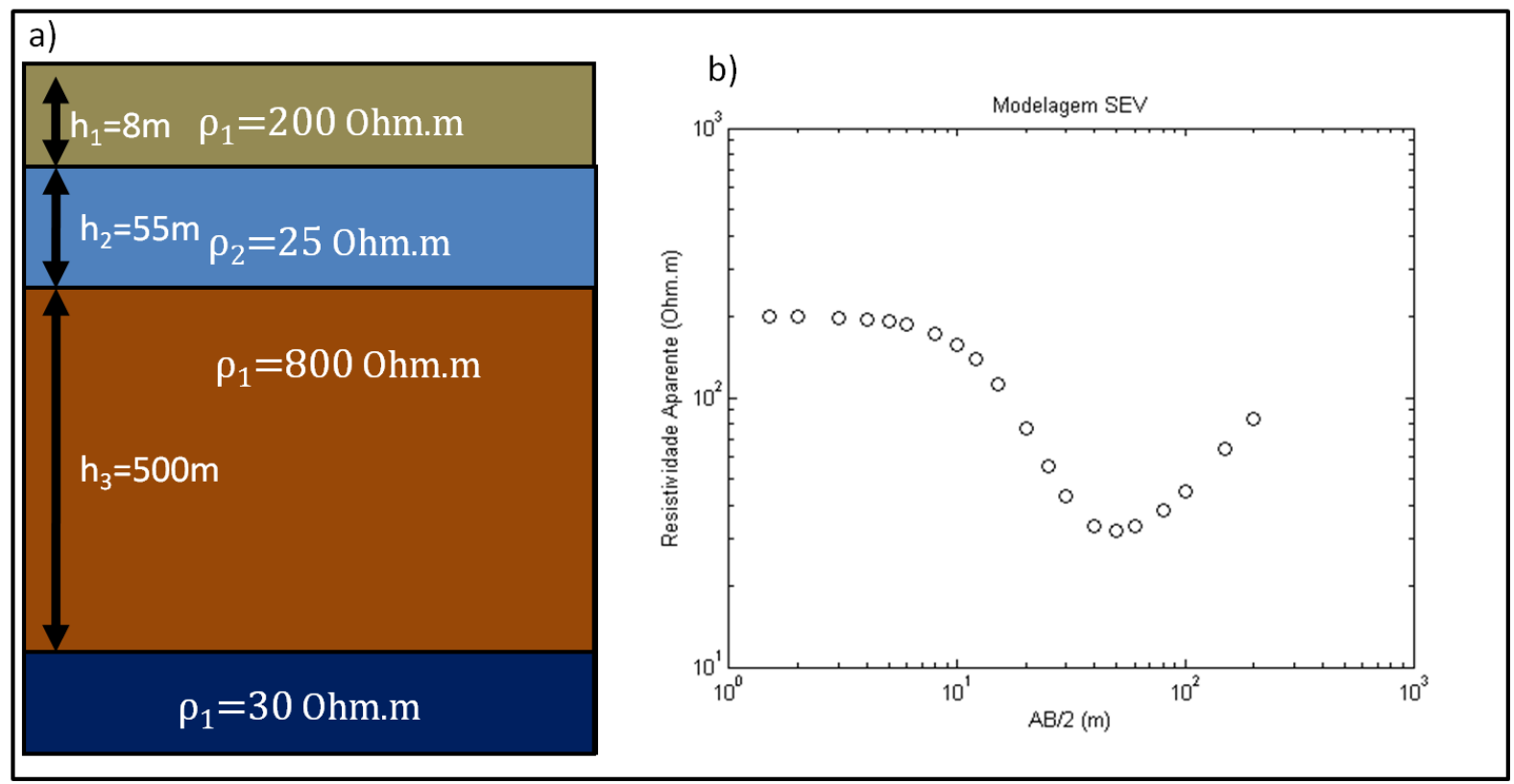

Figura 16: Modelagem SEV. Em "a" é mostrado a representação de modelo geoelétrico. Em "b" é mostrado a resposta desse modelo por meio de um gráfico de resistividade aparente (Ohm.m) por AB/2 (m).

\section{Modelagem TDEM}

Como já discutido no capítulo anterior, o método TDEM nesse trabalho foi usado na forma de levantamentos 1D, com o arranjo de Loop Central. Assim como no caso da sondagem elétrica vertical esse tipo de arranjo explora a variação da resistividade com a profundidade. Mas nesse caso o perfil de resistividade vai ser aproximado como sendo logo abaixo da bobina receptora (no centro do loop transmissor). Da mesma forma que na SEV, a representação do subsolo também será dada na forma de camadas planas e paralelas que possuem espessura e resistividade próprias. A última camada (embasamento geoelétrico) também será aproximada para uma camada que se estende até o infinito e por isso só possui uma resistividade associada e não possui espessura. A esquematização do substrato usado na modelagem TDEM está na Figura 17. 


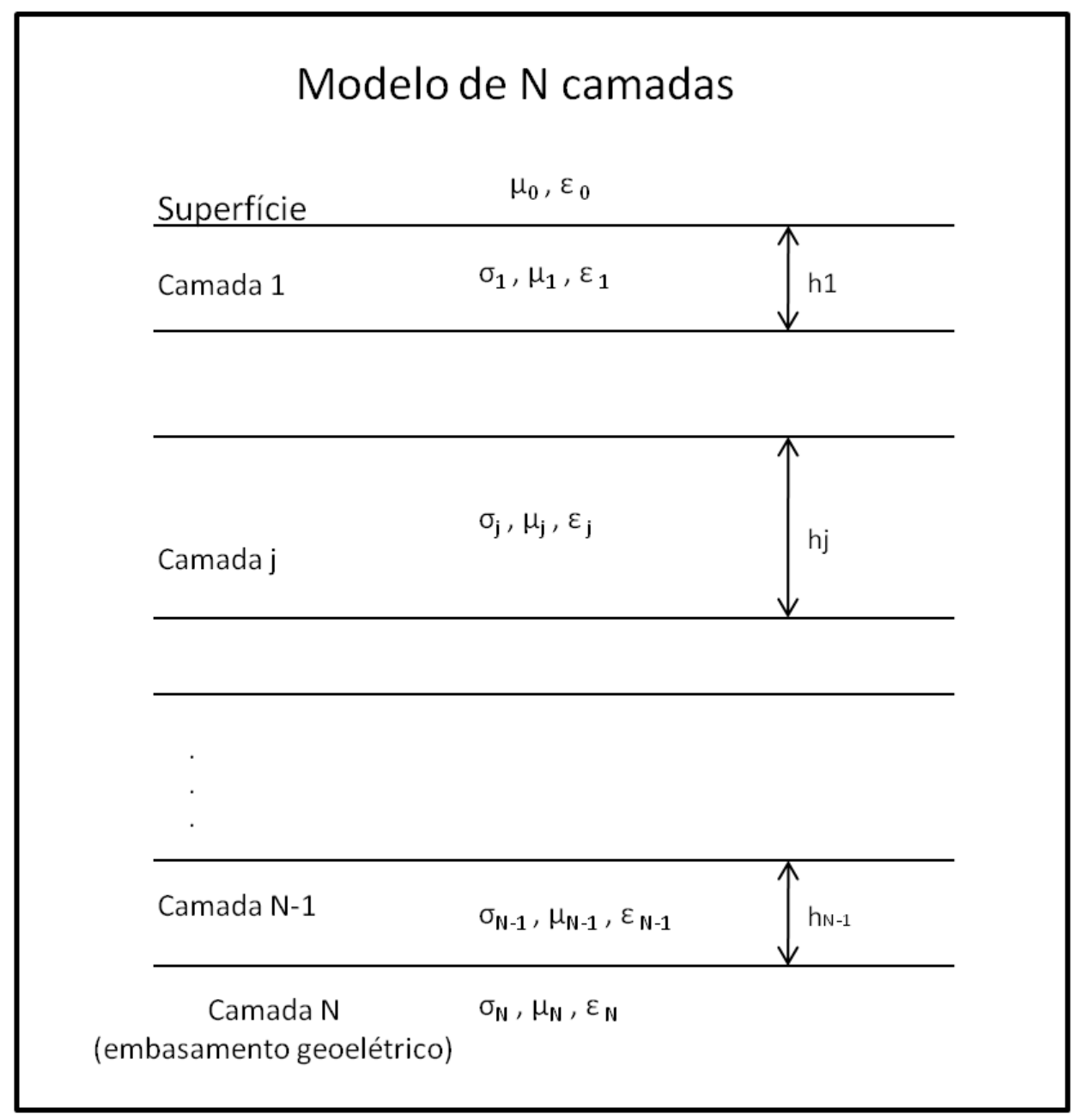

Figura 17: Representação do modelo geoelétrico do subsolo para a sondagem TDEM.

\section{Equações de Maxwell no Domínio da Freqüência}

Todos os fenômenos eletromagnéticos são governados pelas equações de Maxwell. Elas definem que um campo eletromagnético pode ser dado pela combinação de quatro funções vetoriais:

- e: intensidade do campo elétrico

- b: indução magnética

- $\mathbf{d}$ : corrente de deslocamento

- $\mathbf{h}$ : intensidade do campo magnético 
essas funções se relacionam através das equações de Maxwell no domínio do tempo:

$$
\begin{gathered}
\nabla \times \boldsymbol{E}+\frac{\partial \boldsymbol{B}}{\partial t}=0 \\
\nabla \times \boldsymbol{H}-\frac{\partial \boldsymbol{D}}{\partial t}=\boldsymbol{j} \\
\nabla \cdot \boldsymbol{B}=0 \\
\nabla \cdot \boldsymbol{D}=q
\end{gathered}
$$

com $\boldsymbol{j}$ sendo a densidade de corrente elétrica $\left(A / \mathrm{m}^{2}\right)$ e $q$ é a densidade de carga elétrica $\left(C / \mathrm{m}^{3}\right)$.

Apesar de o método TDEM ser usado no domínio do tempo, a formulação para ele é feita inicialmente no domínio da freqüência. Para isso é necessário transformar o domínio das equações de Maxwell. Aplicamos então uma transformada temporal de Fourier nas equações 3.66 a 3.69. Defini-se que a transformada temporal de Fourier é dada por:

$$
F(\omega)=\int_{-\infty}^{\infty} f(t) e^{-i \omega t} d t
$$

e a transformada inversa por:

$$
f(t)=\frac{1}{2 \pi} \int_{-\infty}^{\infty} F(\omega) e^{i \omega t} d \omega
$$

Assim obtemos as equações de Maxwell no domínio da freqüência:

$$
\begin{gathered}
\nabla \times \mathbf{E}=-i \omega \mathbf{B} \\
\nabla \times \mathbf{H}=\mathbf{J}+i \omega \mathbf{D} \\
\nabla \cdot \mathbf{B}=0 \\
\nabla \cdot \mathbf{D}=\rho
\end{gathered}
$$

onde $\mathbf{B}=\mu \mathbf{H}$ e $\mathbf{D}=\varepsilon \mathbf{E}$. 


\section{Dipolo Magnético Horizontal em um Meio Estratificado}

A simetria do problema permite empregar o sistema de coordenadas cilíndricas, uma vez que a direção axial coincide com o eixo $z$, como visto na Figura 17. Como o loop está centrado na origem do sistema de coordenadas e não há variação lateral de resistividade, não vai haver nenhuma dependência de $\omega$. Então as equações de Maxwell podem ser reduzidas as três que se seguem:

$$
\begin{gathered}
i \omega \mu_{i} H_{r}=\frac{\partial E_{\theta}}{\partial z} \\
i \omega \mu_{i} H_{z}=-\frac{1}{r} \frac{\partial}{\partial r}\left(r E_{\theta}\right)
\end{gathered}
$$

e

$$
\frac{\partial H_{r}}{\partial z}-\frac{\partial H_{z}}{\partial r}=\left(i \omega \varepsilon_{i}+\sigma_{i}\right) E_{\theta}+J_{\theta}
$$

levando em conta que $\partial / \partial \phi=0$ e que também $E_{r}=E_{z}=H_{\phi}=0$. Os parâmetros $\sigma_{i}, \varepsilon_{i}$ e $\mu_{i}$ são respectivamente a condutividade elétrica (inverso da resistividade elétrica), a permissividade dielétrica e a permeabilidade magnética. $O$ índice $i$ representa a referência a $i$-ésima camada.

A densidade de corrente no transmissor, $J$, é calculada assumindo que o loop transmissor é representado como uma função delta em coordenadas cilíndricas. Dessa forma, um elemento de corrente, $I(\omega) a d \theta$, na direção $\bar{\theta}$ a uma distância radial $a$ da origem em $z=0$ é representado por

$$
d J_{\theta}=\frac{I(\omega) a d \theta \delta(r-a) \delta(z) \delta\left(\theta-\theta_{0}\right)}{r} \bar{\theta}
$$

onde $\bar{\theta}$ é um vetor unitário na direção $\theta$ e $I(\omega)$ é o espectro de Fourier do pulso de corrente primário. Uma vez que se assume uma corrente constante na direção $\theta$, deve-se integrar sobre $\theta_{0}$. Dessa forma a densidade de corrente da fonte é dada por:

$$
J_{\theta}=\frac{I(\omega) a \delta(r-a) \delta(z)}{r} \bar{\theta}
$$

a notação $\delta$ representa a função Delta de Dirac. 
De volta as equações 3.76 a 3.78, elas mostram claramente que o sistema representado por elas pode ser resolvido apenas para $E_{\theta}$, e assim $H_{r}$ e $H_{z}$ podem ser obtidas por diferenciação. Podese então obter a seguinte equação escalar heterogênea para o campo elétrico da fonte, $E_{S}$ :

$$
\left[\frac{\partial^{2}}{\partial z^{2}}+\frac{\partial^{2}}{\partial r^{2}}+\frac{1}{r} \frac{\partial}{\partial r}-\frac{1}{r^{2}}+k_{0}^{2}\right] E_{s}(r, z, \omega)=\frac{i \omega \mu_{0} I(\omega) a \delta(r-a) \delta(z)}{r}
$$

onde $k_{i}^{2}=\omega^{2} \varepsilon_{i} \mu_{i}-i \omega \mu_{i} \sigma_{i}$ e a fonte está localizada no ar, meio $i=0$. Também a partir deste ponto o índice $\theta$ no campo elétrico será omitido. Em regiões que não contém a fonte de corrente (todas as camadas, exceto no ar onde se encontra a espira) o termo de corrente é zero. Dessa forma a equação 3.81 se torna uma equação homogênea e o campo elétrico pode ser calculado para as regiões que não contém a fonte de corrente.

O cálculo continua transformando 3.81 por transformada de Hankel. Para isso definimos o seguinte par da transformada:

$$
\begin{gathered}
H_{1}[F(r)]=\int_{0}^{\infty} F(r) J_{1}(\lambda r) r d r=F(\lambda) \\
H_{1}^{-1}[F(\lambda)]=\int_{0}^{\infty} F(\lambda) J_{1}(\lambda r) \lambda d \lambda=F(r)
\end{gathered}
$$

e assim a transformada é dada por:

$$
\left[\frac{\partial^{2}}{\partial z^{2}}-\left(\lambda^{2}-k_{0}^{2}\right)\right] E_{S}(\lambda, z, \omega)=i \omega \mu_{0} a I(\omega) J_{1}(\lambda a) \delta(z)
$$

A equação 3.84 pode ser resolvida por uma transformada de Fourier, transformando $z$ em $k_{z}$. A seguir se calcula a inversa pela integral de área. Dessa forma obtêm-se o campo primário (abaixo do loop):

$$
E_{S}(\lambda, z, \omega)=\frac{-i \omega \mu_{0} a I(\omega) J_{1}(\lambda a) e^{-u_{0} z}}{2 u_{0}} \quad(z>0)
$$

onde

$$
u_{i}=\sqrt{\lambda^{2}-k_{i}^{2}}
$$

e $J_{1}(\lambda a)$ é função de Bessel de primeira ordem. Por conveniência usa-se a seguinte notação:

$$
E_{S}(\lambda, z, \omega)=E_{0}^{+}(\lambda, \omega) e^{-u_{0} z}
$$




\section{Condições de Fronteira}

Algumas condições de fronteira derivadas diretamente das equações de Maxwell são adotadas. Essas condições são adotadas para corrente contínua, mas são válidas quando se trabalha com freqüências de até $10^{5} \mathrm{~Hz}$ sobre materiais geológicos. Dessa forma as seguintes condições de fronteira devem ser consideradas:

1. A componente normal de $\mathbf{B}, B_{n}$, é contínua na interface que separa um meio do outro:

$$
B_{n_{1}}=B_{n_{2}}
$$

2. A componente normal de $\mathbf{D}, D_{n}$, é descontínua nas interfaces devido ao acumulo de carga elétrica:

$$
D_{n_{2}}-D_{n_{1}}=\rho_{s}
$$

onde $\rho_{s}$ é a densidade de carga na interface.

3. A componente tangencial do campo elétrico $\mathbf{E}, E_{t}$, é contínua nas interfaces entre as camadas:

$$
E_{t_{1}}=E_{t_{2}}
$$

4. A componente tangencial do campo magnético $\mathbf{H}, H_{t}$, é contínua numa interface se não há corrente na superfície da mesma:

$$
H_{t_{1}}=H_{t_{2}}
$$

5. A componente normal da densidade de corrente $\mathbf{J}, J_{n}$, é contínua nas interfaces:

$$
J_{n_{1}}=J_{n_{2}}
$$

Um conjunto secundário de soluções é obtido transformando (pela transformada de Hankel) a equação 3.81 sem o termo de corrente. E a seguir resolvendo a equação diferencial homogênea em $z$. Para qualquer camada $i$ a solução homogênea para o campo total $E$ é dada por:

$$
E=E_{i}^{+}(\lambda, \omega) e^{-u_{i} z}+E_{i}^{-}(\lambda, \omega) e^{u_{i}}
$$


onde $E_{i}^{+}$e $E_{i}^{-}$são as amplitudes das soluções nas direções positiva (+) e negativa (-) respectivamente na i-ésima camada. Elas são então determinadas aplicando as condições de fronteira que a componente tangencial dos campos elétrico e magnético são contínuas.

\section{Função Impedância}

Um meio conveniente de aplicar as condições de fronteira em um meio horizontalmente estratificado é através da aproximação pela impedância de entrada. Nesse caso a impedância de entrada em qualquer camada $i$ é definida como:

$$
Z^{i}(\lambda, \omega)=\frac{E(\lambda, \omega)}{H_{r}(\lambda, \omega)}
$$

então para qualquer camada $i$ a impedância vai ser:

$$
Z_{i}(\lambda, \omega)=\frac{-j \omega \mu_{i}}{u_{i}}=\frac{E^{+}(\lambda, \omega)}{H_{r}^{+}(\lambda, \omega)}=\frac{-E^{-}(\lambda, \omega)}{H_{r}^{-}(\lambda, \omega)}
$$

Para um meio com $n$-camadas resolve-se a seguinte relação recursiva $n$ vezes para obter dessa forma a impedância na primeira camada (Wait (1962) apud Ryu et. al. (1970))

$$
Z^{i}=Z_{i} \frac{Z^{i+1}+Z_{i} \tanh \left(u_{i} h_{i}\right)}{Z_{i}+Z^{i+1} \tanh \left(u_{i} h_{i}\right)}
$$

onde $h_{i}$ a espessura da camada $i$. O cálculo começa na superfície da última camada (n-ésima camada) onde

$$
Z^{n}=Z_{n}
$$

e o cálculo dessa forma é feito de baixo para cima até a superfície.

Para qualquer meio a impedância na superfície deve ser calculada em função de $\lambda$ e $\omega$. Utilizando as equações 3.87, 3.94 e 3.95 obtêm-se as duas seguintes relações na superfície de um semi-espaço:

$$
E_{0}^{+}(\lambda, \omega) e^{-u_{0} h}+E_{0}^{-}(\lambda, \omega) e^{u_{0} h}=E(\lambda, h, \omega)
$$




$$
\frac{E_{0}^{+}(\lambda, \omega) e^{-u_{0} h}}{Z_{0}(\lambda, \omega)}-\frac{E_{0}^{-}(\lambda, \omega) e^{u_{0} h}}{Z_{0}(\lambda, \omega)}=\frac{E(\lambda, h, \omega)}{Z^{1}(\lambda, \omega)}
$$

Resolvendo o sistema para $E$ tem-se que

$$
E(\lambda, h, \omega)=2 E_{0}^{+}(\lambda, \omega) e^{-u_{0} h} \frac{Z^{1}}{Z_{0}+Z^{1}}
$$

Então se substitui as equações 3.85 e 3.87 e aplica-se a transformada inversa de Hankel na equação 3.100. Assim se obtêm o campo elétrico secundário a uma distância horizontal $r$ do centro do loop:

$$
E_{S}(r, z, \omega)=-i \omega \mu_{0} a I(\omega) \cdot \int_{0}^{\infty} \frac{e^{-u_{0} z}}{u_{0}} \frac{Z^{1}}{Z_{0}+Z^{1}} J_{1}(\lambda a) J_{1}(\lambda r) \lambda d \lambda
$$

Examinando a integral imprópria de 3.101 temos que quando $z$ é zero, no caso do loop em superfície, há uma grande oscilação no integrando devido as duas funções de Bessel. Isso torna impossível uma integração numérica simples da equação 3.101. Mas observa-se que:

$$
\lim _{\lambda \rightarrow \infty} \frac{e^{-u_{0} z}}{u_{0}} \frac{Z^{1}}{Z_{0}+Z^{1}} J_{1}(\lambda a) J_{1}(\lambda r) \lambda \rightarrow \frac{e^{-\lambda z}}{2} J_{1}(\lambda a) J_{1}(\lambda r)
$$

com $\lambda$ se tornando suficientemente grande. De forma a tornar o integrando definitivamente convergente, mesmo que devagar, pode-se escrever a equação 3.101 da seguinte maneira:

$E_{S}(r, z, \omega)=-i \omega \mu_{0} a I(\omega) \cdot$

$$
\left\{\int_{0}^{\infty}\left(\frac{e^{-u_{0} z}}{u_{0}} \frac{Z^{1}}{Z_{0}+Z^{1}} \lambda-\frac{e^{-\lambda z}}{2}\right) J_{1}(\lambda a) J_{1}(\lambda r) d \lambda+\int_{0}^{\infty} \frac{e^{-\lambda z}}{2} J_{1}(\lambda a) J_{1}(\lambda r) d \lambda\right\}
$$

dessa forma não é necessário se preocupar com a natureza oscilante da função de Bessel de primeira ordem.

Agora a primeira integral pode ser calculada numericamente e a segunda pode ser reduzida a uma integral finita. Ela é reduzida por uma relação dada por Watson (1966) tal que:

$$
\begin{aligned}
\int_{0}^{\infty} e^{-a t} t^{\mu-v} J_{\mu}(b t) J_{v}(c t) d t & \\
= & \frac{\left(\frac{b}{2}\right)^{\mu}\left(\frac{c}{2}\right)^{v} \Gamma(2 \mu+1)}{\Gamma\left(v+\frac{1}{2}\right) \Gamma\left(\frac{1}{2}\right)} \int_{0}^{\pi} \frac{\operatorname{sen}^{2 v} \phi d \phi}{\left(a^{2}+2 i c a \cos \phi-c^{2} \cos ^{2} \phi+b^{2}\right)^{\mu+\frac{1}{2}}}
\end{aligned}
$$


A equação 3.104 é aplicável para $(a+i b+i c)>0$ real e $(\mu)>-1 / 2$ real, onde $\Gamma(\cdot)$ é a função gama. A equação 3.103 é reduzida para

$$
\begin{aligned}
& E_{S}(r, z, \omega)=-i \omega \mu_{0} a I(\omega) \cdot \\
& \left\{\int_{0}^{\infty}\left(\frac{e^{-u_{0} z}}{u_{0}} \frac{Z^{1}}{Z_{0}+Z^{1}} \lambda-\frac{e^{-\lambda z}}{2}\right) J_{1}(\lambda a) J_{1}(\lambda r) d \lambda+\right. \\
& \left.\frac{a r}{2 \pi} \int_{-1}^{1} \operatorname{Real}\left[\frac{\left(1-x^{2}\right)^{1 / 2}}{\left(z^{2}+2 i a z x-a^{2} x^{2}+r^{2}\right)^{3 / 2}}\right] d x\right\}
\end{aligned}
$$

Dois pontos devem ser mencionados sobre a segunda integral:

- Ela só é valida quando $z>0$ devido às condições impostas a 3.104. Porém segundo Ryu et. al. (1970) $z$ pode ser assumido como sendo zero sem nenhum tipo de problema. Para o problema em questão, essa situação acaba sendo considerada uma situação limite, mas mesmo assim válida;

- Não há singularidade contanto que $r>a$.

As componentes $H_{r}$ e $H_{z}$ então podem ser deduzidas a partir das equações $3.76,3.77$ e 3.105 da seguinte forma:

$$
\begin{aligned}
& H_{r}(r, z, \omega)=a I(\omega) \cdot \\
& \left\{\int_{0}^{\infty}\left(e^{-u_{0} z} \frac{Z^{1}}{Z_{0}+Z^{1}}-\frac{e^{-\lambda z}}{2}\right) J_{1}(\lambda a) J_{1}(\lambda r) \lambda d \lambda+\right. \\
& \left.\frac{3 a r}{2 \pi} \int_{-1}^{1} \operatorname{Real}\left[\frac{\left(1-x^{2}\right)^{1 / 2}(z+i a x)}{\left(z^{2}+2 i a z x-a^{2} x^{2}+r^{2}\right)^{5 / 2}}\right] d x\right\}
\end{aligned}
$$

e

$$
\begin{aligned}
& H_{z}(r, z, \omega)=a I(\omega) \cdot \\
& \begin{array}{l}
\int_{0}^{\infty}\left(\frac{e^{-u_{0} z}}{u_{0}} \frac{Z^{1}}{Z_{0}+Z^{1}} \lambda-\frac{e^{-\lambda z}}{2}\right) J_{1}(\lambda a) J_{0}(\lambda r) \lambda d \lambda+ \\
\frac{a}{\pi} \int_{-1}^{1} \operatorname{Real}\left[\frac{\left(1-x^{2}\right)^{1 / 2}}{\left(z^{2}+2 i a z x-a^{2} x^{2}+r^{2}\right)^{3 / 2}}\right] d x \\
\left.\frac{3 a r^{2}}{2 \pi} \int_{-1}^{1} \operatorname{Real}\left[\frac{\left(1-x^{2}\right)^{1 / 2}}{\left(z^{2}+2 i a z x-a^{2} x^{2}+r^{2}\right)^{5 / 2}}\right] d x\right\}
\end{array}
\end{aligned}
$$

As equações 3.105, 3.106 e 3.107 possuem todos os componentes do campo eletromagnético fora do loop transmissor (que é finito e carrega a corrente primária). As equações 
dependem dos parâmetros elétricos do subsolo e dos parâmetros geométrico, $a, r$ e $z$. Com $z$ igual a zero as equações são válidas para o caso de um loop na superfície de um meio horizontalmente estratificado.

\section{Campos no interior do Loop}

No centro do loop só a componente vertical do campo magnético será observada. A componente radial do campo magnético e a componente tangencial do campo elétrico são desprezíveis. A componente vertical do campo magnético no centro do loop é escrita no espaço $\lambda$ da transformada de Hankel como:

$$
H_{z}(0, z, \omega)=a I(\omega) \cdot \int_{0}^{\infty} \frac{e^{-u_{0} z}}{u_{0}} \frac{Z^{1}}{Z_{0}+Z^{1}} J_{1}(\lambda a) \lambda^{2} d \lambda
$$

Novamente a equação 3.108 pode ser alterada para a convergência do integrando na forma de

$$
\begin{aligned}
& H_{z}(0, z, \omega) \\
& \quad=a I(\omega) \cdot\left\{\int_{0}^{\infty}\left(\frac{e^{-u_{0} z}}{u_{0}} \frac{Z^{1}}{Z_{0}+Z^{1}} \lambda-\frac{e^{-\lambda z}}{2}\right) J_{1}(\lambda a) \lambda d \lambda+\int_{0}^{\infty} \frac{e^{-\lambda z}}{2} J_{1}(\lambda a) \lambda d \lambda\right\}
\end{aligned}
$$

a primeira integral imprópria pode ser calculada numericamente e a segunda parte pode ser calculada analiticamente, uma vez que

$$
-\frac{\partial}{\partial a} J_{0}(\lambda a)=J_{1}(\lambda a) \lambda
$$

e

$$
\int_{0}^{\infty} e^{-\lambda z} J_{0}(\lambda a) d \lambda=\frac{1}{\left(a^{2}+z^{2}\right)^{1 / 2}} \quad, \quad z>0
$$

Dessa forma a equação 3.109 se torna:

$$
H_{z}(0, z, \omega)=a I(\omega) \cdot \int_{0}^{\infty}\left(\frac{e^{-u_{0} z}}{u_{0}} \frac{Z^{1}}{Z_{0}+Z^{1}} \lambda-\frac{e^{-\lambda z}}{2}\right) J_{1}(\lambda a) \lambda d \lambda+\frac{a^{2} I(\omega)}{2\left(a^{2}+z^{2}\right)^{3 / 2}}
$$


Nielsen et. al. (2006) sugerem uma nova notação para equação 3.112 desenvolvida por Ryo et. al. (1970). Nessa nova notação já se assumi que o loop está na superfície ( $z=0)$, dessa forma é possível reduzir a equação 3.112. Outra mudança é que as relações recursivas são dadas forma de uma função $R_{n}^{T E}$ tal que:

$$
\begin{gathered}
R_{n}^{T E}=\frac{R_{n+1}^{T E}+\psi_{n+1}^{T E}}{R_{n+1}^{T E} \psi_{n+1}^{T E}+1} e^{-2 u_{n} h_{n}} \\
\psi_{n+1}^{T E}=\frac{\frac{u_{n}}{\hat{z}_{n}}-\frac{u_{n+1}}{\hat{z}_{n+1}}}{\frac{u_{n}}{\hat{z}_{n}}+\frac{u_{n+1}}{\hat{z}_{n+1}}} \\
\hat{z}_{n}=i \omega \mu_{n} \\
k_{n}^{2}=\omega^{2} \varepsilon_{n} \mu_{n}-i \omega \mu_{n} \sigma_{n} \\
u_{n}=\sqrt{\lambda^{2}-k_{n}^{2}}
\end{gathered}
$$

e

$$
R_{N}^{T E}=0
$$

onde $h_{n}$ é a espessura da camada $n . R^{T E}$ tem uma forma de ser representada parecida com a transformada da resistividade no caso da sondagem elétrica, como pode ser visto na Figura 18. 


\section{Modelo de $\mathrm{N}$ camadas}
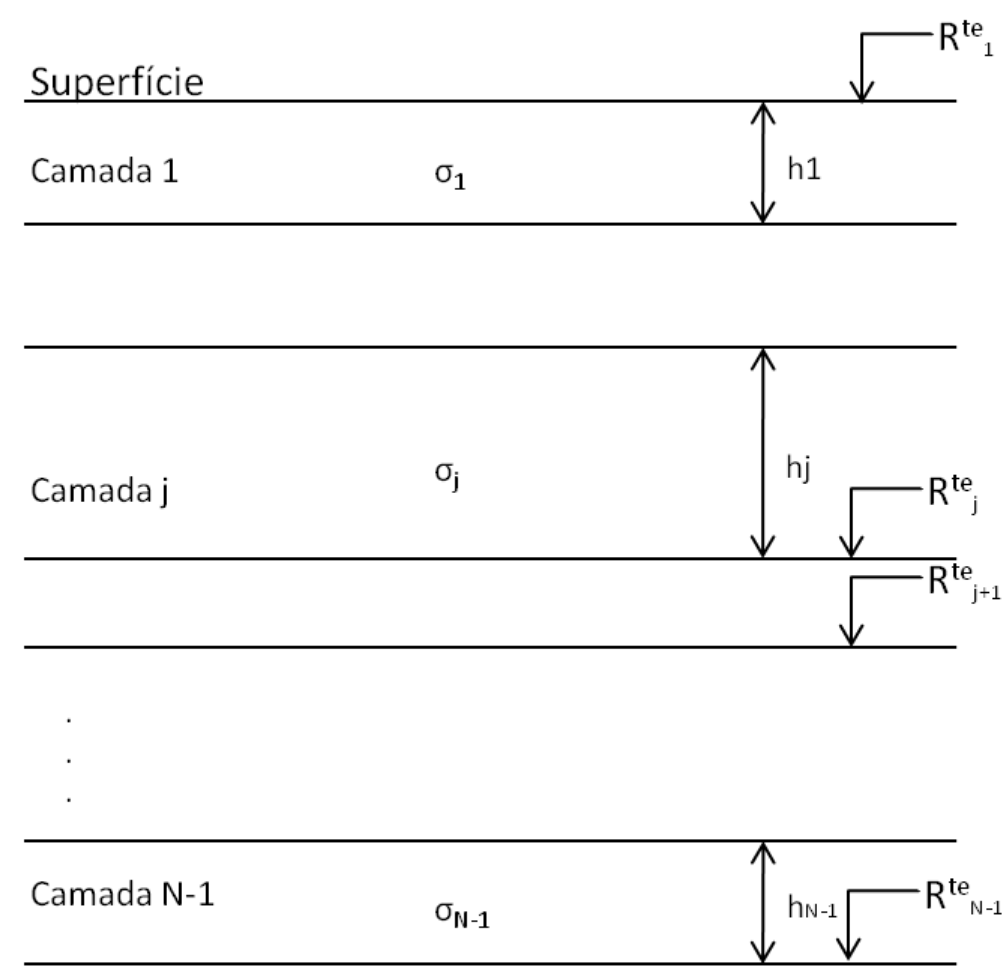

Camada $\mathrm{N} \quad \sigma_{\mathbf{N}}$

(embasamento geoelétrico)

Figura 18: Representação de $R^{T E}$ para uma terra estratificada com $N$ camadas.

A equação 3.112 é escrita agora da seguinte maneira:

$$
H_{z}(\omega)=a I \cdot \int_{0}^{\infty}\left[\left(1+R_{0}^{T E}\right) \frac{\lambda}{2 u_{0}}-\frac{1}{2}\right] J_{1}(\lambda a) \lambda d \lambda+\frac{I}{2 a}
$$

e desenvolvida da seguinte forma:

$$
H_{z}(\omega)=a I \cdot \int_{0}^{\infty}\left[\frac{\left(R_{1}^{T E}+1\right)\left(u_{0}+\left(\hat{z}_{0} / \hat{z}_{1}\right) u_{1}\right)^{-1}}{R_{1}^{T E} \psi_{1}^{T E}+1}-\frac{1}{2}\right] J_{1}(\lambda a) \lambda d \lambda+\frac{I}{2 a}
$$

A função Kernel de $H_{z}(\omega)$ pode então ser simplificada no caso da primeira camada não ser magnética $\left(\mu_{1}=\mu_{0}\right)$. Isso é feito subtraindo um termo representando o espaço homogêneo (Wait, 1952) da função Kernel e adicionando a expressão analítica fora da integral. Assim a expressão para o campo magnético no centro do loop fica sendo: 


$$
\begin{aligned}
H_{z}(\omega)=a I & \cdot \int_{0}^{\infty}\left[\frac{2 R_{1}^{T E} u_{1} \lambda}{R_{1}^{T E}\left(k_{1}^{2}-k_{0}^{2}\right)+\left(u_{0}-u_{1}\right)^{2}}-\frac{1}{2}\right] J_{1}(\lambda a) \lambda d \lambda+\frac{I}{2 a}+ \\
& +\frac{I}{\left(k_{1}^{2}-k_{0}^{2}\right) a^{3}}\left(\left(k_{0}^{2} a^{2}-3 i k_{0} a-3\right)^{-i k_{0} a}-\left(k_{1}^{2} a^{2}-3 i k_{1} a-3\right)^{-i k_{1} a}\right)
\end{aligned}
$$

e em freqüências suficientemente baixas $\left(k_{0} \approx 0\right)$, fazendo com que a equação 3.121 fique simplificada na forma de:

$$
\begin{gathered}
H_{z}(\omega)=a I \cdot \int_{0}^{\infty}\left[\frac{2 R_{1}^{T E} u_{1} \lambda}{R_{1}^{T E} k_{1}^{2}+\left(\lambda+u_{1}\right)^{2}}-\frac{1}{2}\right] J_{1}(\lambda a) \lambda d \lambda+\frac{I}{2 a}+ \\
+\frac{I}{k_{1}^{2} a^{3}}\left(3+\left(k_{1}^{2} a^{2}-3 i k_{1} a-3\right)^{-i k_{1} a}\right)
\end{gathered}
$$

Uma vez que a resposta transiente é uma função causal $\left(h_{z}(t)=0\right.$ para $\left.t \leq 0\right)$, a transformação da resposta no domínio da freqüência para o domínio do tempo pode ser obtida na forma de uma transformada seno ou cosseno. E segundo Anderson $(1974,1981)$ apud Nielsen et. al. (2006):

$$
h_{z}(t)=-\frac{2}{\pi} \int_{0}^{\infty} \frac{1}{\omega} \operatorname{Im}\left[H_{z}(\omega)\right] \cos (\omega t) d \omega
$$

na equação 3.123 assume-se uma fonte excitadora do tipo caixa, assim como mostrada na Figura 11.

Assumindo que o campo não varia na área da bobina receptora, a relação entre o campo magnético vertical e a voltagem induzida é dada por

$$
v(t)=-\mu_{0} n \pi b^{2} \frac{d h_{z}(t)}{d t}
$$

onde $b$ é o raio do loop receptor e $n$ o número de espiras. Depois de fazer algumas substituições a impedância mútua resultante pode ser expressa como:

$$
Z(\tau)=-\frac{2 n b^{2}}{\sigma_{1} a^{3}} \int_{0}^{\infty} \operatorname{Im}\left[H_{z}\left(\frac{2 g}{\sigma_{1} \mu_{0} a^{2}}\right) \frac{2 a}{I}\right] \operatorname{sen}(g \tau) d g
$$

onde $\sigma_{1}$ é a condutividade da primeira camada, $\tau=2 t\left(\sigma_{1} \mu_{0} a^{2}\right)^{-1}$ e $g=\frac{1}{2} \sigma_{1} \mu_{0} \omega a^{2}$. 
De forma análoga a sondagem elétrica vertical a solução vai ser obtida pela filtragem linear. No caso do TDEM existem duas integrais para serem calculadas, a integral de 3.122 e a integral de 3.125. Primeiro é necessário obter o integrando de 3.125 que é o campo magnético no domínio da freqüência (equação 3.122). Para obter o campo magnético, ainda no domínio da freqüência é necessário resolver a integral da equação 3.122 e o melhor jeito é usando um conjunto de filtros. 0 conjunto de filtros usados agora é um dos desenvolvidos por Christensen (1990) para a solução de integrais na forma de:

$$
I(a)=\int_{0}^{\infty} K(\lambda) \lambda J_{1}(\lambda a) d \lambda
$$

onde $K$ é o kernel da função. No caso o kernel vai ser representado pelo termo $K$ da integral que é dado da seguinte forma:

$$
K=\left(\frac{R_{1}^{T E} \lambda}{u_{0}}\right) \lambda
$$

A convolução entre o Kernel e o conjunto de filtros vai ser feito da mesma forma que Nielsen et. al. (2006), de forma parecida como a feita no método elétrico, sendo dada por:

$$
\bar{H}_{z}=\sum \bar{K} * \bar{F}_{J 1}
$$

onde $\bar{F}_{J 1}$ é um conjunto de filtros usados na solução de integrais na forma de 3.126. Assim se obtêm o campo magnético ainda no domínio da freqüência.

Tendo os valores do campo magnético calculados, a integral 3.125 pode ser então resolvida por uma segunda filtragem linear, mas nesse caso vai ser uma filtragem pela função seno. Novamente um conjunto de filtros desenvolvido por Christensen (1990) é usado. Dessa forma a equação para a impedância mútua é resolvida da seguinte forma:

$$
\bar{Z}=\sum \operatorname{Im}\left[\bar{H}_{z}\right] * F_{\text {sen }}
$$

onde $F_{\text {sen }}$ é um conjunto de filtros usado na solução de integrais na forma de:

$$
I(a)=\int_{0}^{\infty} K(\lambda) \operatorname{sen}(\lambda a) d \lambda
$$


Assim foi desenvolvida uma rotina em Matlab para calcular a impedância mútua entre as bobinas segundo a fórmula 3.129. A partir de um modelo conhecido (Figura 19a) podemos obter um gráfico da tensão no receptor $(\partial B / \partial d)$ pelo tempo, como mostra a Figura 19b. E a partir dos valores da impedância mútua, pode-se finalmente calcular a resistividade aparente para o TDEM segundo a fórmula:

$$
\rho_{a}(i)=\left[\frac{\sqrt{\pi} a^{2} n b^{2}}{20 Z(i)}\right]^{2 / 3}+\left(\frac{\mu_{0}}{t(i)}\right)^{5 / 3}
$$

e assim se obtêm o gráfico da resistividade aparente por tempo como mostrado na Figura 20.

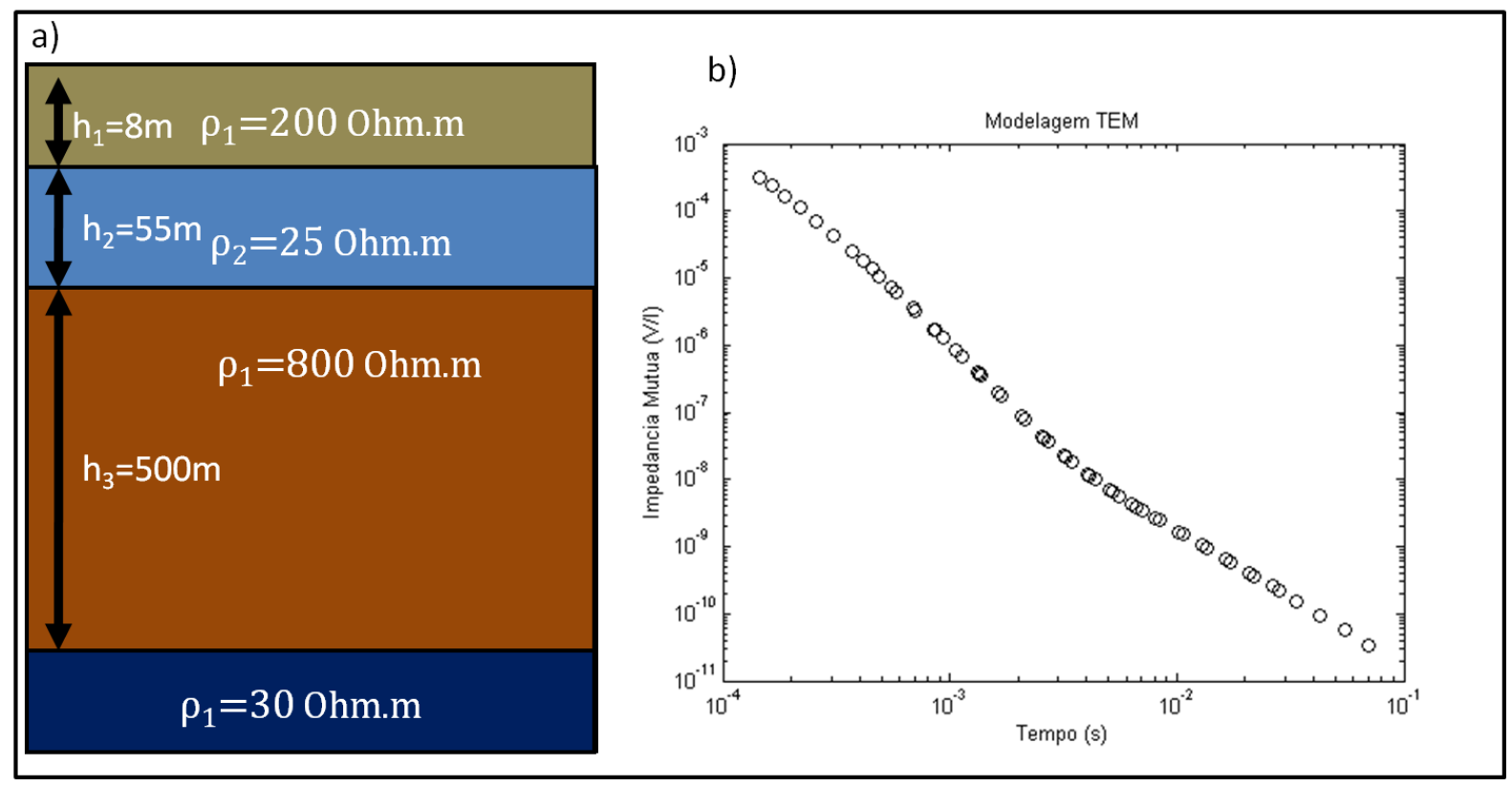

Figura 19: Modelagem TDEM. Em “a” é mostrado a representação de modelo geoelétrico. Em "b" é mostrado a resposta desse modelo por meio de um gráfico de impedância (V/I) por tempo (t). 


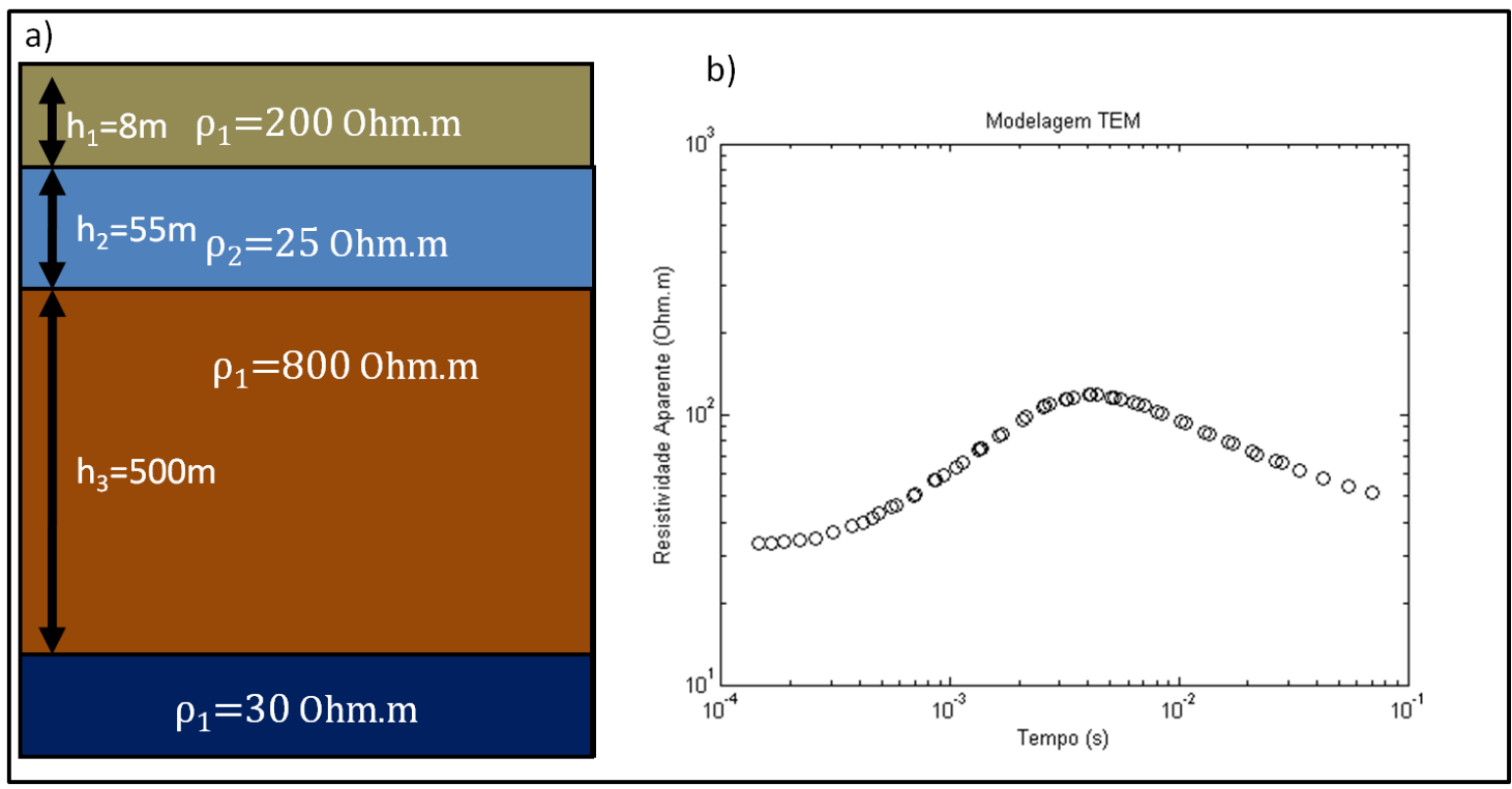

Figura 20: Modelagem TDEM. Em "a" é mostrado a representação de modelo geoelétrico. Em "b" é mostrado a resposta desse modelo por meio de um gráfico de resistividade aparente (Ohm.m) por tempo (t). 


\section{Inversão dos Dados}

Muito do que sabemos sobre o interior da Terra é devido a levantamentos geofísicos feitos em superfície. Esses levantamentos buscam determinar as repostas físicas dos materiais em subsuperfície. As respostas físicas podem ser sísmicas, magnéticas, eletromagnéticas etc. $\mathrm{O}$ que esses levantamentos têm em comum é que normalmente essa resposta física não indica diretamente que tipo de material está no subsolo. Isso independente da escala dos estudos, seja de alguns centímetros até centenas de quilômetros. Para poder determinar que tipo de material que está no subsolo é necessário obter a partir da resposta física (dados) as propriedades físicas do meio que gerou essa resposta. Esse processo é chamado de inversão de dados. Através da inversão é possível determinar os parâmetros geológico-geofisicos que estão contidos nos dados, porém não podem ser obtidos a partir da análise direta deles. O objetivo então da teoria da inversão geofísica é determinar os parâmetros físicos do interior da Terra através dos dados observados ou pelo menos determinar o máximo possível sobre eles, tendo em vista as limitações dos levantamentos geofísicos.

\section{Inversão Geofísica}

O problema inverso em geofísica envolve três etapas bem definidas:

1. formulação do problema e definição de um modelo interpretativo;

2. obtenção de parâmetros que definem esse modelo e

3. análise do modelo obtido.

A etapa de formulação do problema tem como objetivo definir um modelo interpretativo que, em princípio, pode representar as principais feições do substrato (problema direto). O modelo interpretativo é caracterizado por um conjunto de parâmetros conhecidos (muitas vezes relacionados aos parâmetros de aquisição de dados) e parâmetros desconhecidos do modelo. A segunda etapa, ou de inversão propriamente dita, consiste em obter um conjunto de parâmetros que propicia o ajuste aos dados medidos e, ao mesmo tempo, satisfaz vínculos geológicos eventualmente disponíveis. A análise da solução consiste em determinar a incerteza associada aos parâmetros obtidos na etapa anterior. Na inversão de um modelo 1D, os parâmetros desconhecidos 
a serem obtidos são: número de camadas, espessura das camadas e resistividade elétrica das camadas e do embasamento geoelétrico.

\section{Caracterização de um problema inverso}

A solução do problema direto pode ser simplificada por meio da seguinte equação:

$$
d=h(\boldsymbol{p})
$$

onde $h(\boldsymbol{p})$ representa um funcional que a partir dos parâmetros que descrevem o modelo $(\boldsymbol{p})$, calcula a resposta física, $d$, que são os valores da resposta física do modelo. No cálculo do problema direto $\boldsymbol{p}$ é conhecido e dessa forma calcula-se a resposta $d$. Já no problema inverso o vetor $\boldsymbol{p}$ representa os valores desconhecidos, que descrevem o modelo físico desconhecido. Dessa forma o problema inverso pode ser representado como sendo

$$
\boldsymbol{p}=h^{-1}(d)
$$

Porém poucos problemas inversos em geofísica podem ser de fato calculados analiticamente como mostrado na fórmula 4.2. Normalmente o que acontece é que problema direto pode ser resolvido de forma analítica ou semi-analitica. A solução do problema inverso normalmente é feita simulando um modelo $\boldsymbol{p}_{\text {conhecido }}$ e comparando a resposta desse modelo ( $\left.d_{\text {calculado }}\right)$ com os dados obtidos $(d)$. E a diferença entre as duas resposta é dada pela norma calculada da seguinte maneira:

$$
N(d, \boldsymbol{p})=\|d-h(\boldsymbol{p})\|
$$

e quando $N(d, \boldsymbol{p})$ é zero representa um ajuste perfeito entre os dois conjuntos de dados.

Porém toda medida experimental (tanto num laboratório quanto em campo) está sujeita a certo fator de ruído. Então a equação 4.1 na verdade deveria ser representada de fato por:

$$
d=h(\boldsymbol{p})+\delta
$$

onde $\delta$ representa o ruído inerente as medidas experimentais. Esses ruídos inerentes aos dados dificultam a obtenção de $\boldsymbol{p}$ e impende o ajuste perfeito entre os dados e os dados ajustados calculados. 
Deve-se ressaltar que mesmo parecendo que na ausência de ruído a equação 4.2 o modelo $\boldsymbol{p}$ não geraria um conjunto de dados $d_{i}$ iguais ao medido em campo. Isso não necessariamente acontece, uma vez que como já dito a modelagem numérica da subsuperfície é feita com um modelo simplificado do substrato. O interior da Terra é normalmente mais complexo que a aproximação numérica. Também é importante ter um cálculo direto bem representativo na inversão, já que um modelo incapaz de representar o substrato não ajustar os dados obtidos em campo. Alguns outros fatores, como a existência e a unicidade, também são muito importantes quando se trabalha na inversão de dados geofísicos.

\section{Existência}

A existência do problema inverso é um problema que normalmente recebe pouca atenção na literatura geofísica, mas é de grande importância para seu uso. O que ocorre é que nem sempre o modelo direto usado na inversão representa bem o que está na subsuperfície. Dessa forma o problema inverso não consegue reproduzir os valores medidos. Isso acontece porque para simplificar os cálculos do problema direto são normalmente adotados modelos simples que podem ser inadequados para representar o substrato (mais complexo). O modelo de camadas planas paralelas adotadas nesse trabalho, por exemplo, podem ser inadequados em áreas com geologia complexa, com estruturas bi ou tridimensionais. Mas em áreas sedimentares com estratificação simples são muito adequados. Uma vez que tanto os levantamentos quanto os cálculos são mais simples e os resultados muito confiáveis.

\section{Unicidade}

A unicidade é outra questão importante quando se trata de problemas inversos. A nãounicidade acarreta que vários (até infinitos) modelos satisfaçam um mesmo conjunto de dados. Isso acontece porque o número de dados obtidos é finito, e muitas vezes ele não é suficiente para que o número de soluções seja pelo menos igual ao numero de incógnitas. Isso gera uma ambigüidade no processo final de inversão, uma vez que muitos modelos podem gerar uma resposta que ajusta os dados. O método mais comum para contornar esse problema é usando vínculos que limitam o 
espaço de busca da solução reduzindo dessa forma o número de soluções possíveis. Esse processo de colocar vínculos é chamado de regularização. Porém ele tem a desvantagem de poder distorcer a solução final uma vez esses vínculos podem forçar situações não desejáveis. Outra forma de lidar com problema das muitas soluções é analisar as soluções para ver se elas são compatíveis com a área estudada. Ou incorporar mais informação na hora da inversão. Neste trabalho foi estudada uma forma de aumentar o numero de informações pela inversão conjunta de duas metodologias. Com uma base de dados maior espera-se que o problema da ambigüidade seja resolvido ou pelo menos suavizado. E assim o modelo final seja mais confiável possível.

\section{Estabilidade}

A estabilidade de um problema está relacionada com a repetibilidade do processo de inversão frente a um mesmo conjunto de dados. Isto é, se um modelo for obtido a partir de um conjunto de dados, um modelo similar deve ser obtido se o processo de inversão for feito novamente. Mesmo com erros associados (erros de grandeza aceitável) os modelos gerados pelo processo de inversão devem sempre ser próximos. Caso não aconteça o problema inverso é o que se chama de não estável. Uma forma de avaliar se o problema é estável ou não é executar o processo de inversão diversas vezes com a mesma base de dados (se for numérica deve-se perturbá-la com ruído sintético). Se os modelos gerados forem sempre compatíveis o problema é estável. Caso os modelos derivem muito o processo de inversão não está confiável e os modelos obtidos provavelmente não tem significado físico.

\section{Otimização}

Com as definições dadas acima agora é possível definir uma problema geofísico inverso genérico com uma função objetivo tal que:

$$
F_{\text {min }}(\tilde{d}, \boldsymbol{p})=\|\tilde{d}-h(\boldsymbol{p})\|+\beta S(m)
$$

onde $\beta$ é um parâmetros que pesa a importância do ajuste aos dados e da condição de regularização. Dessa forma o processo de otimização busca minimizar a função $F_{\min }$. 
Pode-se ver que um problema geofísico de inversão típico acaba sendo resumido a um problema de otimização. Entretanto, a formulação matemática do problema de otimização não é única. Diversas técnicas de otimização foram e são desenvolvidas paras os mais diversos problemas. A própria função objetivo pode adotar diversas formas, lineares, quadráticas ou até mesmo mais complexas. A definição clara do método de inversão usado e da função objetivo é fundamental para um bom resultado no processo de inversão.

\section{Funções Objetivo}

A função objetivo é um aspecto do problema de inversão que deve ser muito bem definido para poder se obter bons resultados. No caso deste trabalho vamos usar funções objetivas quadráticas tanto para a inversão individual como para a inversão conjunta. Para a inversão individual dos métodos vamos usar a seguinte função objetivo:

$$
\phi(\tilde{d}, \boldsymbol{p})=\|\tilde{d}-h(\boldsymbol{p})\|
$$

onde $\tilde{d}$ são os dados e $h(\boldsymbol{p})$ a resposta do modelo $\boldsymbol{p}$. Como pode ser visto nessa função objetivo não há nenhum termo de ponderação ou regularização. Dessa forma a inversão fica sem vínculos. A experiência com os métodos DC e TDEM mostrou que esse tipo de função é bastante adequada para os métodos em questão. A convergência é muito boa e a inversão é bem robusta.

No caso da inversão conjunta a função objetivo minimizada incorpora os termos da sondagem elétrica e da sondagem TDEM da seguinte forma

$$
\phi_{C O N J}(\tilde{d}, \boldsymbol{p})=\left\|\tilde{d}_{S E V}-h_{S E V}(\boldsymbol{p})\right\|+\left\|\tilde{d}_{T D E M}-h_{T D E M}(\boldsymbol{p})\right\|
$$

onde $\tilde{d}_{S E V}$ são os dados da sondagem elétrica, $\tilde{d}_{T D E M}$ da sondagem TDEM e $h_{S E V}(\boldsymbol{p})$ e $h_{T D E M}(\boldsymbol{p})$ as respostas calculadas para a SEV e a sondagem TDEM respectivamente. Como pode ser visto a função objetivo utilizada neste trabalho não carrega nenhum termo para ponderação dos métodos. A idéia inicial era ponderar a inversão dando mais peso para a sondagem elétrica nas camadas mais rasas e mais peso para o TDEM nas camadas mais profundas. Mas uma análise mais apurada da situação mostrou que esse tipo de ponderação não é necessário. Naturalmente o processo de inversão fará a seleção dos modelos mais adequados devido a natureza das profundidades investigas com os dois métodos. 
Como será visto a diante, o método TDEM não consegue definir com segurança estruturas que se encontram até cerca de $10 \%$ o tamanho do loop. Isso que dizer que num levantamento com um loop quadrado de $100 \mathrm{~m}$ de lado as estruturas até $10 \mathrm{~m}$ não serão bem definidas. No caso da SEV as camadas rasas são bem marcadas nas primeiras posições de $A B / 2$. Já a profundidade de investigação é limitada pelo tamanho do arranjo. Considera-se que a profundidade máxima de investigação seja cerca de um quarto do espaçamento total, ou seja, $A B / 3$. Porém em áreas tropicais como as do Brasil onde os solos são muito condutivos e normalmente existem camadas saturadas muito condutivas as profundidades de investigação tendem a ser consideravelmente menores.

Dessa forma no processo de inversão espera-se que a própria natureza do problema se encarregue de ponderar os métodos a profundidade de investigação. Uma vez que a sondagem elétrica não vai ser sensível as camadas mais profundas as características dessas camadas não vão influenciar na curva de resistividade. O mesmo acontece com o TDEM com relação as camadas mais rasas. Sendo assim existe uma ponderação natural desse problema inverso. Uma ponderação imposta não está errada porem pode gerar uma distorção nessa característica natural do problema, levando a soluções que podem ser distorcidas de certa forma.

\section{Problema Linear}

Quando a relação entre o modelo e os dados é linear o processo de inversão é dito linear. Esse tipo de inversão possui métodos de solução bem desenvolvidos e entendidos. Para parametrizações de modelos contínuos e discretos, métodos de solução foram desenvolvidos para diferentes critérios de otimização. Por exemplo, quando há ruído presente e sua distribuição é conhecida, soluções precisas estão disponíveis. Medidas da resolução tanto no espaço das medidas quanto do modelo também podem ser feitas, dessa forma permitindo as estimativas quantitativas do ajuste dos dados e da unicidade do modelo. Outra característica dos problemas lineares é que eles trabalham bem com regularizações. Porém nesse caso é necessário tomar cuidado para ponderar os pesos dado para a regularização de forma que o problema se torne melhor posto, porem sem que a regularização distorça a solução. 


\section{Problema Linearizado}

Devido as ferramentas e as facilidades encontradas nos problemas lineares existe uma tendência em formular problemas para que os métodos de resolução dos métodos lineares possam ser usados sempre que possível. Para problemas que não são muito não-lineares essas ferramentas podem ser usadas se for feito um processo de linearização do problema. O conceito consiste em aproximar as equações envolvidas para equações lineares de fácil solução. Normalmente adota-se que alguns termos que não são lineares tendem a zero ou a alguma valor assimptótico.

\section{Problema Não-linear}

Grande parte dos problemas geofísicos se encaixa na categoria de problemas não-lineares. Onde tanto a função objetivo quanto a relação dos dados com o modelos são estritamente não linear. A não-linearidade complica a estimação do problema consideravelmente. A maioria dos métodos elétricos e eletromagnéticos se encaixa nesse tipo de problema. Incluindo a sondagem elétrica vertical e a sondagem TDEM. Existem muitos algoritmos para a inversão de dados não lineares, porém esse tipo de inversão é complexa e sempre exige um estudo detalhado de seu funcionamento. Alguns métodos usam derivadas, outros gradientes e alguns são os de busca aleatória global. No trabalho de Monteiro Santos et. al. (2010) os autores testaram alguns algoritmos de inversão para a inversão conjunta de dados de SEV e TDEM. A conclusão do estudo mostrou que os algoritmos de busca aleatória global geraram os melhores resultados. Dessa forma foi escolhido para essa pesquisa o algoritmo de busca aleatória global denominado CRS - Controlled Random Search desenvolvido por Price (1977). 


\section{Algoritmo CRS - Controlled Random Search}

\section{Desenvolvimento do Algoritmo}

Mesmo não sendo um dos algoritmos usados no trabalho de Monteiro Santos et. al. (2010) o CRS é um algoritmo robusto, muito adequado a problemas como o usado na presente pesquisa (SEV/TDEM). Apesar de não ser um método de busca rápido, possui grande capacidade de convergência e é muito estável. Com praticamente nenhuma tendência a divergir para um modelo sem representatividade física. Ele também é usado na inversão conjunta dos dados de SEV e TDEM, uma vez que a estrutura da inversão continua praticamente a mesma. O que muda no caso da inversão conjunta é a função objetivo. Esse aspecto da função objetivo será discutido adiante.

O funcionamento básico do algoritmo se encontra na Figura 21. Inicialmente deve-se ter o numero total de parâmetros, $n$, a serem invertidos. No caso os $n$ parâmetros serão relacionado aos parâmetros do modelo geoelétrico (resistividade e espessuras das camadas). A seguir é necessário definir o espaço de busca dos $n$ elementos a serem invertidos. Isso dará um domínio onde o algoritmo irá trabalhar. A seguir são obtidos $m$ modelos aleatórios, que devem estar contidos no espaço de busca previamente definido. O valor de $m$ normalmente é dado na forma de $3 \cdot n$, mas um valor diferente pode ser ajustado para cada problema. Dessa forma esses $m$ modelos vão consistir num conjunto de modelos que serão trabalhados. São calculadas as respostas físicas (cálculo do problema direto) de todos esses modelos. Então é calculada a função objetivo para um dos $m$ modelos. Esses processos consistem na etapa inicial do algoritmo. A etapa iterativa do algoritmo começa com a obtenção de um modelo $P$ que é obtido pela média de $n$ modelos escolhidos aleatoriamente entre os $m$ modelos disponíveis. A seguir mais um modelo é escolhido aleatoriamente (um modelo diferente dos já selecionados) e uma média do modelo $P$ com esse outro modelo é calculada. Tendo esse modelo $T$ resultante, sua função objetivo é calculada. Se a norma desse modelo $T$ for maior que a maior norma dos $m$ modelos tidos esse modelo $T$ é descartado e o processo iterativo continua. Se a norma do modelo $T$ for menor que a maior norma entre os $m$ modelos, o modelo $T$ entra no lugar do modelo que possui a maior norma e o processo iterativo continua. Dessa forma sempre que um novo modelo obtido a partir dos $m$ modelos do conjunto possuir uma norma menor que a maior norma do conjunto, o conjunto de modelos será atualizado. No final do processo (que pode ser determinado por um numero de iterações ou pelo valor das normas do conjunto), existirão um conjunto de modelos que idealmente ajustam os dados. 
O modelo final é o modelo de menor norma do conjunto. Uma representação com todos os modelos finais também pode ser feita. Quanto a probabilidade de que todos os modelos obtidos convirjam para o mínimo global isso irá depender do valor de $n$, da complexidade da função objetivo, dos constrangimentos e do espaço de busca inicial.

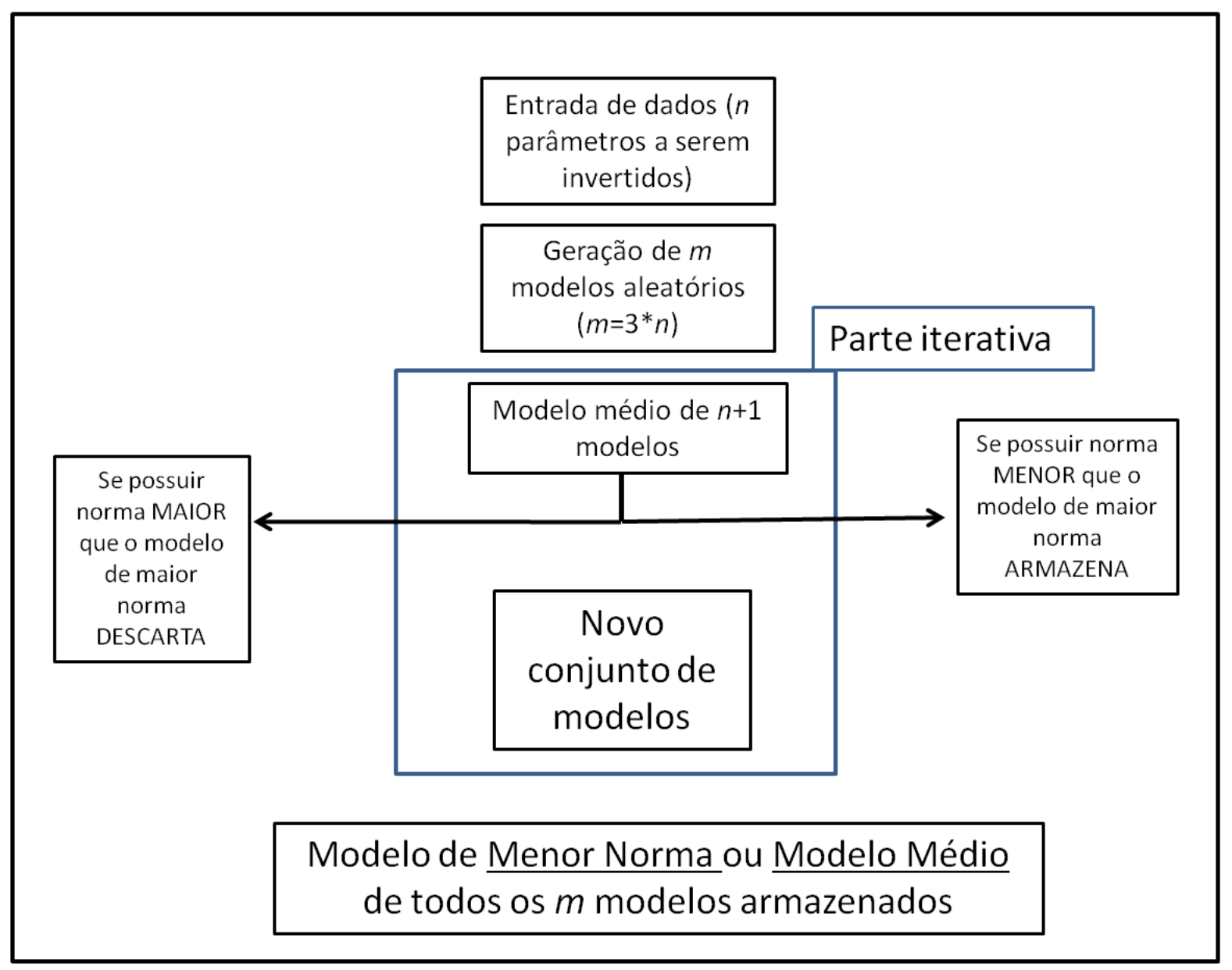

Figura 21: Fluxograma do funcionamento do algoritmo CRS - Controlled Random Search.

\section{Implementação do Algoritmo}

O algoritmo de inversão foi implementado segundo a descrição anterior, mas possui algumas peculiaridades. Quanto à entrada do espaço de busca do algoritmo está é feita de uma forma um tanto indireta. Como entrar com os limites para cada modelo parece ser um tanto quanto nãointuitivo a entrada é feita como se fosse necessário um modelo inicial. Esse modelo inicial na 
verdade é o ponto central do espaço de busca inicial. Ele corresponde ao centro de um espaço que tem como limite inferior o valor de $(\boldsymbol{p}-(\boldsymbol{p} \cdot 0,9))$ e limite superior sendo $(\boldsymbol{p}+(\boldsymbol{p} \cdot 0,9))$. Dessa forma o modelo inicial neste algoritmo de inversão implementado não tem o mesmo sentido que em outros algoritmos que de fato partem de um modelo inicial. Foi elabora por essa implementação pois ela se torna mais intuitiva para o usuário e não influi na eficácia do programa.

Outra particularidade de destaque deste algoritmo é que mesmo que o conjunto inicial de modelos esteja dentro do espaço delimitado inicialmente os modelos calculados no processo iterativo não estão sujeitos a esse vínculo. Não há controle do espaço que será amostrado no processo iterativo. A princípio isto parece algo não adequado, mas assim como a decisão de uma função objetivo sem ponderações, essa decisão foi tomada analisando a natureza da situação. Com uma busca de um espaço não delimitado há a possibilidade de o algoritmo encontrar a solução mesmo que esta não esteja compreendida no espaço delimitado inicial. Quanto a divergência da solução isso não acontece, pois o algoritmo é bem estável quanto a isso. A obtenção de modelos iterativos a partir do cálculo de pontos médios impede que um modelo muito longe do núcleo de modelo apareça rapidamente. $O$ que acontece é que gradualmente todos os modelos irão caminhar para um ponto de mínimo. Além disso, soluções muito fora da solução real provavelmente gerarão uma norma elevada, dessa forma o modelo será descartado. Assim o processo de inversão tem como restrição do espaço de busca apenas a própria natureza do modelo gerador.

\section{Dados Sintéticos}

\section{Modelo Sintético}

Modelo Sintético é um modelo matemático que não necessariamente tem algum valor físico. Quando se trabalha com inversão de dados é necessário desenvolver um modelo sintético que será usado para testar os algoritmos de inversão. Nesse caso a correspondência de um modelo sintético com alguma correspondência física é muito recomendada, pois afinal a idéia de um algoritmo de inversão é ser usado em situações reais. No caso deste projeto um modelo sintético baseado na geologia da Bacia Sedimentar do Paraná na região de Bebedouro - SP - Brasil foi elaborado. Ele 
pode ser visto na Figura 22. A geologia da região pode ser vista em mais detalhe no capítulo seguinte, mas por enquanto vamos nos ater ao modelo sintético. A camada inicial de $8 \mathrm{~m}$ de espessura e 200 Ohm.m de resistividade representa uma camada de solo/sedimentos que não contêm água. A segunda camada de $25 \mathrm{Ohm} . \mathrm{m}$ de resistividade e $55 \mathrm{~m}$ de espessura representa uma zona saturada. A camada mais resistiva abaixo $(800 \mathrm{Ohm} . \mathrm{m})$ de $500 \mathrm{~m}$ de espessura representa uma rocha basáltica. A última camada de $30 \mathrm{Ohm} . \mathrm{m}$ representa um outro aqüífero sedimentar mais profundo. Esse modelo sintético será usado em todos os testes de inversão, tanto no caso da SEV, como no TDEM e na inversão conjunta (SEV/TDEM).

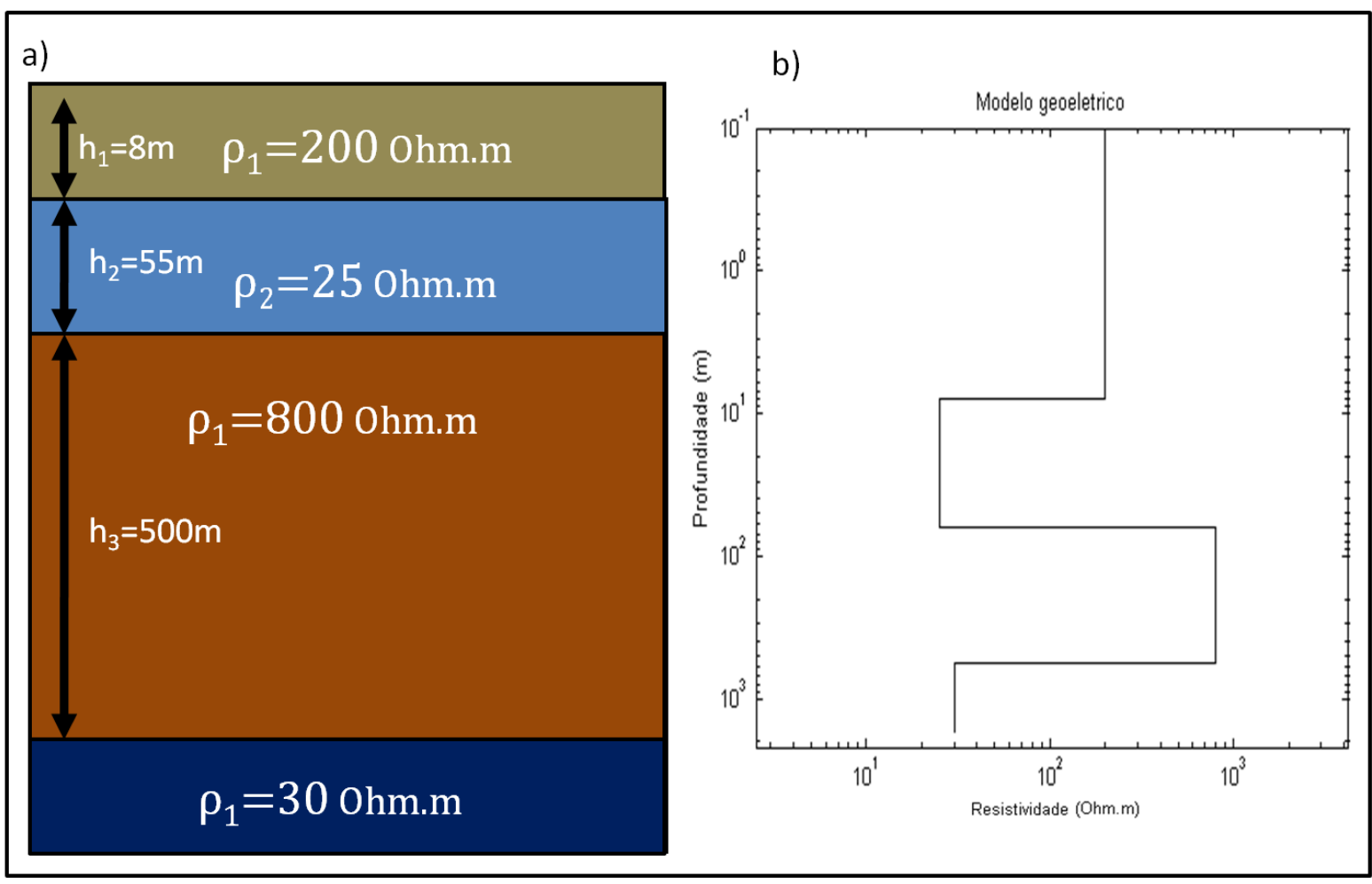

Figura 22: Modelo geoelétrico sintético. Em "a" uma representação gráfica do modelo e em "b" um gráfico com a profundidade $x$ a resistividade 


\section{Introdução de Erro Artificial}

Para a inversão ser validada é necessário inserir algum tipo de ruído numérico para simular um levantamento real. Inserir ruídos nos dados pode ser uma tarefa complexa, porque deve-se ponderar entre colocar um ruído considerável, porém sem adulterar de forma não representativa sua base de dados. A forma mais recomendada para inserir os dados é fazer uma analise dos erros apresentados em dados reais e tentar representá-los numericamente. No caso deste trabalho a idéia era buscar uma representação numérica para os ruídos reais apresentados nas curvas de SEV e na sondagem TDEM.

\section{Introdução de Erro Artificial na SEV}

Os ruídos no caso da SEV foram tratados como sendo aleatórios em todo o conjunto de dados. Foi considerado que os ruídos são distribuídos de forma equivalente, mas aleatória em toda a curva. Isso quer dizer que se assume que os ruídos não possuem uma amplitude máxima de ruído diferente na curva. A amplitude do ruído sim varia de ponto a ponto. Um valor máximo de amplitude de ruído foi adotado, como foi feito será discutido a frente no texto. Tendo o valor Máximo de amplitude, uma percentagem dela foi acrescida ou subtraída de cada ponto da curva. Assim simulamos qualquer variação no sinal que pudesse ocorrer em campo. Pode-se comparar a curva sintética com uma curva real para se ter uma idéia da pequena dispersão nos dados que as curvas de SEV normalmente apresentam, conforme se observa na Figura 23. 


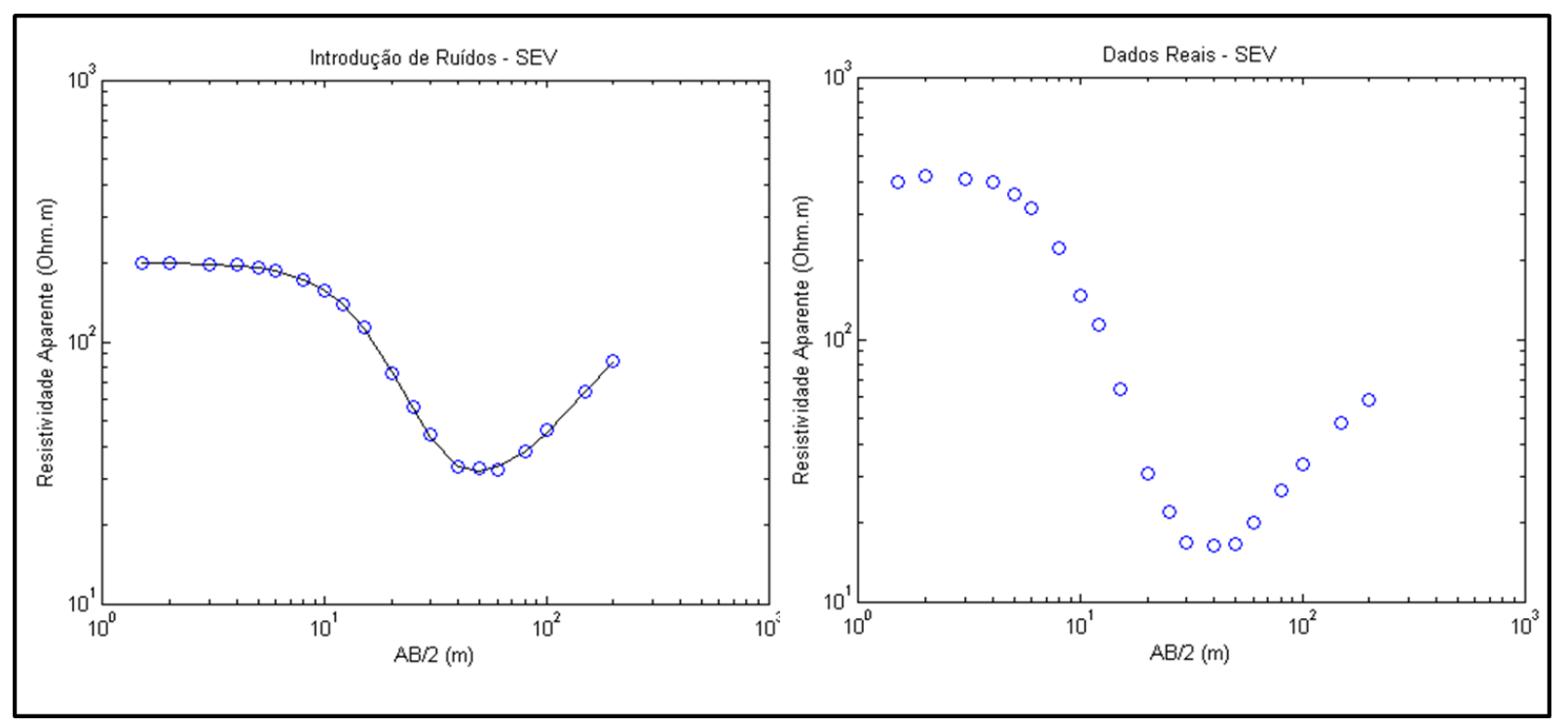

Figura 23: Comparação entre uma curva sintética com ruído e uma curva real de SEV.

Quanto à amplitude do erro, esta foi determinada a partir de dados obtidos em campo. Foi feito isso assumindo a seguinte premissa: o erro no último ponto de medida, com maior $A B / 2$, deve ser o ponto com maior erro associado. Sendo assim a idéia para obter o erro do levantamento era repetir a última medida com parâmetros ligeiramente diferentes. Assim usando um recurso do equipamento Syscal R2 (usado em campo e disponível no laboratório), na última medida de cada levantamento foi feita a repetição da medida com uma tensão de saída diferente. $O$ equipamento permite utilizar 4 tensões de saída diferentes. Assim tínhamos mais pontos na última medida, e quanto maior a tensão de saída melhor a relação sinal ruído. Não eram repetidos todos os pontos devido ao grande consumo de tempo e bateria deste processo. Dessa forma a diferença de resistividade aparente entre as várias medidas era checada. Deve-se salientar que os valores de saída do equipamento já são uma media de diversas medidas e os dados são muito confiáveis. De fato é que a maior parte das vezes que era checado o erro do levantamento, o valor de resistividade aparente era o mesmo. Mas em alguns casos esses valores oscilavam. Dessa forma foi calculado o desvio padrão para diversas sondagens e a seguir foi calculado o desvio padrão médio. $O$ valor obtido foi de 0,42 Ohm.m. Assim a perturbação nos dados foi feita adicionando ou subtraindo uma porcentagem de até três vezes o valor do desvio padrão médio. $O$ valor dessa porcentagem é aleatório e diferente para cada ponto. 


\section{Introdução de Erro Artificial na Sondagem TDEM}

No caso da sondagem TDEM a introdução dos erros artificiais foi bem diferente. No caso do TDEM a propagação dos erros ao longo da curva não pode ser considerada homogênea. Nos tempos mais curtos a amplitude dos erros é bem pequena, enquanto que no final da curva a amplitude é normalmente muito grande. Chegando até em alguns casos forçar a retirada dos últimos pontos devido a grande dispersão. Por isso foi elaborada uma fórmula para o incremento de erro na curva TDEM, com auxilio do Prof. Fernando Santos, da Universidade de Lisboa. A fórmula usada é a seguinte:

$$
\delta_{T D E M}=S \sqrt{-2 \ln \left(r_{1}\right)} \cos \left(2 \pi r_{2}\right) e^{-\left(\frac{\left(t_{\max }-t\right)^{2}}{t}\right)}
$$

onde $r_{1}$ e $r_{2}$ são números aleatórios e $S$ é o desvio padrão, $t_{\max }$ é o ultimo valor de tempo da curva e $t$ é o valor de tempo correspondente ao tempo que seja introduzido ruído. O cálculo do desvio padrão também foi baseado em dados reais. O equipamento TDEM denominado Protem-57-MK2 (Geonics) usado em campo gera um arquivo com os valores de resistividade de três curvas, correspondendo às freqüências de $30 \mathrm{~Hz}, 7,5 \mathrm{~Hz}$ e $3 \mathrm{~Hz}$. Dessa forma foi calculado o desvio padrão em cada ponto e no final um desvio padrão médio era calculado. Feito isso para várias sondagens foi calculado então o desvio médio dos desvios de cada sondagem. Chegou-se dessa forma no valor de 0,74 Ohm.m, que foi o valor utilizado na fórmula. Na Figura 24 pode ser visto o dado sintético com ruído comparado com um dado real. Como pode ser visto o padrão de dispersão do ruído sintético se aproxima muito do real. 


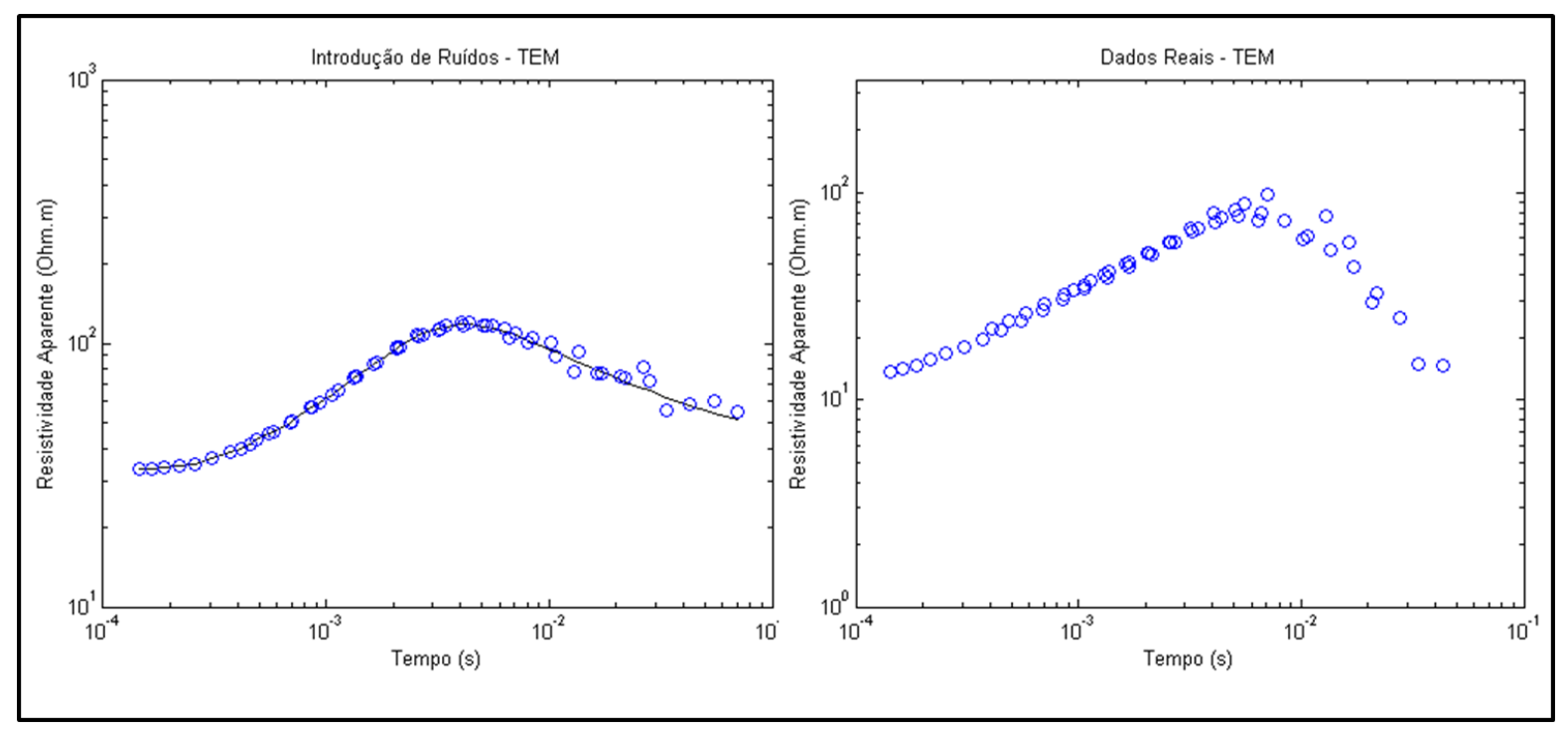

Figura 24: Comparação entre uma curva sintética com ruído e uma curva real de sondagem TDEM.

\section{Correção do Static-Shift}

No artigo de Meju (2005) uma forma de colocar alguns resultados de métodos elétricos e eletromagnéticos na mesma escala foi desenvolvida. No trabalho foram obtidas algumas fórmulas empíricas para passar sondagens elétricas verticais para a escala de tempo ou freqüência, sondagens TDEM para a escala de $A B / 2$ ou freqüência e sondagens $M T$ para as escalas de $A B / 2$ ou tempo. Dessa forma os levantamentos das várias metodologias poderiam ser analisados num mesmo gráfico. Deve-se ressaltar que nenhum tipo de transformada é utilizada. As fórmulas usadas são empíricas, obtidas a partir de modelagem numérica e estudos de campo. As fórmulas obtidas em Meju (2005) são:

1. Para passar uma SEV para a escala de tempo é usada a seguinte fórmula:

$$
t=\frac{\pi \mu_{o} \sigma L^{2}}{2}
$$

onde $\sigma$ é a condutividade aparente na abertura de eletrodos $A B / 2=L$.

2. Para passar uma SEV para a escala de período é usada a seguinte fórmula:

$$
T=2 \pi \mu_{o} \sigma L^{2}
$$


3. Para passar uma sondagem TDEM para a escala de metros $(A B / 2)$ é usada a seguinte fórmula:

$$
L=711,8 \sqrt{t \rho}
$$

onde $\rho$ é a resistividade aparente no tempo $t$.

4. Para passar uma sondagem TDEM para a escala de período é usada a seguinte fórmula:

$$
T \cong 4 t
$$

5. Para passar uma sondagem MT para a escala de metros $(A B / 2)$ é usada a seguinte fórmula:

$$
L=355,9 \sqrt{T \rho}
$$

onde $\rho$ é a resistividade aparente no período $T$.

A aplicação das fórmulas 4.9 a 4.13 são no sentido de retirar o static shift que pode estar presente nos levantamentos elétrico e no levantamento MT. Essas metodologias podem conter static shift porque possuem eletrodos em contato com o solo. Dessa forma eles estão sujeitos a heterogeneidades pontuais na área do eletrodo. Essas heterogeneidades podem fazer com que os dados possuam um static shift, ou seja, um desvio contínuo na curva de resistividade aparente. Esse static shift faz com que a curva se desloque para cima ou para baixo no eixo da resistividade aparente. A correção desse static shift é necessária para uma correta inversão conjunta dos dados.

Na inversão dos dados é necessário retirar o efeito de static shift (se houver) para que assim o modelo obtido consiga ajustar as duas curvas com precisão. Mais uma nota importante é deixar claro que a correção do static shift na SEV serve para somente ajustar os dados do método elétrico. Não se deve em hipótese alguma tentar inverter todo o conjunto de dados como se fosse apenas uma metodologia. As fórmulas em questão só servem para mudar a escala no eixo $x$ (escalada de amostragem), ela não altera a resistividade aparente. E não mudam o domínio dos dados. As duas metodologias devem ser invertidas usando a rotina de cálculo direto correspondente. De outra forma o processo de inversão estará errado.

A correção do static shift é feita da seguinte forma, os resultados das duas metodologias são plotados no mesmo gráfico. A idéia é deixar a curva dos dados de SEV (ou MT) o mais próxima da curva de TDEM. Isso é feito multiplicando toda a curva por um fator de correção, para que a curva toda seja deslocada no eixo y (eixo da resistividade aparente). O ajuste como será visto não será perfeito, mas dessa forma um efeito que traria grande dificuldade no processo de inversão será 
corrigido. As Figuras Figura 25 e Figura 26 mostram a representação dessa idéia, feita com dados sintéticos. Obviamente não há static shift na curva de SEV uma vez que os dados são sintéticos. Mas ela serve para mostrar o porquê não é possível inverter esse conjunto de dados como uma só metodologia. Como se pode notar as curvas mudadas de escala (SEV na Figura 25 e TDEM na Figura 26) não possuem o mesmo tipo de comportamento que a curva do outro método. Por isso o modelo inverso não conseguiria ajustar essa curva se esses dados mudados fossem usados como sendo do outro método. O cálculo direto para um mesmo modelo gera curvas diferentes, mesmo se eles estiverem na mesma escala.

No artigo de Meju (2005) ele trás uma serie de figuras com as escalas transformadas para diversos métodos. Os dados nesse caso são reais e assim pode-se ter idéia de como as curvas se comportam e como deve ser feito o ajuste do static shift nas curvas. Para ilustrar o stati shift a Figura 27 mostra os levantamentos na escala de $A B / 2$. São referentes a uma serie de levantamentos feitos no vale de York, no norte da Inglaterra. As curvas mostradas na Figura 27 mostram uma serie de curvas de sondagens elétricas comparadas com curvas de sondagem TDEM na escala de AB/2. Nas figuras sempre que necessário houve uma correção do static shift da sondagem elétrica. Esses são exemplos de como deve ser usado essa correção. Toda a curva de SEV deve ser multiplicada por um fator de escala de forma que se aproxime da curva TDEM. Essa metodologia é muito útil quando se faz a inversão conjunta, porém deve-se ter bem claro suas vantagens e limitações. 


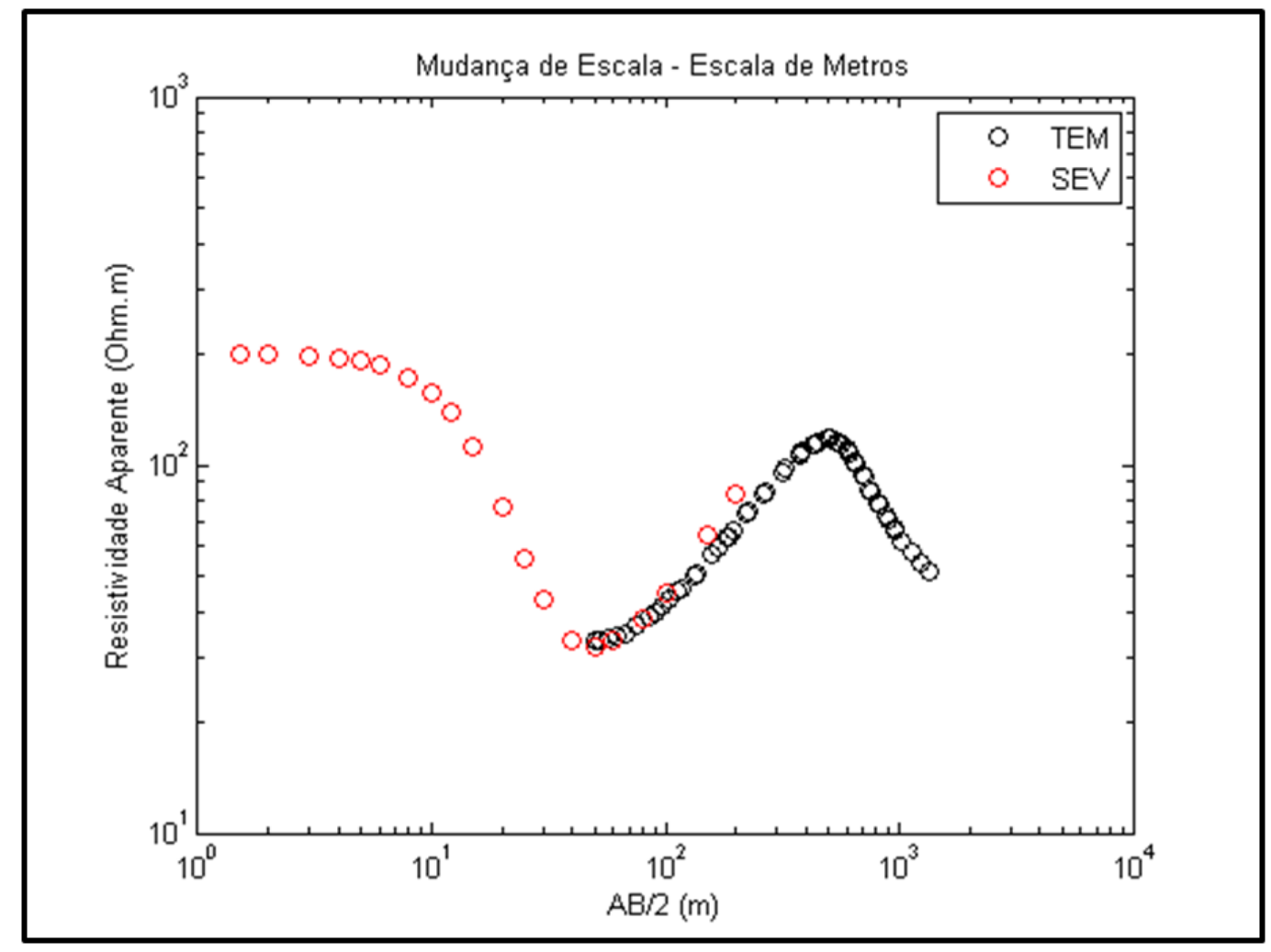

Figura 25: Curvas de sondagem elétrica e sondagem TDEM na escala de AB/2 (m).

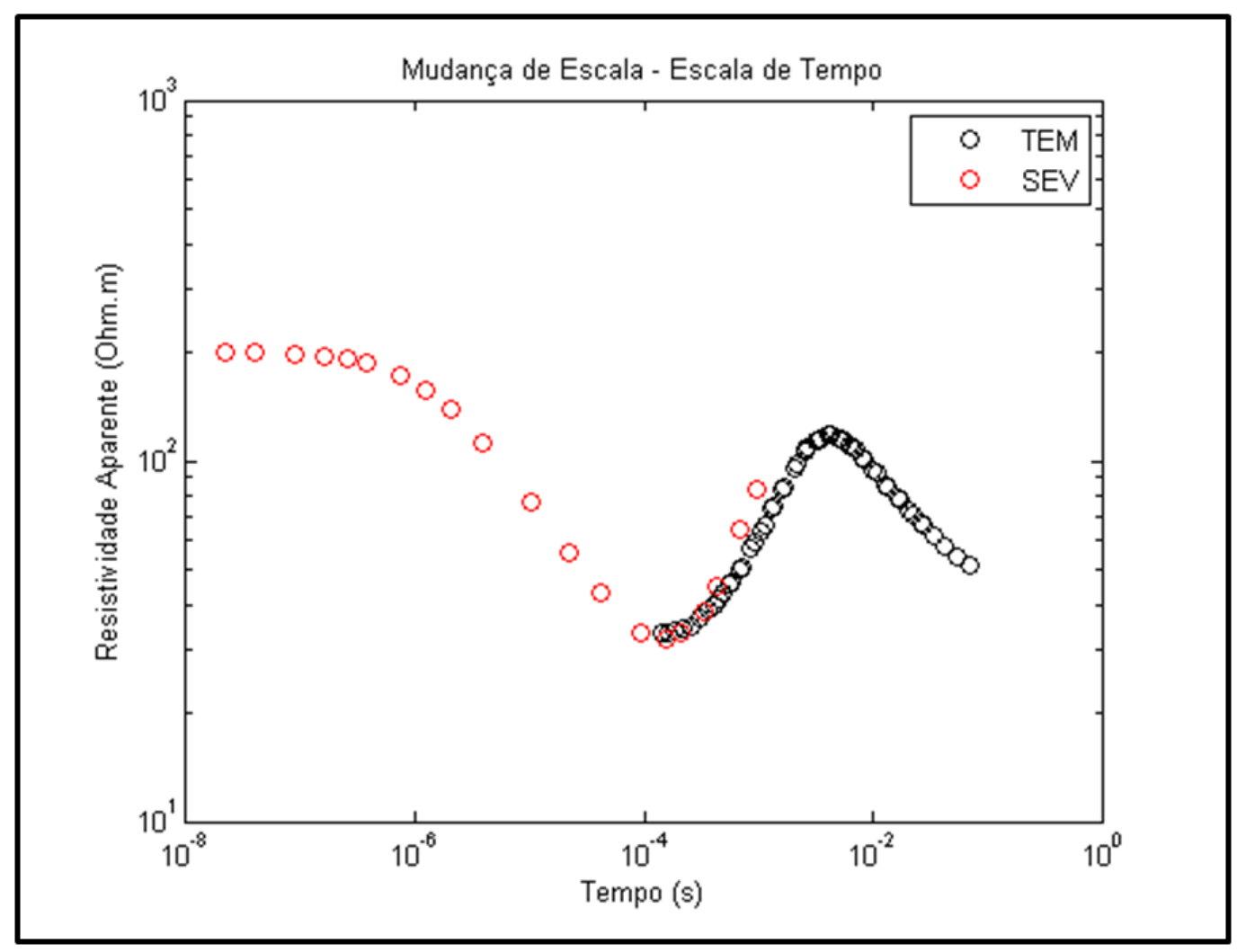

Figura 26: Curvas de sondagem elétrica e sondagem TDEM na escala de tempo (s). 


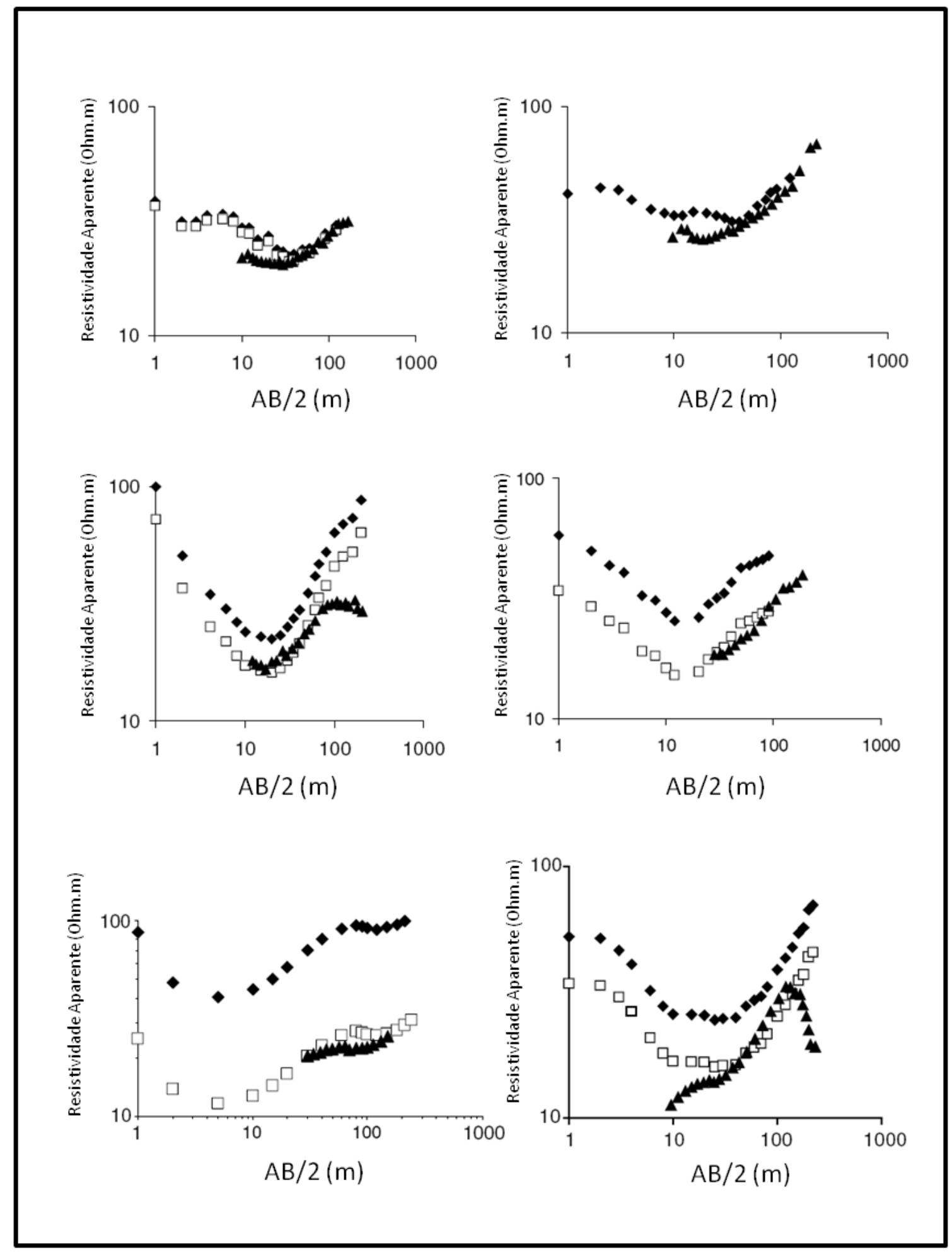

Figura 27: Figura com vários gráficos de resistividade aparente (Ohm.m) por $A B / 2(\mathrm{~m})$. Os quadrados pretos representam as curvas de SEV sem correção do static shift. Os quadrados brancos as curvas de SEV com a correção do static shift. E os triângulos pretos as curvas TDEM com a escala mudada para AB/2 (m). Adaptado de Meju (2005) 


\section{Inversão dos Dados Sintéticos de SEV}

O algoritmo desenvolvido em Matlab para a inversão de dados de sondagem elétrica vertical foi então testado, usando dados sintéticos que foram calculados a partir do modelo sintético já descrito. Os parâmetros do levantamento sintético simulam uma SEV com AB/2 variando de 1,5 m até $200 \mathrm{~m}$. Os espaçamentos usados no levantamento correspondem os espaçamentos usados nas sondagens feitas pelo IAG/USP. Dessa forma buscou-se fazer um teste o mais parecido com o que é feito na pratica.

\section{Inversão dos dados}

Para ilustrar, os resultados da inversão dos dados sintéticos de SEV são apresentados na Figura 28. A curva sintética com o ajuste do modelo invertido está representada em "a" e a parte "b" é a comparação do modelo real com o modelo invertido e o modelo inicial (centro do espaço inicial de busca). 


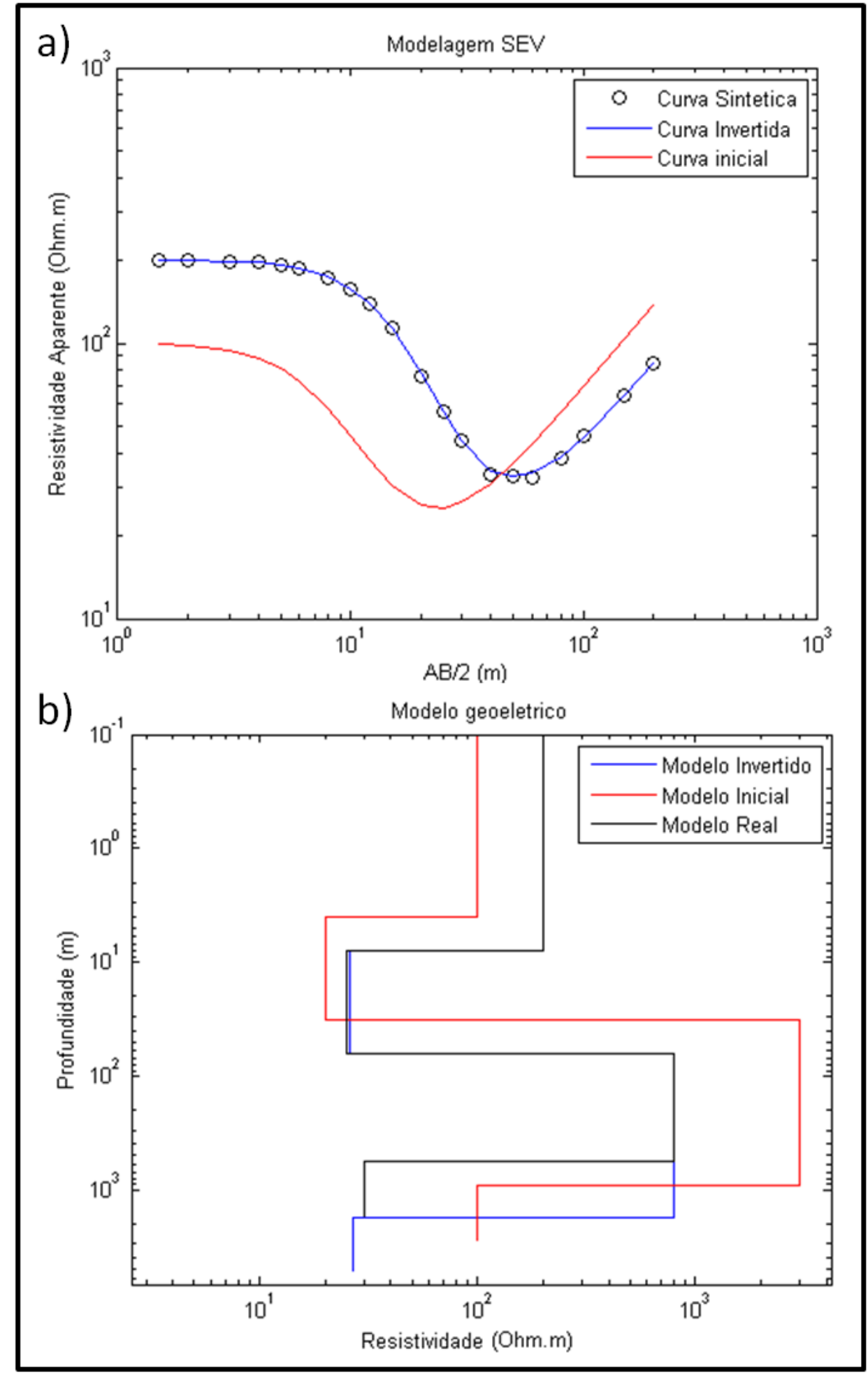

Figura 28: Resultados da inversão de SEV: em "a" a curva sintética com a curva invertida ajustada e em "b" o modelo invertido comparado com o real. 


\section{Discussão dos Resultados}

Os resultados da inversão para a sondagem elétrica são muito claros e apresentam consistência com o que era esperado da teoria. A SEV conseguiu determinar com boa precisão as camadas superficiais, ie, mais rasas. Sendo que a abertura total do arranjo foi de $400 \mathrm{~m} \mathrm{a}$ profundidade máxima de investigação seria de cerca de $100 \mathrm{~m}$. Mas como já dito, em áreas condutivas, como a simulada no modelo sintético, essa profundidade é consideravelmente menor. No caso desta sondagem sintética ela conseguiu definir até o topo da camada resistiva (terceira camada) que está a $63 \mathrm{~m}$ de profundidade. Nessa profundidade o resultado conseguiu marcar com precisão a profundidade e a resistividade da camada. Mas a última interface, entre a camada resistiva e o embasamento geoelétrico, a sondagem não conseguiu determinar. Isso porque a profundidade simulada é demais para um levantamento com apenas $200 \mathrm{~m}$ de abertura de $A B / 2$.

\section{Inversão dos Dados Sintéticos de Sondagem TDEM}

O algoritmo para a inversão individual da sondagem TDEM também foi testado com os dados sintéticos. Os parâmetros simulados do levantamento TDEM consistem numa bobina receptora de $1 \mathrm{~m}$ de diâmetro instalada no centro de um loop transmissor quadrado de $100 \mathrm{~m}$ de lado (arranjo loop central). Os tempos de amostragem usados na simulação são os mesmos usados com o equipamento TEM57 da Geonics.

\section{Inversão dos dados}

Os resultados da inversão dos dados sintéticos da sondagem TDEM podem ser vistos na Figura 29. A curva sintética com o ajuste do modelo invertido está apresentada em "a" e a parte " $b$ " é a comparação do modelo real com o modelo invertido e o modelo inicial (centro do espaço inicial de busca). 


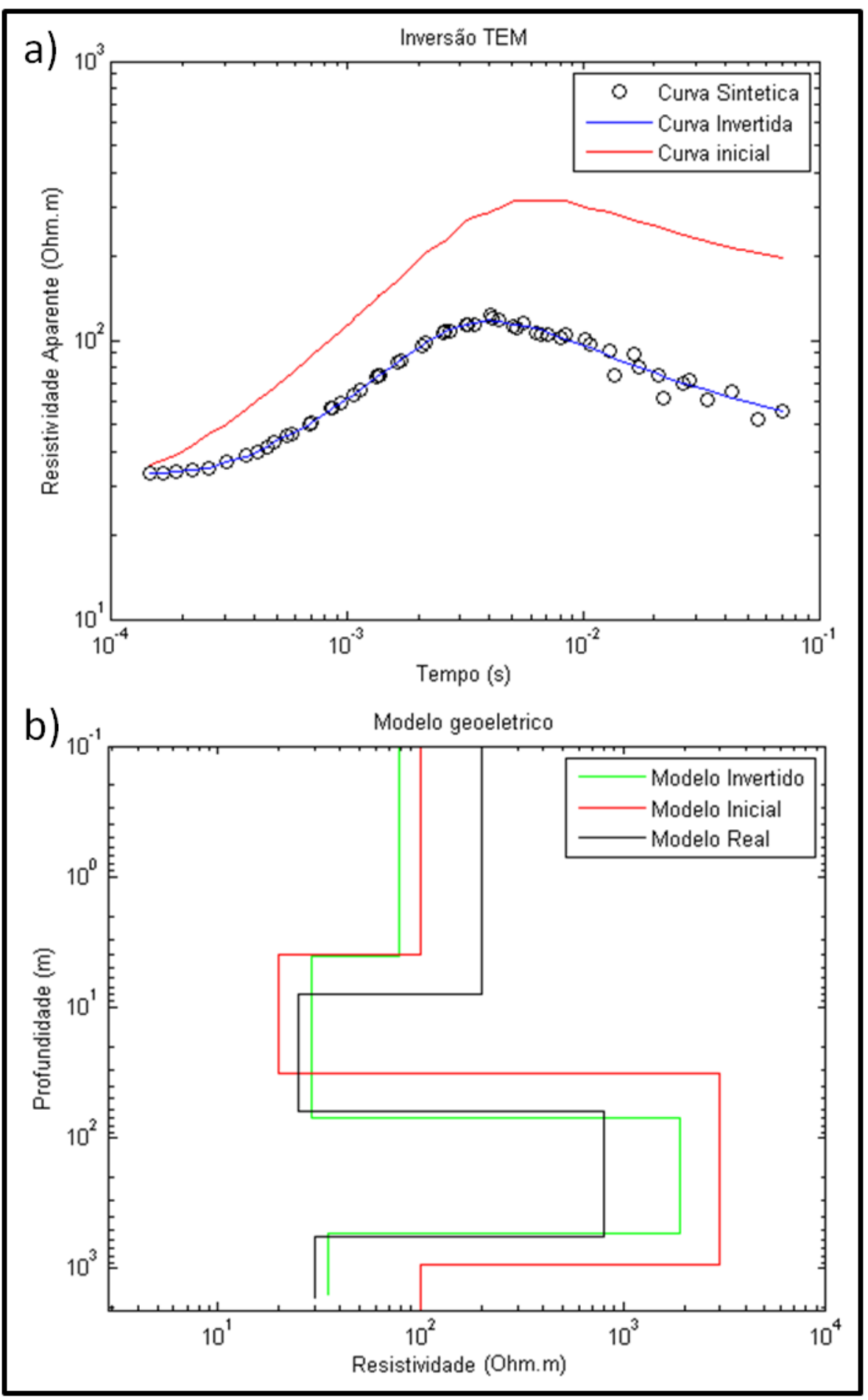

Figura 29: Resultados da inversão do TDEM: em "a" a curva sintética com a curva invertida ajustada e em "b" o modelo invertido comparado com o real. 


\section{Discussão dos Resultados}

A inversão da sondagem TDEM assim como a da SEV gerou resultados condizentes com a teoria descrita. As camadas rasas, até $10 \mathrm{~m}$ de profundidade (10\% do tamanho do loop) não foram bem definidas de acordo com o esperado. Já as camadas mais profundas foram bem definidas, incluindo a última camada (embasamento geoelétrico) que está a quase $600 \mathrm{~m}$ de profundidade. que pode ser observado que as interfaces entre as camadas foram bem marcadas, demonstrando grande precisão. Quanto a resistividades das camadas, apesar de uma leve discrepância, também foram muito bem definidas. A camada resistiva foi a que teve a resistividade mais superestimada. Mas esse tipo de super-estimativa não invalida de forma alguma o modelo e é normal em qualquer método eletromagnético. O mais importante que a discrepância não é grande e os contrates de resistividade foram muito bem marcados.

\section{Inversão Conjunta - SEV/TDEM}

O algoritmo para a inversão conjunta de SEV e TDEM foi testado com os dados sintéticos. Os parâmetros de aquisição para as duas metodologias foram os mesmos que os usados para as inversões individuais, apresentados anteriormente. Para a SEV o levantamento sintético simula uma SEV com $A B / 2$ variando de $1,5 \mathrm{~m}$ até $200 \mathrm{~m}$. E para o TDEM uma bobina receptora de $1 \mathrm{~m}$ de diâmetro está no centro de um loop transmissor quadrado de 100 m de lado (arranjo loop central). Ressaltando que a inversão conjunta assume que o centro do arranjo da SEV está no centro do loop transmissor do TDEM.

\section{Inversão dos dados}

Os resultados da inversão conjunta dos dados sintéticos podem ser vistos na Figura 30, onde em "a" tem-se a curva sintética da SEV com o ajuste do modelo invertido referente a SEV, a parte "b" é a curva sintética da sondagem TDEM com o ajuste do modelo invertido referente ao TDEM e 
em " $c$ " tem-se a comparação do modelo real com o modelo da inversão conjunta e o modelo inicial (centro do espaço inicial de busca).

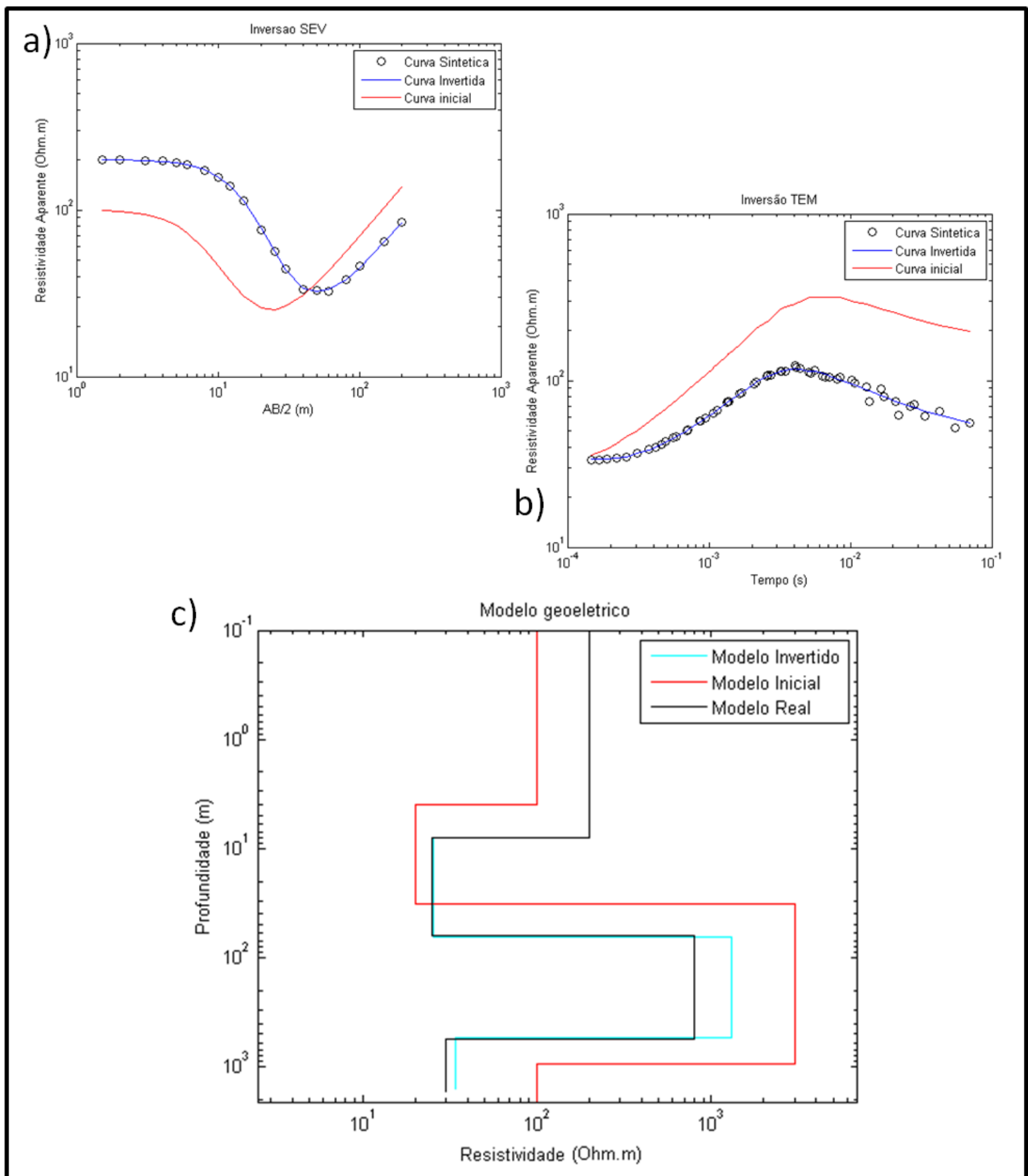

Figura 30: Resultados da inversão conjunta SEV/TDEM: em "a" a curva sintética da SEV com a curva invertida ajustada, em "b" a curva sintética do TDEM com a curva invertida ajustada e em "c" o modelo invertido comparado com o real. 


\section{Discussão dos Resultados}

O que se pode notar da inversão conjunta SEV/TDEM é que o modelo obtido é exatamente o que era pretendido. O modelo final possui o melhor dos dois modelos individuais e consegue determinar com muita precisão o modelo real. As camadas superficiais foram muito bem determinadas assim como na SEV. E as camadas mais profundas também foram bem marcadas assim como no TDEM. Tanto a determinação de interfaces quanto a determinação das resistividades é muito superior no modelo conjunto. A única leve discrepância é a resistividade da camada resistiva. Porém essa discrepância é muito menor que no caso da inversão individual do TDEM e não acarretaria nenhum tipo de má interpretação do modelo final. 


\section{Caso Real: Bebedouro - SP - Brasil}

Este projeto faz parte de um projeto maior que busca investigar a região de atividades sísmicas de Bebedouro - SP. Foram feitos diversos levantamentos elétrico e TDEM, e muitas das medidas visavam à inversão conjunta das duas metodologias. Neste capítulo serão mostrados os resultados da inversão individual e conjunta de um par SEV/TDEM adquiridas na região. Foi utilizado o programa desenvolvido para a inversão individual e conjunta de SEV/TDEM chamado "Curupira", desenvolvido nesta pesquisa. Os aspectos práticos de toda a metodologia descrita nesta dissertação podem ser vista na aplicação deste caso real.

\section{Localização da Área}

A área de estudos está localizada no norte do estado de SP no município de Bebedouro. Os levantamentos foram feitos em dois distritos da cidade: Andes e Botafogo. Aqui serão mostrados os resultados de um par de sondagens feitos no distrito de Andes. A área pode ser vista na Figura 31.

\section{Aspectos Geológicos}

A área de estudo está localizada sobre a bacia do Paraná. Existem três formações superiores na área de estudo. A mais rasa é a formação Adamantina (arenito Botucatu) com uma espessura que varia de 50 a $100 \mathrm{~m}$. Abaixo dela está a formação Serra Geral, composta de basaltos com espessura variando de 400 a 600 m. Abaixo da formação Serra Geral está a formação Botucatu, que é onde se localiza o aqǘfero Guarani. De acordo com alguns poços profundos, o topo do embasamento na bacia do Paraná está entre 2500 e 3000 m de profundidade. O contexto hidrogeológico da área pode ser dividido em dois sistemas de aqüífero, um sedimentar (formações Adamantina/Botucatu) e outro cristalino (fraturas nos basaltos da formação Serra Geral). 


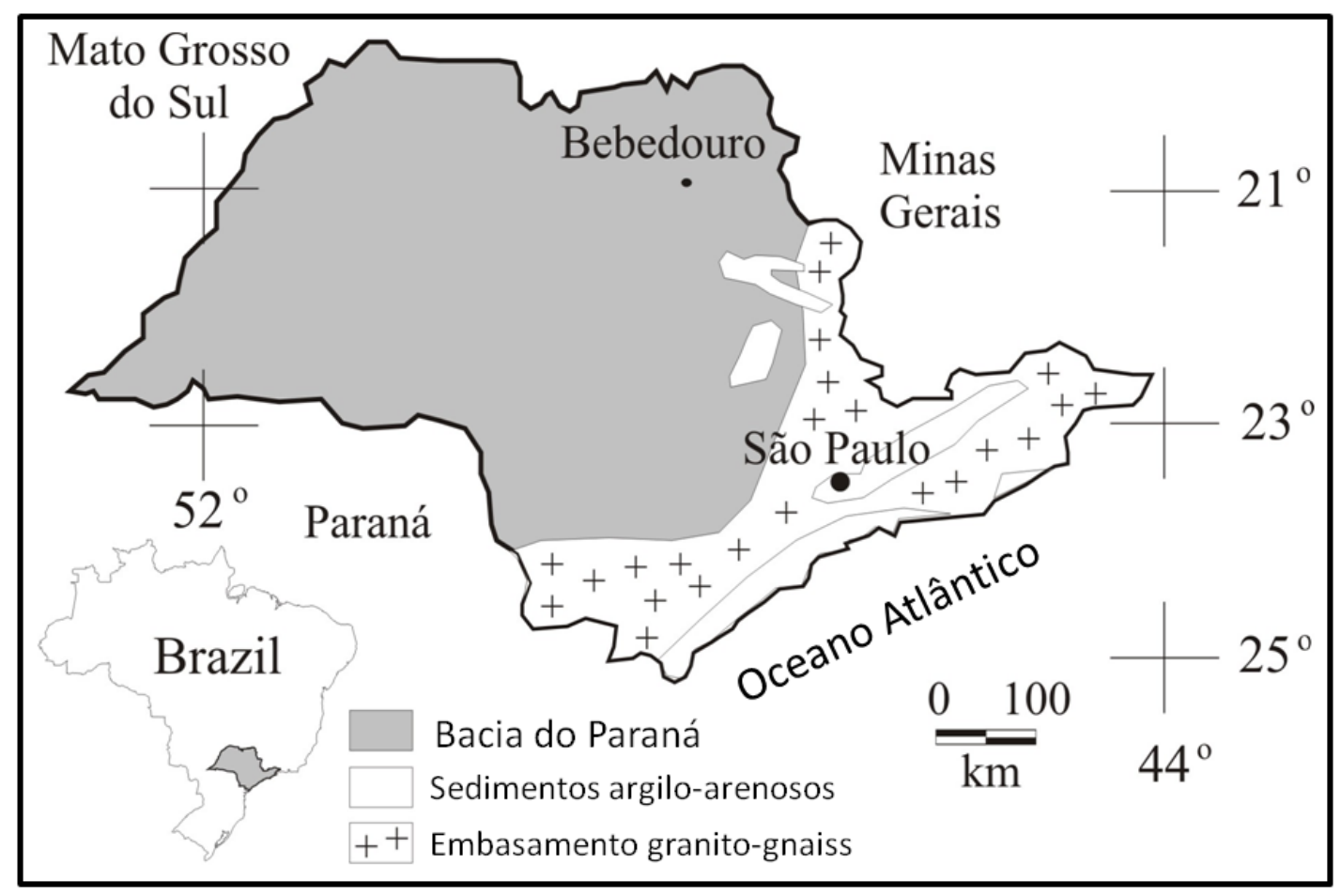

Figura 31: Localização e geologia da área de estudo.

\section{Metodologia}

A metodologia empregada nos levantamentos consistiu de fazer um levantamento TDEM com um loop quadrado de $100 \mathrm{~m}$ de lado com o centro de uma sondagem eletrica vertical (com $A B / 2$ de $200 \mathrm{~m}$ ) coincidindo com o centro do loop transmissor do TDEM. Um esquema do levantamento pode ser visto na Figura 32:

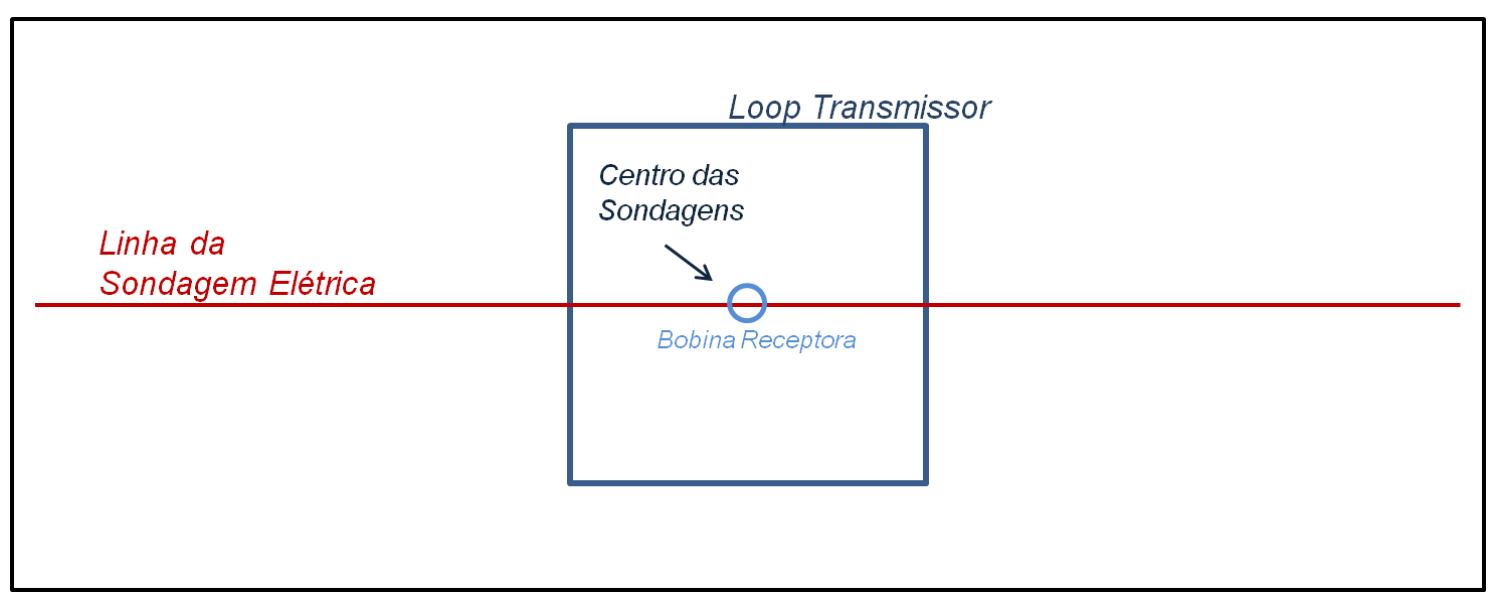

Figura 32: Esquema do levantamento de campo de SEV e TDEM. 


\section{$\underline{\text { Resultados }}$}

\section{Informações de Poços}

Na região existem muitos poços e boa parte deles possui o perfil geológico disponível. Os dados de um poço próximo ao local das sondagens foram obtidos e usados para a interpretação. Os dados referentes ao poço estão na Figura 33

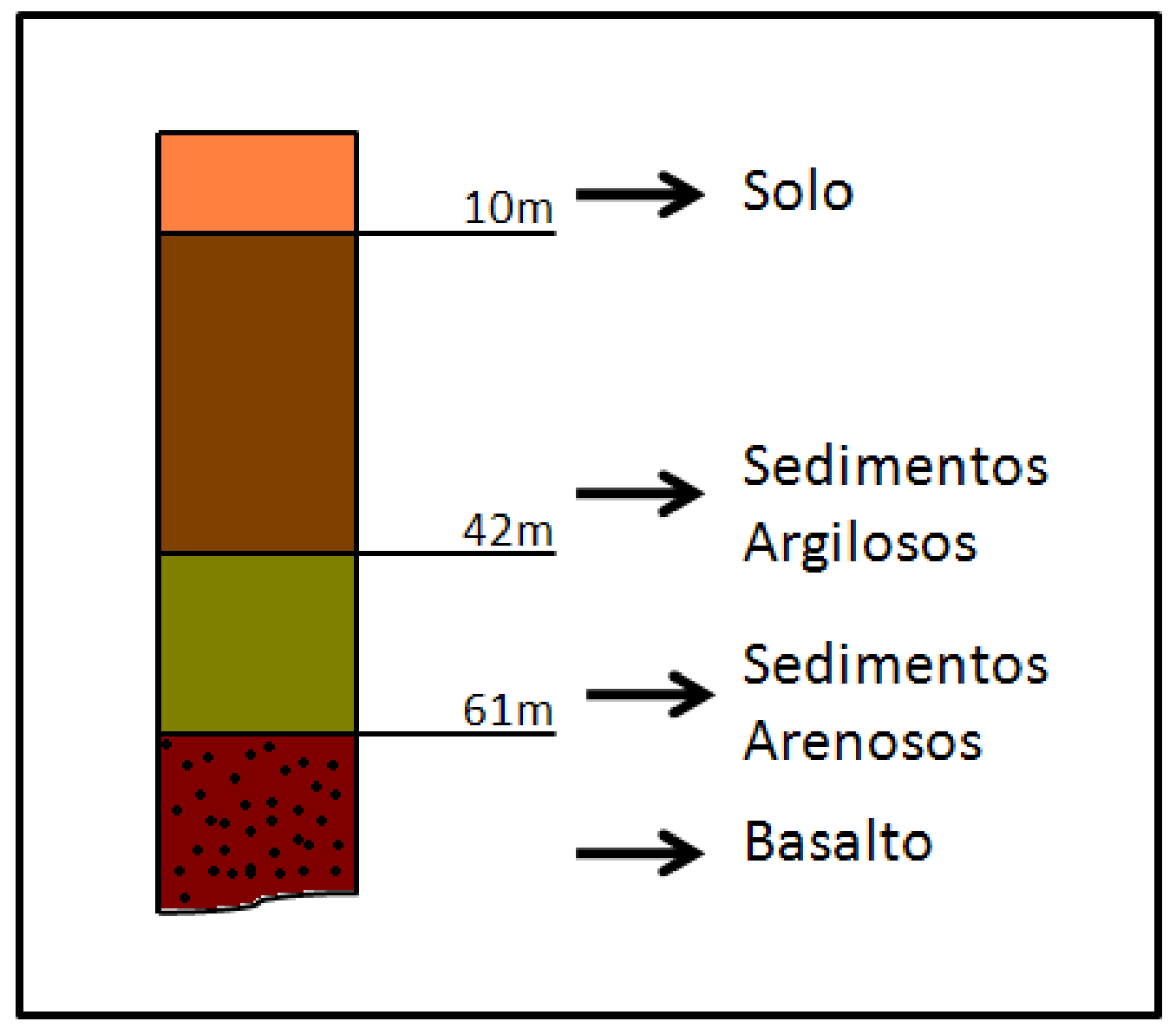

Figura 33: Dados de um poço próximo aos levantamentos de SEV e TDEM. 


\section{Base de Dados}

As bases de dados usadas nesse capítulo consistem em uma sondagem elétrica vertical e uma sondagem TDEM. As duas curvas podem ser vistas abaixo nas Figuras Figura 34 e Figura 35.

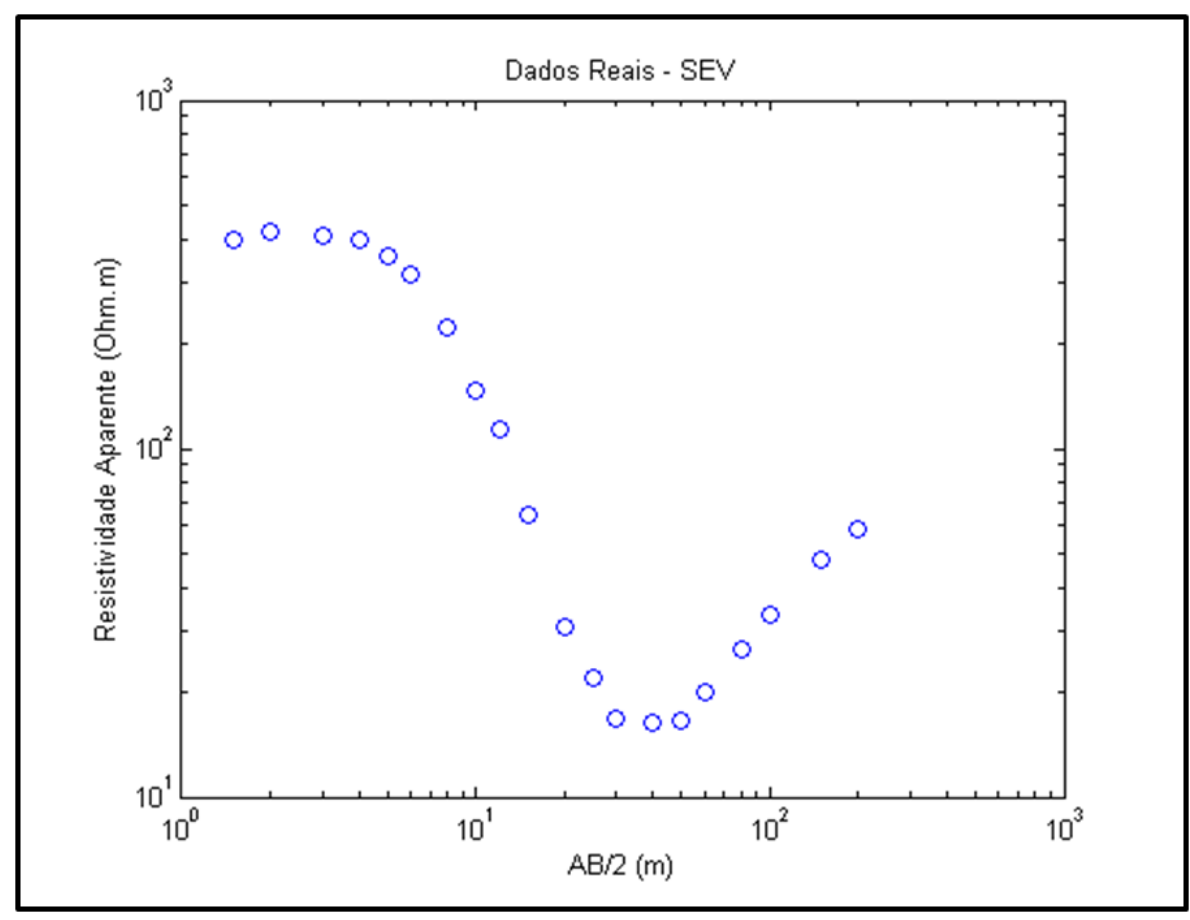

Figura 34: Dados reais de uma SEV.

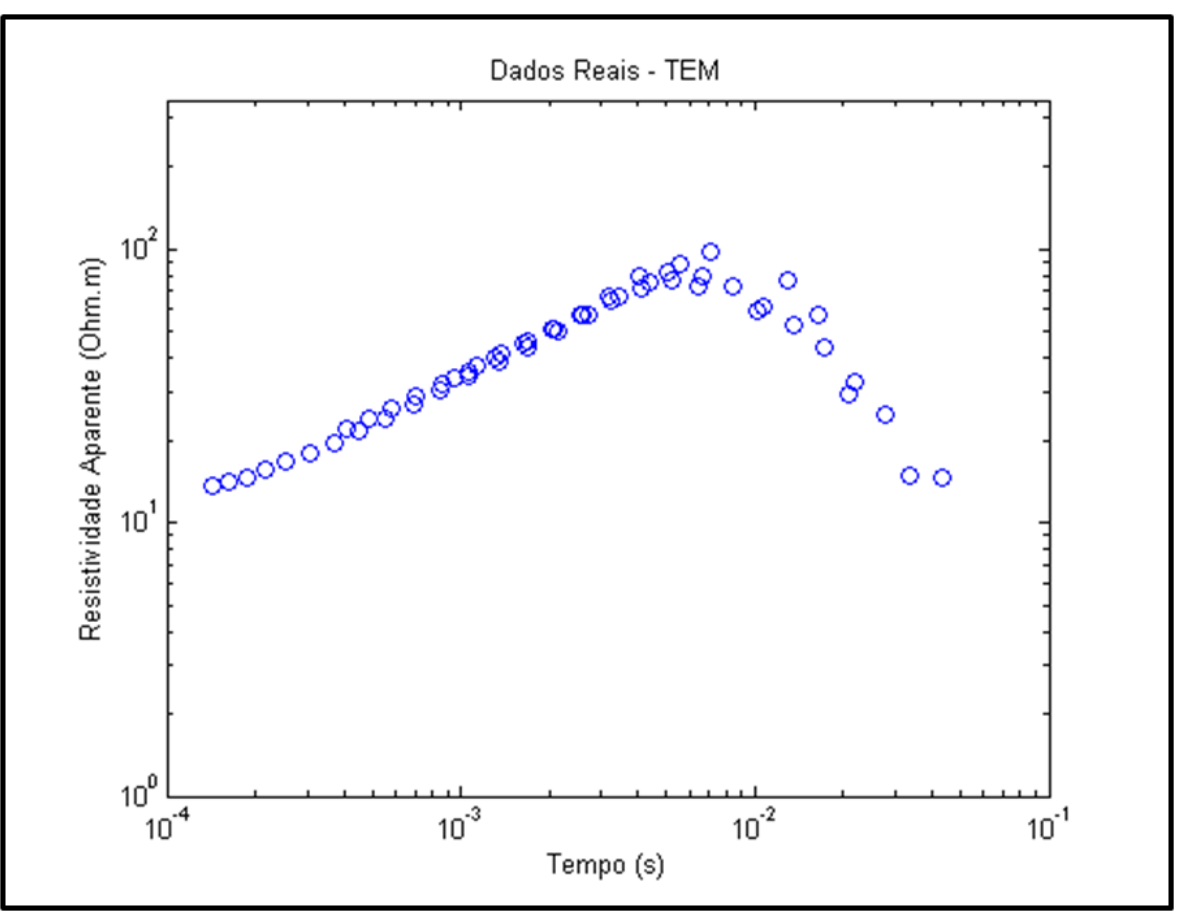

Figura 35: Dados reais de uma sondagem TDEM. 


\section{Correção do Static Shift}

Os dados de sondagem elétrica vertical receberam uma leve correção do static shift num fator de 0,88 . Ou seja, os valores de resistividade aparente tiveram os valores baixados para $88 \%$ do seu valor original. Esse valor de correção não é muito alto, mas sua correção ajuda na inversão conjunta. Os dados ajustados também foram os invertidos na inversão individual da sondagem elétrica para que tivesse consistência entre as inversões. A curva de sondagem TDEM comparada com as curvas de sondagem elétrica com e sem a correção do static shift podem ser vistas na Figura 36.

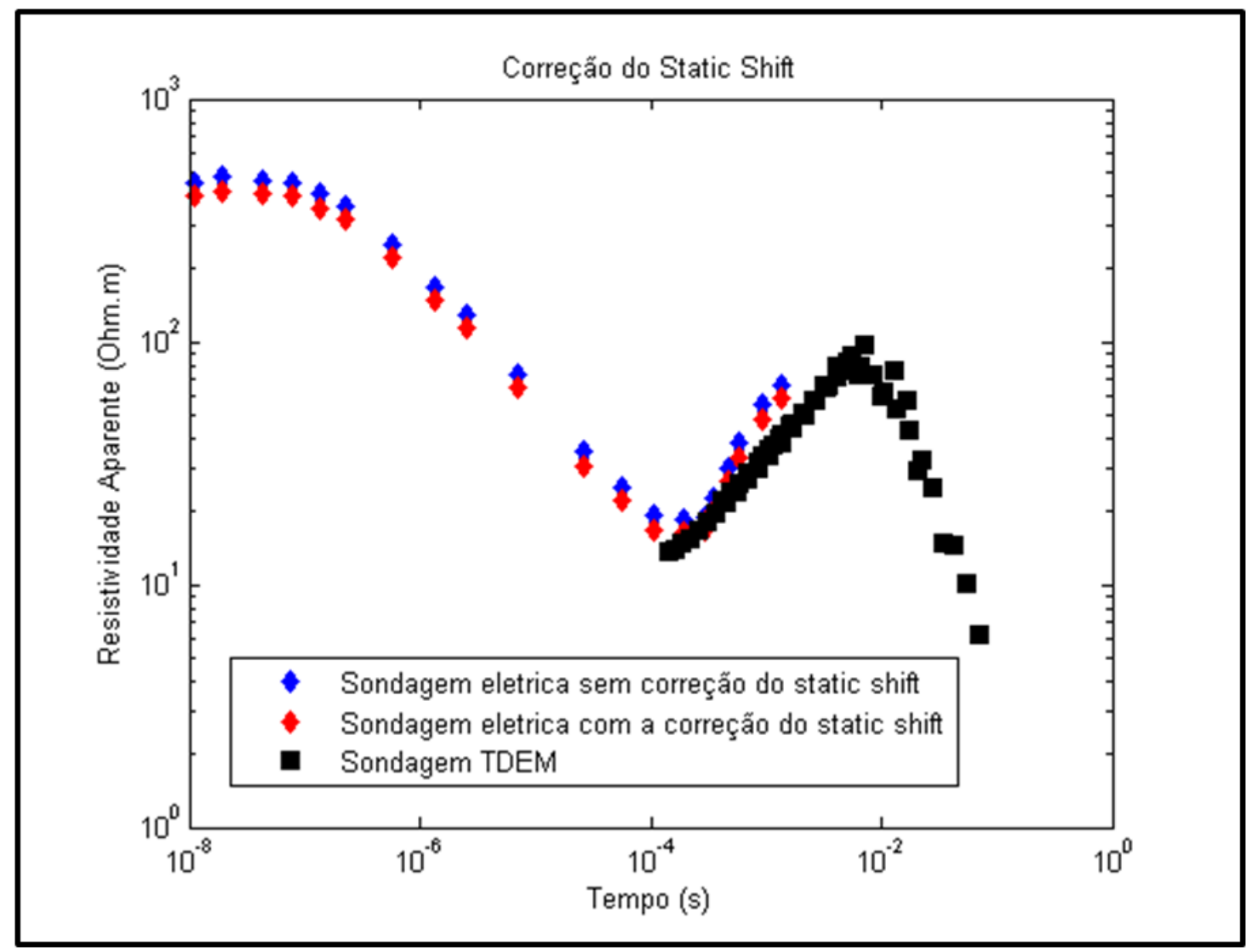

Figura 36: Correção do estatic shift da curva de SEV na escala de tempo (s). Em azul a curva sem correção do static shift, em vermelho a curva corrigida e em preto a curva da sondagem TDEM. 


\section{Inversão de Dados}

Os dados de sondagem elétrica vertical e sondagem TDEM foram invertidos de forma individual e conjunta com o programa "Curupira". Os resultados são mostrados abaixo e deve-se ressaltar que o modelo médio inicial foi o mesmo para todas as inversões. Mesmo sabendo a priori que a SEV não seria capaz de determinar as estruturas mais profundas.

\section{Inversão dos Dados Reais de SEV}

A Figura 37 mostra o resultado da inversão da SEV usando o programa "Curupira". Como se pode ver a convergência do programa para dados reais é ótima mostrando que o algoritmo é robusto o suficiente para ser usado na prática. A análise visual da curva da SEV mostra um modelo de quatro camadas, mas como foi buscado usar o mesmo espaço inicial de busca para todas as inversões optou-se por tentar inverter um modelo de cinco camadas. A sondagem conseguiu determinar algumas camadas rasas, uma de alguns centímetros que provavelmente é um solo superficial e outra camada de cerca de quatro metros que provavelmente é uma camada sedimentar seca. Logo abaixo uma camada condutiva com pouco mais de $50 \mathrm{~m}$ podendo ser o aqǘfero sedimentar presente na região. Abaixo dessa camada está uma camada resistiva (mais de 400 Ohm.m) que corresponde ao basalto da formação Serra Geral. A profundidade da base desta camada está sendo marcada como sendo cerca de $4000 \mathrm{~m}$ de profundidade. Isso indica claramente que a SEV não possui resolução para investigar a essa profundidade. Isso também não era esperado, já que como já dito uma sondagem com abertura de $200 \mathrm{~m}$ não enxerga mais de $100 \mathrm{~m}$ de profundidade e a base do basalto está muito mais profundo que isso. A última camada também não foi definida, uma vez que não há resolução para essa profundidade. 


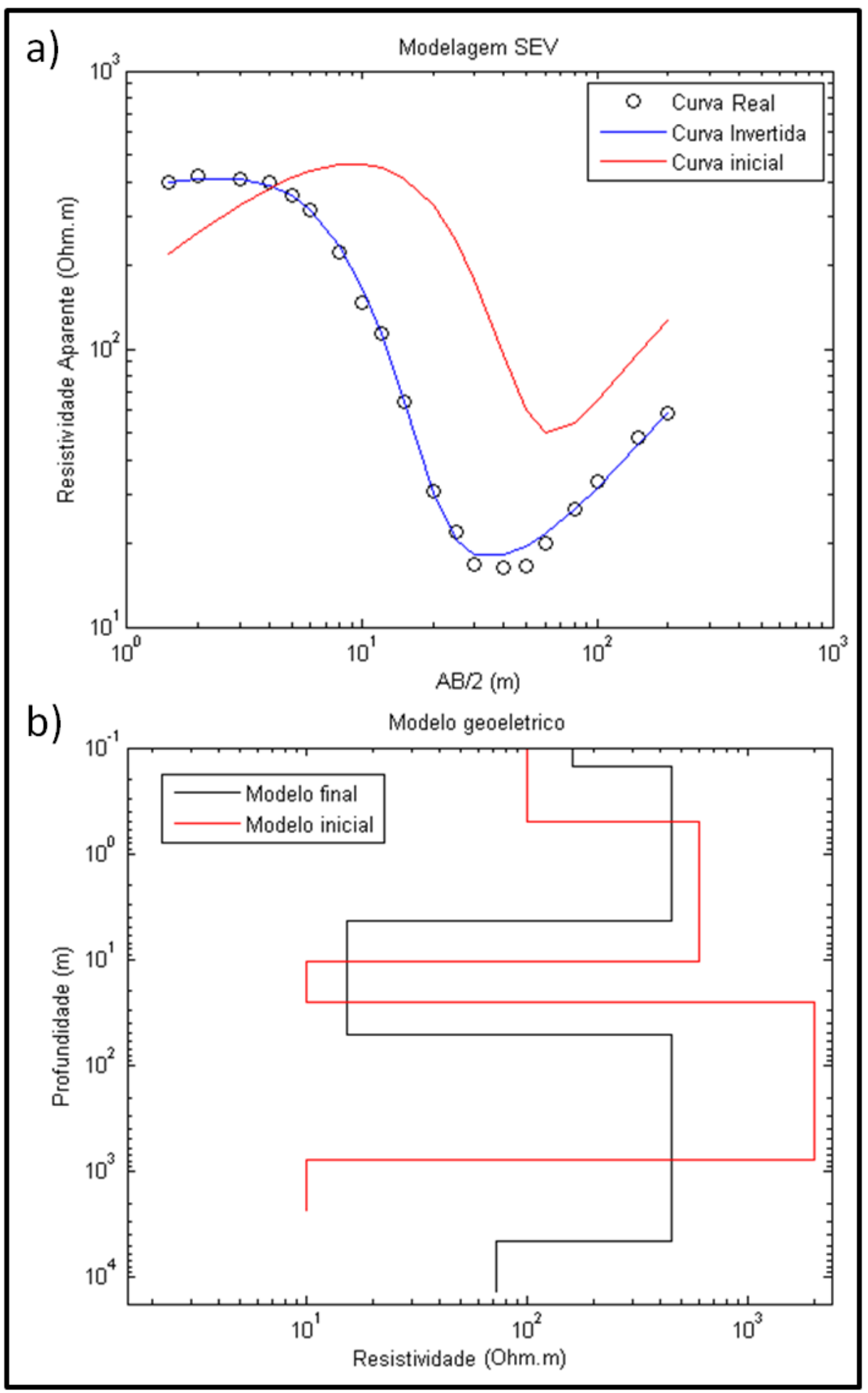

Figura 37: Resultados da inversão da SEV: em "a" a curva real com a curva invertida ajustada e em "b" o modelo invertido comparado com o modelo médio inicial. 


\section{Inversão dos Dados Reais de TDEM}

Ao contrário da curva de SEV a curva de TDEM não possui um comportamento tão intuitivo quanto ao número de camadas. Mas podem-se obter informações sobre o modelo a partir da curva também. No caso é bem claro que existe uma camada bem resistiva entre duas porções condutivas. Isso já indica que a sondagem TDEM pode ter passado a camada de basalto e chegou a investigar abaixo dela. O espaço de busca foi o mesmo que o da SEV para manter a consistência e ser possível uma comparação. A inversão também foi feita pelo programa Curupira e os resultados podem ser vistos na Figura 38. Sobre o modelo invertido o que se pode ver é que a camada superficial de solo não foi determinada, o que era esperado. A primeira camada (até cerca de $4 \mathrm{~m}$ ) do modelo invertido representa a camada sedimentar seca vista na inversão da SEV. A segunda camada do modelo acabou se tornando então uma camada apêndice, já que a camada superficial não foi definida. Na interpretação dos resultados essa camada pode ser desconsiderada. Assim como na SEV a última camada (aqüífero Guarani) não era definida por causa da grande profundidade, no TDEM o problema é inverso, a camada mais superficial que não é definida. Mas como já dito foi mantido o mesmo espaço de busca para manter a consistência entre as inversões.

Abaixo dessa camada de sedimento seco está uma camada condutiva (cerca de 6 Ohm.m) que corresponde a camada sedimentar saturada. Essa camada está muito menos espessa que o esperado, chegando a apenas cerca de $20 \mathrm{~m}$ de profundidade. Essa sub-estimativa da camada

referente ao aqüífero sedimentar foi algo recorrentes em algumas sondagens da região. É de se estranhar, pois dados de poços próximos indicam uma profundidade maior para a interface entre essa camada e a inferior (camada de basalto). Sobre a camada de basalto (a camada resistiva de cerca de $150 \mathrm{Ohm} . \mathrm{m}$ ) ela está muito mais rasa que o esperado uma vez que a profundidade que ela é encontrada nessa área é de cerca de 50-80 m. Essa discrepância foi associada a algum tipo de influência lateral que o TDEM foi sensível e a SEV não, uma vez que a sondagem elétrica marcou a interface com o basalto a uma profundidade condizente com os dados de poços. Mas a base do basalto foi marcada a quase $600 \mathrm{~m}$ de profundidade o que é condizente com a geologia da área, mostrando que o TDEM teve resolução para marcar o fim do basalto e começo do aqǘfero Guarani, ie, formação Botucatu (camada com 3 Ohm.m de resistividade). 


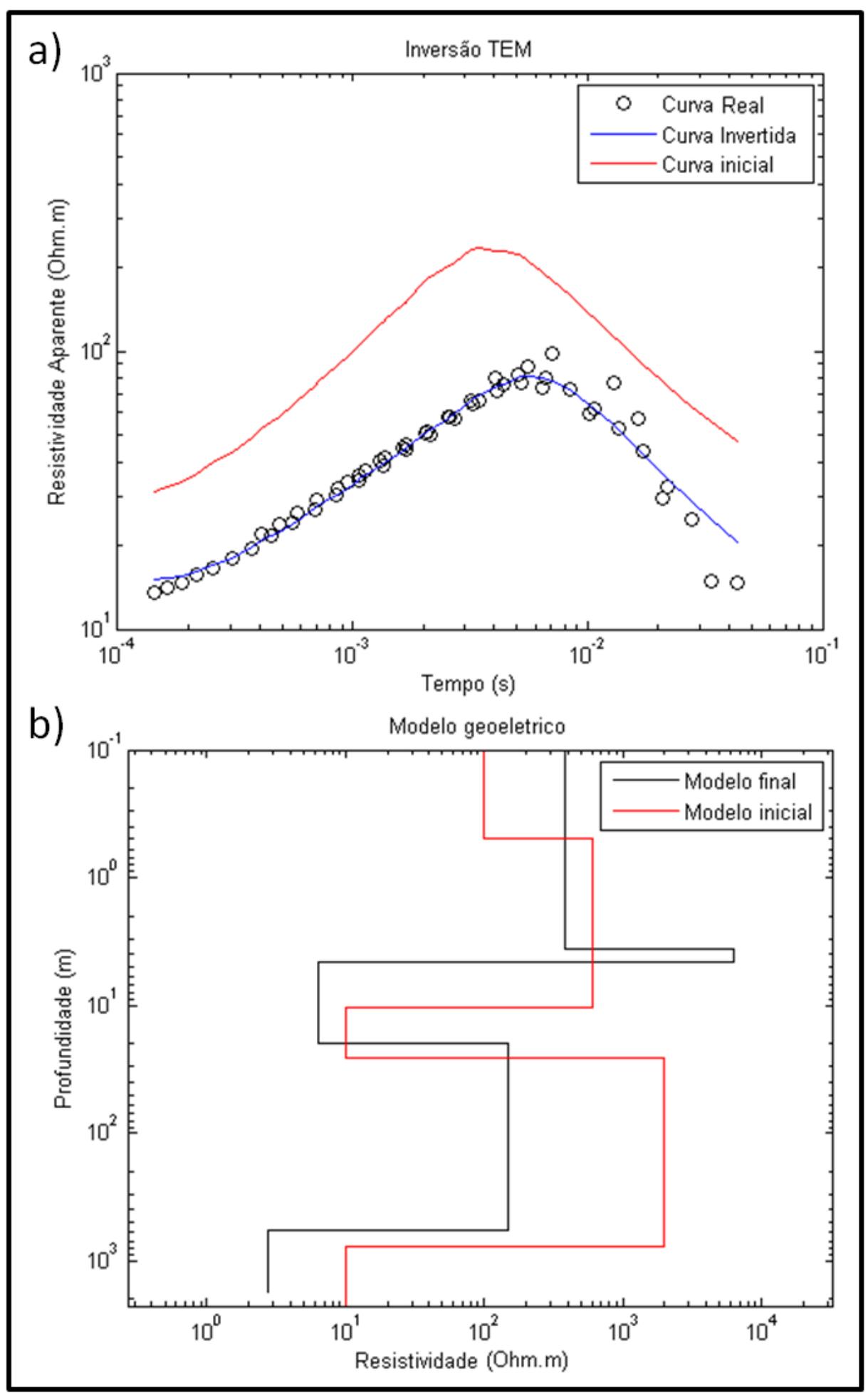

Figura 38 Resultados da inversão do TDEM: em "a" a curva real com a curva invertida ajustada e em "b" o modelo invertido comparado com o modelo médio inicial. 


\section{Inversão Conjunta dos Dados Reais - SEV/TDEM}

A Figura 39 mostra o resultado da inversão conjunta dos dados de SEV e da sondagem TDEM. Pode-se ver claramente que a inversão conjunta conseguiu ajustar bem as duas bases de dados. O começo da curva da sondagem TDEM não foi muito bem ajustado, provavelmente devido a influencia lateral já mencionada. O que pode-se analisar da inversão conjunta que assim como no caso sintético a inversão conjunta dos dados reais juntou o melhor das duas inversões individuais. As camadas iniciais foram bem marcadas, tanto a camada de solo que possui alguns centímetros como a camada sedimentar superior de cerca de $4 \mathrm{~m}$ e $400 \mathrm{Ohm} . \mathrm{m}$. A camada abaixo que provavelmente se trata do aqüífero sedimentar também foi definida com valores condizentes com os dados de poço, com a base em cerca de $50 \mathrm{~m}$ de profundidade e resistividade com cerca de $15 \mathrm{Ohm} . \mathrm{m}$. A camada resistiva abaixo que provavelmente é o basalto da formação Serra Geral com resistividade de cerca de 320 Ohm.m e que se estende até $550 \mathrm{~m}$ de profundidade. Abaixo do basalto o aqüífero Guarani também foi marcado com resistividade menor que $3 \mathrm{Ohm} . \mathrm{m}$, mostrando dessa forma que a inversão conjunta possui a capacidade de enxergar as estruturas rasas como a SEV e as estruturas profundas como o TDEM. 


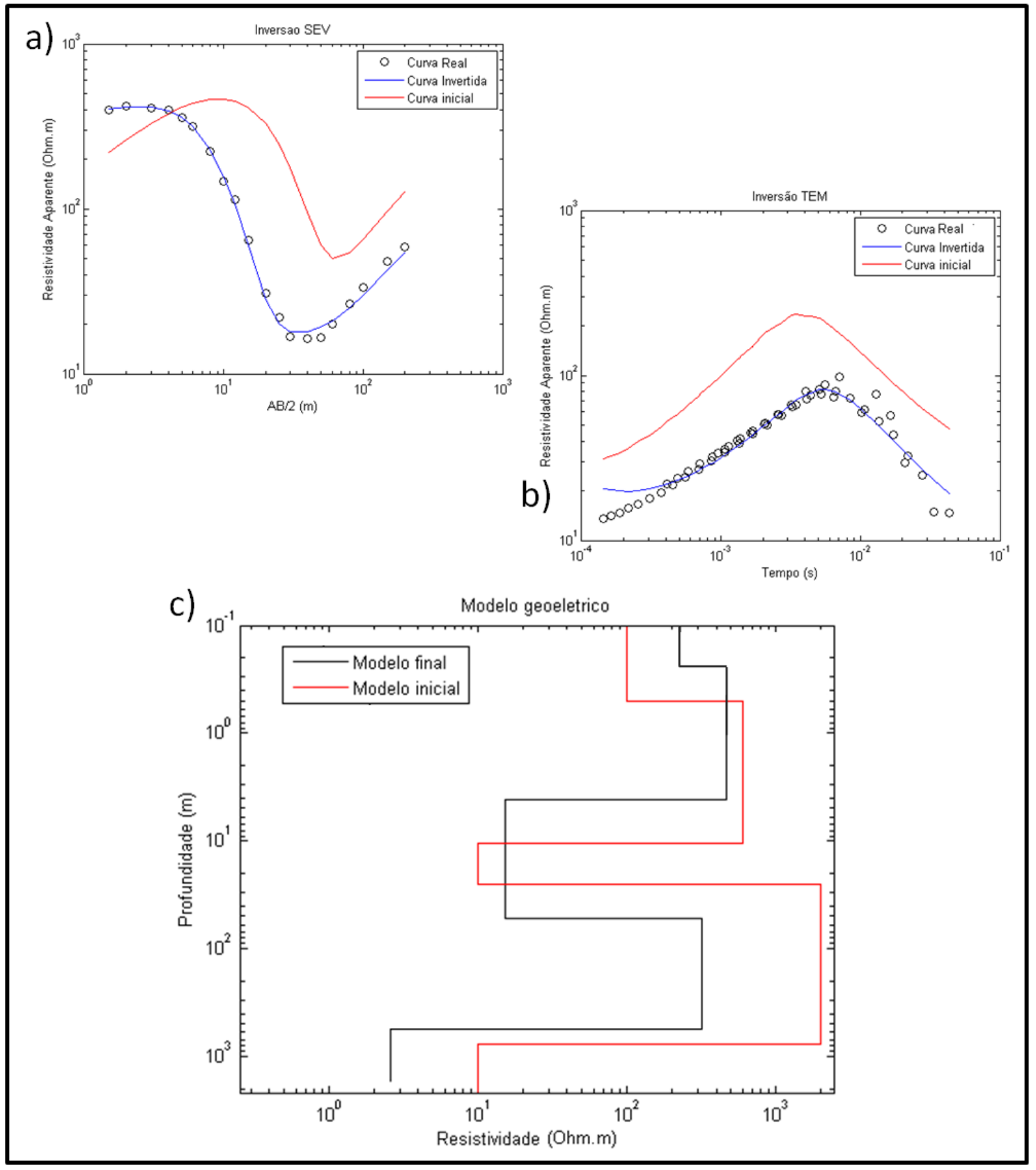

Figura 39: Resultados da inversão conjunta SEV/TDEM: em "a" a curva real da SEV com a curva invertida ajustada, em " $b$ " a curva real do TDEM com a curva invertida ajustada e em "c" o modelo invertido comparado com o modelo médio inicial. 


\section{Considerações Sobre os Estudos Práticos}

A inversão conjunta nos dados reais de Bebedouro mostrou que essa metodologia pode ser empregada na prática sem grandes dificuldades. Esse tipo de metodologia também ajudou a resolver um problema de influência bidimensional nos dados de TDEM. Uma situação normalmente difícil de resolver devido à falta de informação sobre essas estruturas. Uma forma de resolver esse tipo de situação seria através da modelagem 2D da área, para ajustar os dados obtidos. Mas isso é uma tarefa complicada e necessita de softwares que não são facilmente obtidos. Assim foi possível mostrar que a inversão conjunta é uma ferramenta importante para executar levantamentos com ótima resolução de subsuperfície com menos problemas com relação a interferências externas.

As implicações de se ter uma metodologia com boa resolução e capacidade de investigação de grande profundidade permite mapear estruturas de interesse com boa resolução. Um tipo de alvo muito visado ultimamente são aqǘf́reros, principalmente os de grande capacidade. Isso porque devido a contaminação de águas superficiais há uma grande demanda por água subterrânea. Muitas cidades já dependem dessa água e nosso país tem grande potencial nessa área. Porém para um uso correto, de forma a aproveitar o máximo dos investimentos e também conseguir manejar esses recursos de maneira sustentável é necessário mapeá-los com precisão. A metodologia aqui empregada pode ser muito útil nessa linha de pesquisa. Uma vez que o tipo de levantamento não é invasivo, gera resultados precisos e com um custo baixo. 


\section{Conclusões}

Os resultados obtidos com o programa de inversão conjunta 1D de dados de SEVs e TDEM são bastante promissores e todas as expectativas da pesquisa foram alcançadas. O programa de inversão, denominado de "Curupira", mostrou claramente que a inversão conjunta usufrui das vantagens dos dois métodos. As SEVs permitiram determinar com precisão as camadas mais rasas e as sondagens TDEM forneceram informações até cerca de $1000 \mathrm{~m}$ de profundidade. Outra vantagem é que as interferências que afetam os dois métodos também são minimizadas, uma vez que cada metodologia é sensível a algum tipo de interferência, por exemplo, o que afeta um não fará diferença na curva do outro método e vice versa. Dessa forma, os erros na inversão e na interpretação dos dados são reduzidos.

Quanto à questão prática, os dados reais mostraram como essa metodologia de inversão conjunta é facilmente aplicável. Os levantamentos não são diferentes dos levantamentos feitos individualmente. As únicas recomendações são que os levantamentos devem ter os centros o mais próximo possível, pois variações locais de resistividade podem influenciar de maneira diferente os dados. E que se faça a correção do static shift dos dados de SEV usando os dados TDEM, pois assim a inversão terá resultados mais precisos.

Para finalizar recomenda-se o uso, quando possível, da inversão conjunta SEV/TDEM, uma vez que esta metodologia se mostrou muito eficiente e totalmente factível em campo. Dessa forma a confiabilidade dos modelos invertidos aumenta consideravelmente e a ocorrência de influências externas pode ser minimizada, possibilitando assim trabalhos com maior precisão. 


\section{Bibliografia}

Albouy, Y., Andrieux, P., Rakotondrasoa, G., Ritz, M., Descloitres, M., Join, J.L. and Rasolomanana, E., 2001, Mapping Coastal Aquifers by Joint Inversion of DC and TEM Soundings-Three Case Histories: Ground Water. Vol. 39, no. 1, pp. 87-97.

Anderson, W.L., 1974. Electromagnetic fields about a finite electric wire source: USGS-GD 74-041, U.S. Geological Survey, 205.

Anderson, W.L., 1979. Numerical Integration of Related Hankel Transform of Order 0 and 1 by Adaptive Digital Filtering: Geophysics, 44, 1287-1305.

Anderson, W.L., 1981. Calculation of transient soundings for a central induction loop system (program TCILOOP): Open-File Report 81-1309, U.S. Geological Survey, 80.

Asten, M.W., 1987, Full transmitter waveform transient electromagnetic modeling and inversion for soundings over coal measures: Geophysics, 52, 279-288.

Bhattacharyya, B. K., 1959. Electromagnetic fields of a transient magnetic dipole on the earth's surface: Geophysics, 24, 89-108.

Bhattacharyya, B.K., 1957. Propagation of transient electromagnetic waves in a medium of finite conductivity: Geophysics, 22, 75-88.

Bhattacharyya, B.K., 1963. Electromagnetic fields of a vertical magnetic dipole placed above the earth's surface: Geophysics, 22, 75-88.

Burguer, H.R., Sheehan, A.F., Jones, C.H., 2006. Introduction to applied geophysics - Exploring the shallow subsurface. W.W. Norton \& Company. 1a edição.

Christensen, N.B., 1990. Optimized fast Hankel transform filters: Geophysical Prospecting 38 (5), $545-568$.

Christiansen, A.V., Auken, E., Sørensen, K., 2006. The transient electromagnetic method, in R. Kirsch ed., Groundwater geophysics a tool for hydrogeology, Cap.6, 179-225.

Descloitres M., Guerin R., Albouy Y., Tabbagh A., Ritz M., 2000. Improvement in TDEM sounding interpretation in presence of induced polarization: a case study in resistive rocks of the Fogo volcano, Cape Verde Islands: Journal of Applied Geophysics, 45, 1-18. 
Dey, A., Ward, S.H., 1970. Inductive sounding of a layered earth with a horizontal magnetic dipole: Geophysics 35 (4), 660-703.

Fitterman, D.V.; Stewart, M. T.; 1986. Transient electromagnetic sounding for groundwater: Geophysics, 51, 995-1005.

Geonics, 1994. PROTEM-47D, operating manual. Geonics Limited, Mississauga, Ontario, Canadá.

Ghosh, D.P., 1971a. The application of linear filter theory to the direct interpretation of geoelectrical resistivity sounding measurements: Geophysical Prospecting, 19 (1), 192-217.

Ghosh, D.P., 1971b. Inverse filter coefficients for the computation of apparent resistivity standard curves for a horizontally stratified earth: Geophysical Prospecting, 19 (4), 769-775.

Goldman M., Mogilatov V. and Rabinovich M., 1996. Transient response of a homogeneous half space with due regard for displacement currents: Journal of Applied Geophysics, 34 (4), 291 305.

Goldman, M., Du Plooy, A., Eckard, M., 1994. On reducing ambiguity in the interpretation of transient electromagnetic sounding data: Geophysical Prospecting 42, 3-25.

Grant, F.S., 1965. Interpretation theory in applied geophysics. 1a edição.

Jens, E.D., Auken, E., Jørgensen, F., Søndergaard, V., Sørensen, K.I., 2003. The application of the transient electromagnetic method in hydrogeophysical surveys: Journal Applied Geophysics 53, 181-198.

Johansen, H.K., 1975. An interactive computer/graphic-display-terminal system for interpretation of resistivity sounding: Geophysical Prospecting 23, 449-450.

Kaufman, A.A. and Keller, G.V., 1983. Frequency and Transient Soundings. Elsevier, Amsterdam. 1a edição.

Keller, G.V., 1987. Rock and mineral properties. Investigations in Geophysics, no 3, Electromagnetic Methods in Applied Geophysics. Society of Exploration Geophysicists, Ed. Misac N. Nabighian, 1, p.13-51.

Kirsch, R., 2006. Groundwater geophysics. Ed. Springer. 1a edição.

Knight, J.H. and Raiche, A.P., 1982. Transient electromagnetic calculations using the Gaver-Stehfest inverse Laplace transform method: Geophysics 47, 47-50.

Koefoed, O., 1970. A fast method for determining the layer distribution from the raised kernel function in geoelectrical sounding: Geophysical Prospecting, 18, 564-570. 
Koefoed, O., 1972. A note on the linear filter method of interpreting resistivity sounding data: Geophysical Prospecting, 20, 403-405.

Koefoed, O., 1979. Geosounding principles 1: Resistivity sounding measurements, Elsevier. 2a edição.

Lee, T. and Lewis, R., 1974. Transient response of a large loop in layered ground: Geophysical Prospecting, 22, 430-444.

McNeill, J.D, 1994, Principles and application of time domain electromagnetic techniques for resistivity souding. Tech. Note TN-27 Geonics Ltd, Mississauga, Ontario, Canada.

Meju, M.A., 1994b. Geophysical Data Analysis: Understanding Inverse Problem Theory and Practice: Society of Exploration Geophysicists Course Notes Series, Vol. 6, SEG Publishers, Tulsa, Oklahoma.

Meju, M.A., 1996. Joint inversion of TEM and distorted MT soundings: some effective practical considerations: Geophysics 61 (1), 56-65.

Meju, M.A., 2005. Simple relative space-time scaling of electrical and electromagnetic depth sounding arrays: implications for electrical static shift removal and joint DC-TEM data inversion with the most-squares criterion: Geophysical Prospecting, 53, 1-17.

Monteiro Santos, F.A., and El-Kaliouby, H., 2010. Comparative study of local versus global methods for 1D joint inversion of direct current resistivity and time-domain electromagnetic data: Near Surface Geophysics, 8, 135-143.

Morrison, H.F., Phillips, R.J., and O'Brien, D.P., 1969. Quantitative Interpretation of Transient Electromagnetic Fields over a Layered Half Space: Geophysical Prospecting, 21, 1-20.

Nabighian, M.N. \& Macnae, J.C., 1991. Time domain electromagnetic prospection methods. Investigations in Geophysics, no 3. Electromagnetic Methods in Applied Geophysics. Society of Exploration Geophysicists, Ed. Misac N. Nabighian, v.2, Application, Parts A and B, chapter 6, 427-520.

Nielsen, L., Jørgensen N., Gelting, P., 2006. Mapping of the freshwater lens in a coastal aquifer on the Keta Barrier (Ghana) by transient electromagnetic soundings: Journal Applied Geophysics, 62, 1-15.

Nielsen, T.I., Baumgartner F., 2006. CR1Dmod: A Matlab program to model 1D complex resistivity effects in electrical and electromagnetic surveys: Computers \& Geosciences, 32 (9), 1411-1419. 
O'Brien, D.M., and Smith, R.S., 1985. Transient Electromagnetic Response of a Layered Conducting Medium at Asymptotically Late Times: J. Austral. Math. Soc. Ser. B 27, 1-30.

Parasnis, D.S., 1962. Principles of applied geophysics. Chapman and Hall. 4a edição.

Parker, R.L., 1994. Geophysical Inverse Theory. Princeton University Press. 1a edição.

Price, W.L., 1977. A Controlled Random Search Procedure for Global Optimization: The Computer Journal, 20, 367-370.

Raiche, A.P., Jupp, D.L.B., Rutter, H., Vozoff, K., 1985. The joint use of coincident loop transient electromagnetic and Schlumberger sounding to resolve layered structures: Geophysics 50, 1618-1627.

Rathor, B.S., 1978. Transient electromagnetic field of a polarizable halfspace due to various current pulses: Geophysical Prospecting, 26, 337-351.

Ryu, J., Morrison, F., Ward, S.H., 1970. Electromagnetic fields about a loop source of current: Geophysics 35 (5), 862-896.

Schmutz, M., Albouy, Y., Guerin, R., Maquaire, O., Vassal, J., Schott, J.J., Descloitres, M., 2000. Joint electrical and time domain electromagnetism (TDEM) data inversion applied to the Super Sauze earthflow (France): Surveys in Geophysics 21, 371- 390.

Schmutz, M., Guérin, R., Andrieux, P., Maquaire, O., 2009. Determination of the 3D structure of an earthflow by geophysical methods:: The case of Super Sauze, in the French southern Alps: Journal of Applied Geophysics, 68, 500-507.

Slichter, L.B., 1933. The interpretation of the resistivity prospecting method for horizontal structures: Physics 4, 307-322.

Sørensen, K.I., Auken, E., Thomsen, P., 2000. TDEM in groundwater mapping - a continuous approach. Proceedings of the Symposium on the Application of Geophysics to Engineering and Environmental Problems, Arlington, Virginia, 485-491.

Sørensen, K.I.; Auken E.; Christensen N.B.; Pellerin L., 2003. An Integrated Approach for Hydrogeophysical Investigations: New Technologies and a Case History, publication in SEG NSG Vol II: Applications and Case Histories, 63p.

Spies, B.R. and Raiche, A.P., 1980. Calculation of apparent conductivity for the transientelectromagnetic (coincident loop) method using an HP-67 calculator: Geophysics 45, 1197-1204. 
Spies, B.R., and Eggers, D.E., 1986. The Use and Misuse of Apparent Resistivity in Electromagnetic Methods: Geophysics 51, 1462-1471.

Stefanescu, S., Schlumberger, C., Schlumberger, M., 1930. Sur la distribution électrique potentielle autour d'une prise de terre pontuelle dans un terrain à couches horizontales, homogènes et isotropes: Journal de Physique et du Radium 1 (4), 132-140.

Tarantola, A.,1987. Inverse problem theory. Elsevier. 2a edição.

Telford, W.M., Geldart, L.P., Sheriff, R.E., 1990. Applied Geophysics, Cambridge University Press, 2a edição.

Vozoff, K., Jupp, D.L.B., 1975. Joint inversion of geophysical data: Geophysical Journal International $42(3), 977-991$.

Wait, J.R., 1952. Current carrying wire loops in a single inhomogeneous region: Journal of Applied Physics, 23, 497-498.

Wait, J.R., 1962. Theory of magnetotelluric fields: J. Res. XBS, Rad. Prop., v. 66D, p. 509-541.

Wait, J.R., 1982. Geoelectromagnetism. Academic Press. 1a edição.

Ward, S.H., Hohman, G.W., 1988. Electromagnetic Theory for Geophysical Applications, vol. 1. Society of Exploration Geophysicists, 131-311.

Watson, G.N., 1966. A treatise on the theory of Bessel functions. Cambridge University Press. 2a edição.

Weidelt, P., 1982. Response characteristics of coincident loop transient electromagnetic systems: Geophysics, 47, 1325-1330.

Yang, C.H.; Tong, L.T., 1998. A study of joint inversion of direct current resistivity, transient electromagnetic and magnetotelluric sounding data: Terrestrial, Atmospheric and Oceanic Sciences (TAO), 10 (1), 293-301.

Zhadnov, M. S. \& Keller, G.R., 1994, Geolectrical methods. Elsevier. 2a edição. 


\section{Apêndice 1}

Os seguintes filtros correspondem a uma freqüência de amostragem de 10 pontos por década $(\Delta x=(\ln 10) / 10), j_{1}=-100, j_{2}=40, S=-1,7239458, C_{*}^{-100}=6,174 \cdot 10^{-5}, C_{*}^{40}=6,0905$. $10^{-4}$.

\begin{tabular}{|c|c|c|c|c|c|c|c|}
\hline$j$ & $C^{(j)} .10^{8}$ & $j$ & $C^{(j)} .10^{8}$ & $j$ & $C^{(j)} .10^{8}$ & $j$ & $C^{(j)} .10^{8}$ \\
\hline-99 & -12484 & -64 & 28016 & -29 & -110741 & 6 & 61285163 \\
\hline-98 & 12726 & -63 & -28830 & -28 & 117248 & 7 & $-2,9 \mathrm{E}+07$ \\
\hline-97 & -12975 & -62 & 29680 & -27 & -124303 & 8 & 15817356 \\
\hline-96 & 13231 & -61 & -30568 & -26 & 132085 & 9 & -9504597 \\
\hline-95 & -13494 & -60 & 31496 & -25 & -140461 & 10 & 6226174 \\
\hline-94 & 13765 & -59 & -32467 & -24 & 149959 & 11 & -4353505 \\
\hline-93 & -14043 & -58 & 33484 & -23 & -159826 & 12 & 3198475 \\
\hline-92 & 14330 & -57 & -34549 & -22 & 171917 & 13 & -2441493 \\
\hline-91 & -14625 & -56 & 35666 & -21 & -182946 & 14 & 1920840 \\
\hline-90 & 14930 & -55 & -36838 & -20 & 199955 & 15 & -1548505 \\
\hline-89 & -15244 & -54 & 38069 & -19 & -209469 & 16 & 1273595 \\
\hline-88 & 15567 & -53 & -39363 & -18 & 239052 & 17 & -1065148 \\
\hline-87 & -15901 & -52 & 40724 & -17 & -234543 & 18 & 903512 \\
\hline-86 & 16246 & -51 & -42156 & -16 & 304916 & 19 & -775750 \\
\hline-85 & -16602 & -50 & 43666 & -15 & -234124 & 20 & 673079 \\
\hline-84 & 16971 & -49 & -45259 & -14 & 453990 & 21 & -589375 \\
\hline-83 & -17352 & -48 & 46940 & -13 & -106745 & 22 & 520264 \\
\hline-82 & 17746 & -47 & -48717 & -12 & 899282 & 23 & -462558 \\
\hline-81 & -18154 & -46 & 50596 & -11 & 550573 & 24 & 413891 \\
\hline-80 & 18577 & -45 & -52587 & -10 & 2442523 & 25 & -372478 \\
\hline-79 & -19015 & -44 & 54697 & -9 & 3250077 & 26 & 336951 \\
\hline-78 & 19469 & -43 & -56936 & -8 & 7926675 & 27 & -306251 \\
\hline-77 & -19941 & -42 & 59314 & -7 & 13023345 & 28 & 279543 \\
\hline-76 & 20429 & -41 & -61845 & -6 & 25610307 & 29 & -256168 \\
\hline-75 & -20936 & -40 & 64540 & -5 & 41150741 & 30 & 235594 \\
\hline-74 & 21463 & -39 & -67414 & -4 & 64231809 & 31 & -217394 \\
\hline-73 & -22009 & -38 & 70484 & -3 & 72803988 & 32 & 301216 \\
\hline-72 & 22577 & -37 & -73767 & -2 & 36118538 & 33 & -186773 \\
\hline-71 & -23166 & -36 & 77284 & -1 & -100406442 & 34 & 173826 \\
\hline-70 & 23779 & -35 & -81057 & 0 & -242172543 & 35 & -162176 \\
\hline-69 & -24416 & -34 & 85111 & 1 & 20052460 & 36 & 151657 \\
\hline-68 & 25079 & -33 & -89475 & 2 & 444506381 & 37 & -142126 \\
\hline-67 & -25768 & -32 & 94183 & 3 & -489348908 & 38 & 133463 \\
\hline-66 & 26487 & -31 & -99267 & 4 & 294899398 & 39 & -125568 \\
\hline-65 & -27235 & -30 & 104775 & 5 & -137791072 & & \\
\hline
\end{tabular}

